University of Rhode Island

DigitalCommons@URI

Open Access Dissertations

2017

\title{
Agency in Eating Disorders: American Literary and Visual Memoirs of Anorexia and Bulimia
}

Jenny Platz

University of Rhode Island, jennplatz1955@gmail.com

Follow this and additional works at: https://digitalcommons.uri.edu/oa_diss

\section{Recommended Citation}

Platz, Jenny, "Agency in Eating Disorders: American Literary and Visual Memoirs of Anorexia and Bulimia" (2017). Open Access Dissertations. Paper 646.

https://digitalcommons.uri.edu/oa_diss/646

This Dissertation is brought to you for free and open access by DigitalCommons@URI. It has been accepted for inclusion in Open Access Dissertations by an authorized administrator of DigitalCommons@URI. For more information, please contact digitalcommons-group@uri.edu. 
AGENCY IN EATING DISORDERS: AMERICAN LITERARY AND VISUAL MEMOIRS

OF ANOREXIA AND

BULIMIA

BY

JENNY PLATZ

A DISSERTATION IN PARTIAL FULFILLMENT OF THE

REQUIREMENTS FOR THE DEGREE OF

DOCTOR OF PHILOSOPHY

IN

ENGLISH

UNIVERSITY OF RHODE ISLAND

2017 
DOCTOR OF PHILOSOPHY DISSERTATION

OF

JENNY PLATZ

APPROVED:

DISSERTATION COMMITTEE:

MAJOR PROFESSOR Jean Walton

Colleen Redding

Stephen Barber

Nasser H. Zawia,

DEAN OF THE GRADUATE SCHOOL

UNIVERSITY OF RHODE ISLAND

2017 


\begin{abstract}
In my dissertation I examine the representation of self-creation through anorexia and bulimia in memoiristic narratives, blogs, and YouTube videos in contemporary American culture. I argue that the highly crafted characterizations and structures of the anorexic and bulimic memoirs and blogs implement the disorders into temporary tools of self-care that grant the subjects agency through their pursuits of maturation and identity creation and cannot be simplified into mere warnings and retellings of the dangers of the eating disorders. I am locating my research in the late twentieth and early twenty-first century to encompass the emergence of eating disorder memoirs, Ana and Mia blogs, and My Anorexia and Bulimia YouTube videos in American culture. With its focus on literary, visual, and formal conventions this Humanities-based approach to self-representation and disordered eating adds to and distinguishes itself from the work of psychologists and physicians who conduct scientific and medical studies on disordered eating in clinical studies. In this study I begin with an exploration of the role of confession, branding, subjection, and shame in YouTube's My Eating Disorder Story videos. These videos differ from the memoirs and blogs that chronicle the creation of a self and care of the self through anorexia and bulimia. I then investigate Wasted and the author Marya Hornbacher's creation of self through the culture of disordered eating and memoir writing. The third chapter outlines how bloggers use the hupomnemata medium of blogging and disordered eating in order to understand the self and better the self. I conclude with an examination of Dana Shavin's memoir The Body Tourist and her narrative of truth telling and recovery. Through the dissertation I push for new readings of the
\end{abstract}


representations of disordered eating and to give voice to the writers rather than silencing them. 


\section{ACKNOWLEDGMENTS}

I began this dissertation in 2014 and I am extremely thankful for the members of my committee who have helped me with endless drafts, rewrites, and revisions. My major Professor Dr. Jean Walton has always been helpful and encouraging throughout the process and provided me with guidance and reassurance that I will forever be grateful for. Dr. Stephen Barber, Dr. Colleen Redding, Dr. Naomi Mandel, and Dr. Mary Healey Jamiel have also been essential to the creation of my dissertation. Dr. Barber has been a constant source of creative inspiration and support and Dr. Colleen Redding has always given me crucial advice. Working with Dr. Naomi Mandel has made me a better scholar and more precise writer and the mentorship of Dr. Mary Healey has been a pleasure and helped transform my dissertation into a more interdisciplinary text.

I could also not have finished this dissertation without the continuous support of the English Department and the hard work of Michelle Caraccia. I am further indebted to the direction and generosity of Dr. Kathleen Davis, the director of Graduate Studies, and my seminar professors Dr. Ryan Trimm, Dr. Carolyn Betensky, Dr. Gitahi Gititi, Dr. Mary Cappello, and Dr. Gina Valentino. 


\section{TABLE OF CONTENTS}

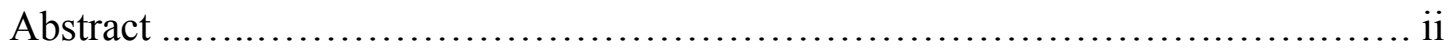

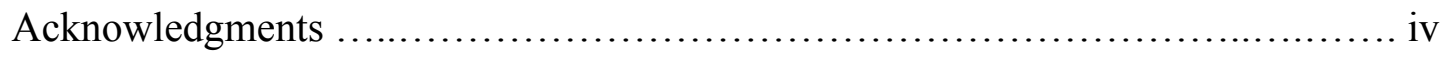

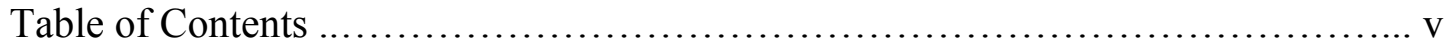

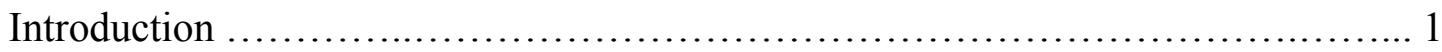

Chapter 1: Confession, Branding of Anorexia and Bulimia, and the YouTube Subject in My Eating Disorder Story Videos ...................................... 37

Chapter 2: Creation of Self Through Eating Disorders and Memoir Writing in Wasted .80

Chapter 3: Disordered Eating and Blogging as Hupomnemata, Control, and Means of

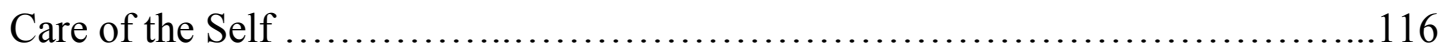
Chapter 4: Narrative of Truth and Ethos Through the Representation of Disordered Eating and Recovery in The Body Tourist...................................... 161

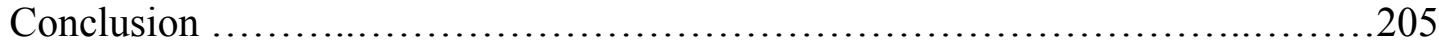

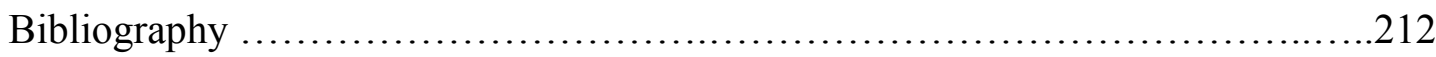




\section{Introduction}

Some write that people stop eating just to lose weight, while others argue that the media is the dominant influence contributing to people's attempts to reduce their appetite. Other groups of scholars and scientists claim not eating and purging are "disorders" and women are the only ones affected, while others lecture the only avenue to recovery is the constant monitoring and control of affected bodies by clinical gazes. Still others view anorexia and bulimia as infectious diseases that become contagious to all who are exposed to them. Numerous writings and debates exist about "eating disorders" in real life, but what do literary scholars and theorists write about anorexia and bulimia when they are represented in memoirs and other life writings and visual mediums? What happens when narratives of "eating disorders" are from the point of view of authors or subjects who have experienced the eating practices themselves? And in those narratives, what happens when the representations of "eating disorders" in memoirs and blogs do not label the anorexic and bulimic people as objects affected by beauty standards but as active agents creating and claiming their identities through eating and purging?

This work will examine memoirs, blogs, and videos of anorexia and bulimia to explore a genre of writing and story-telling largely untouched by literary, feminist, philosophical, and cultural scholars. The scholarly writing that does exist on "eating disorders" within feminist, philosophical, and cultural theory is not focused on representations of anorexia and bulimia and the majority of literary criticism and theory on narratives of eating habits that does exist is limited to Pro Anorexic and bulimic blogs. When feminists, philosophers, and cultural theorists write about 
anorexia and bulimia they often objectify the practitioners into symbols of patriarchal influences such as the media and family, and imply the people are too weak to resist bodily pressures of being slender. The literary criticism also places women (most of the criticism is focused on blogs of women with "eating disorders") into the position of an object without an identity by claiming the blogs are too dangerous for young readers and will lead to the spread of anorexia and bulimia.

By focusing on representations of "eating disorders" in memoiristic texts and videos instead of clinical cases of "eating disorders" my dissertation, unlike the majority of current theoretical work on anorexia and bulimia, avoids turning anorexic and bulimic people into objects without identities and people who are only shaped by patriarchal influences. This work instead argues that the highly crafted characterizations and structures of the anorexic and bulimic memoirs, blogs, and videos published and created between 1998-presnet, use the "disorders" as temporary tools of self-care that grant the subjects agency through their pursuits of maturation and identity creation. By agency I mean the assertive act of self-creation and care for the self that occurs through the practices of anorexia and bulimia that lead to understanding of one's subjectivity and how one is made a subject by one's historic moment, culture, and the networks of power that subjugate. The texts of "eating disorders" cannot be simplified into mere warnings and retellings of the dangers of anorexia and bulimia.

My readings of anorexic and bulimic memoirs, blogs, and videos rely on the later writings of Michel Foucault and his interpretation of the Ancient Greeks' use of care of the self and parrhēsia, also known as "truth telling", to explain how the 
memoir subjects and online communities engage in parrhēsia for understanding of the self, self betterment, and identity creation. Through the free and candid writing and speeches in the blogs, memoirs, and videos, the subjects write or talk about their life experiences without restraint in order to better understand their selves and their positions in the historical moment. By better understanding the self and the relations of power that subjugate them, the subjects attempt to transform their current social positions, leading to the memoir subjects' self-creation. My work does not aim to romanticize or encourage eating disorders, or to overlook the tragic effects of the eating habits. Instead my dissertation shows how representations of anorexia and bulimia in the memoir texts and videos are largely not about objectification of the subjects, but are about self-understanding, fulfillment, and betterment. By bringing a humanities perspective into the domain of "disordered eating" many of the overlooked questions and components of the "disorders" from other fields can be applied through tools of literary analysis that examine the language, structures, aesthetics, and character constructions in representations of anorexia and bulimia. Above I place the terms "eating disorders" in quotations to highlight the appropriation of the medical classification into a term of agency that defies the label of disorder and idea of uniformity. Henceforth however I will use the terms without quotations to avoid the quotations marks becoming unyielding to the reader.

In what follows I will give a brief history on the cultural consensus of eating disorders in American popular culture from the 1970s to the present, provide an overview of theoretical work that already exists on anorexia and bulimia, and then 
outline the importance of the later work of Foucault and his discussion of care of the self, the true life, and parrhēsia.

\section{Cultural Consensus of Anorexia and Bulimia in American Popular Culture from Post WWII-present:}

Although my research will be focused on texts from the 1990s-the present, in order to understand the culture of anorexia in the $20^{\text {th }}$ and $21^{\text {st }}$ century, the phenomenon of eating disorders needs to be traced back to the post WWII period. Before the 1960s anorexia was largely understood by the psychiatric establishment as a disorder unrelated to the desire to lose or maintain weight. Instead it was classified as a neurotic illness and fasting was a psycho physiological reaction (DSM-1). This theory mirrors the early work on anorexia that began in France when doctors such as Fleury Imbert, Louis-Victor Marce, and Pierre Briquet noticed young girls refusing to eat. The doctors did not connect the behavior to the attempt to control weight and considered the lack of appetite to be caused by internal stomach problems or hysteria (Vandereychken and Deth 146-151). William Withey Gull and Ernest Charles Lasegue were the first to use the term anorexia nervosa and by 1873 the disorder was recognized by the medical community, although doctors still did not relate anorexia to fear of fat or desires to lose weight (162-175). In the early 1970s with the work of psychoanalyst Hilde Bruch thoughts on anorexia no longer focused on biological causes and instead theorized on psychological causes of anorexia (180). In 1973 Hilde Bruch published Eating Disorders: Obesity, Anorexia Nervosa, and the Person Within. Bruch relates anorexia to problems of body image and anorexic women's 
inabilities to have an accurate perception of their own bodies. Bruch also argues anorexia is a result of society's pressures to conform to an ideal body type (Bruch 8788).

Highlighting the emergence of the medical world's theories on anorexic women's desire to lose weight is not to suggest that weight loss is the only or most important quality of eating disorders. Instead I am highlighting this history because the longing to lose weight and actual weight loss are still the qualities most recognized by the medical community and the media when diagnosing someone with anorexia or bulimia.

The contemporary medical community's concept of bulimia and anorexia collided with popular culture in the late 1970s when Karen Carpenter became a public figure for anorexia after the success of her musical group was followed by her increasingly rapid weight loss and the media's and fans' commentary on her emaciated frame. Shortly after her death in 1983 from anorexia related medical complications, news segments were quickly released diagnosing her as anorexic. Because Carpenter was from a middle class white family, her economic background and race were suggested to be a trigger for her eating problems. Carpenter's death continued to be sensationalized in the late 1980s when the made for TV movie The Karen Carpenter Story was released in 1989, which depicts Carpenter as a tragic victim to standards of beauty (Saukko 65-66). Due to the media's coverage of her death Carpenter's anorexia and its effects became more widely known and her tragic demise became a symbol of the dangerous consequences of unrealistic beauty standards on women's bodies, thus entrenching the idea that eating disorders are a 
result of these impossible standards of feminine beauty and women, specifically white middle class women, are naturally more susceptible to being influenced.

Carpenter's death also brought attention to the change in standards of beauty at the time. Beginning in the 1950s slender bodies became the cultural obsession when magazines and advertisements equated fatness to weakness. Post WWII American society's dedication to losing weight was connected to fears of Americans becoming soft and weak after the war. With stronger and healthier bodies Americans would be able to defend their country and defeat foreign enemies (Seid 4-6). The desire to be healthy was reflected in the rise of health food stores at the time. According to author Roberta P. Seid, this slender ideal applied to both men and women but was more contagious to women due to gender pressures that equated female identity to beauty (4-6). Seid also explains that unlike representation of male bodies, female bodily ideals became emaciated instead of strong and healthy and were represented in a greater abundance in magazines, advertisements, television, and film. The new standard of beauty post WWII was reflected in the international popularity of the model Twiggy (6). The Twiggy standard of beauty was a contrast to pre war standards of beauty, as well as standards of beauty during the Victorian age, which valued slim corset adorned waists but fuller hourglass figures (Seid 4-6).

The ideal size of women continued to get smaller and smaller in the 1980s and 90s. In the 1980s due to the rise in popularity of aerobics and gyms the media featured slender but muscular female bodies. The 1980s was also the time when bulimia became more widely known. This corresponded to the DSM-III's inclusion of bulimia in their 1980 edition. Unlike anorexia, bulimia often led to a slender but not 
emaciated body type, similar to the aesthetic ideal of the 1980s. Society's value of smaller body sizes escalated again in the 1990s when extremely skinny women were valued as possessing the ideal version of beauty due to the popularity of heroin chic (Wykes and Gunter 65). The new standard of beauty made popular by Calvin Klein advertisements featuring Kate Moss and other models, depicted emaciated women with pale skin and dark circles under their eyes. Because the women looked close to death and on drugs, many political leaders, including President Clinton, critiqued the fashion industry for glamorizing a strung out look. Because the models were so tiny and often spoke to the public about using drugs and other methods to control their weight, anorexia and bulimia and their dangers continued to be part of the public's consciousness (65-66).

By the 2000s multiple made for television films exposing the peril of eating disorders were released and rebroadcast. Between 1994 and 2014 the films For the Love of Nancy, When Friendship Kills, Dying to be Perfect: The Ellen Hart Pena Story, Perfect Body, Sharing the Secret, Dying to Dance, Hunger Point, and Starving in Suburbia were released, all featuring white teenagers developing and succumbing to the dangers of bulimia and anorexia. Pro Anorexia and Bulimia sites, also known as Ana and Mia Websites, were also sensationalized in the news in 2000s after Oprah Winfrey covered the websites on a 2003 episode of her show. Quickly after the show aired protest groups emerged and many of the sites were shut down (James). Since then Ana and Mia sites have remained popular and active despite censorship. The websites can be extremely troubling due to the cult-like mentality of the writers and followers and are thus labeled by the media and some feminist theorists as promoting 
self-starvation and purging. Author Paula Saukko describes the media's and public's response to the websites as a moral panic, seen through search engines like Yahoo's attempts to shut down the sites (Saukko 60). As social media technology developed, concern with the danger of the websites and eating disorders in general also grew. Psychologists and feminists warned the public of the dangers of the websites and social media in spreading the contagion of the disease. Through the public warning against the sites, the blogs and posts were viewed as reflections of mental illnesses rather than autobiographical pieces of writing (Hess).

Notably the films, websites, advertisements, and changing standards of beauty have mostly been culturally associated with white, young, and middle class women, creating the assumption that women of color and men were immune to pressures to be thin (Bordo 46).

To reiterate, discussing the changing standards of beauty after WWII is not to claim there is a pressing need to research anorexia's relationship to the media or claim the media is the dominant cause of the eating practices. Instead, it is to explain the general understanding and culture of the disorders in America.

\section{Overview of Literary Criticism on Eating Disorder Memoirs and Blogs}

Little literary critical work has been done on the representations of eating disorders in literature and social media. Marya Hornbacher's 1998 anorexia and bulimia memoir Wasted is a bestseller and is often identified as the most famous memoir on eating disorders. Despite the book's praise, literary criticism on the work is lacking and the criticism that does exist often only focuses on the book as a 
psychological tool to understand the disorders or a book that triggers disordered eating. These critical approaches ignore the literary technique at play in the memoir such as use of literary allusions, genre conventions, syntax, characterizations, and other devices. Emma Seaber's 2016 publication on Wasted does make similar arguments as I do when I analyze the memoir, and insists Hornbacher uses disordered eating in order to create a non-normative story of anorexia and bulimia. Her article though differs from mine in that she criticizes Hornbacher's use of disordered eating as a form of identity and suggests that Hornbacher misreads and misrepresents her past relationship with anorexia and bulimia. According to Seaber the lack of representation of the negative aspects of anorexia and bulimia results in a glamorization of disordered eating and although accidental, the memoir is thus what she refers to as a disordered reading of anorexia and bulimia (498-503). Seaber's argument is fascinating, but suggests that there is a correct way to present a story of disordered eating and even that there is a correct way for Hornbacher to remember her own story. Her problematic article further supports my claim that more scholarly writing on Wasted is needed.

Other prominent eating disorder memoirs such as the 1979 Solitaire, by Aimee Liu, Stephanie Covington Armstrong's 2009 book Not All Black Girls Know How to Eat, and The Body Tourist from 2014 have minimal or no literary criticism written about them.

Since the early 2000s numerous Pro Anorexic and Bulimic blogs have populated the Internet. Although there are numerous writings on Pro Anorexic and Bulimic blogs, most of the work is concerned with the harmful effects of the sites and 
the need for censorship. Almost none of the writings that do exist on Ana and Mia sites study the websites through literary and rhetorical analysis. The structures of the websites resemble genre conventions of the memoir through the creation of a persona, questions of authenticity, self reflection, and thematic focuses. Similar to the blogs, little analytical writing exists on the genre of videos on YouTube tilted My Eating Disorder Story. These videos differ from the blogs and memoirs in that the videos are centered on the need to confess disordered eating in order to return to a state of normalcy.

\section{Overview of Feminist Theory on Anorexia and Bulimia:}

Philosopher Susan Bordo's Unbearable Weight: Feminism, Western Culture, and the Body has a canonical position within feminist writing on anorexia and bulimia. Published in 1993, Unbearable Weight examines images of women in popular culture, cosmetic surgery, and dieting practices to understand the prominence of eating disorders in American culture. Unbearable Weight is an important text in the history of gender studies and critical theory because it is one of the first texts to investigate the social meanings behind the media's influence in contributing to an anorexic and bulimic aesthetic of beauty. The majority of the texts outside of psychology instead only blamed the media for escalating rates of eating disorders in young girls and did not explain the cultural significance of this issue (Bordo 1-2). The little work on the cultural meaning of anorexia and bulimia pre Bordo was conducted by feminist writers such as Suzie Orbach, who claimed anorexia was the result of the then current (1970s and early 80s) struggles of women in America. According to 
Orbach the women were attempting to find self worth by denying their biological needs to eat during a period when concepts such as gender were radically changing due to the effects of second wave feminism (2-4). Although works of Orbach such as Fat is a Feminist Issue from 1978 and Hunger Strike published in 1986 explored the cultural and psychological conditions of anorexia and bulimia, the books do not theorize what causes the cultural pressures that encourage women to abstain from eating.

In Unbearable Weight Bordo attempts to locate the specific reasons behind the media's influence in sparking eating disorders and claims the physical effects of anorexia and bulimia are enactments of the ideological constructions of femininity that govern women's bodies and silence their voices. Because the dominant culture enforces a specific ideal body, which is a skinny body, women achieve that ideal through self-starvation and purging. The secrecy of anorexia and bulimia, many people who practice eating disorders do so in secret, also relates to the media's representation of women and eating because most ads feature women eating in isolation, compared to ads where men eat joyfully in groups of people (Bordo 14-16). Bordo goes on to explain that because of these cultural pressures and images, "the anorectic thus appears, not as the victim of a unique and 'bizarre' pathology, but as the bearer of very distressing tidings about our culture" (16). Anorexic women are embodiments of dangerous cultural ideas of female beauty. For Bordo, anorexia and bulimia then become political statements about the deadly consequences of gender expectations, and through the protest society becomes aware of the demands of 
femininity. Eating disorders become protests even when the anorexic and bulimic person is not consciously protesting against the requirements of femininity (121-132).

Women with eating disorders also represent the contradictions between the media's enforcement of capitalism and constant consuming and the media's enforcement of a standard of beauty that values emaciated female bodies. In the book Bordo argues that self-starvation is the result of American women living in a consumerist society that requires Americans to constantly consume products to support capitalism, but also demands that women have slender bodies and therefore not consume food products. The media attempts to manage the contradictions by showcasing women in diet ads where food, and therefore products, can be ingested, but only the company's products will prevent weight gain. Anorexia and bulimia are also unconscious responses women engage in to manage the contradictions of a consumerist culture (154-157).

In 1994 feminist theorist and sociologist Becky W. Thompson published another key theoretical text focused on eating disorders. Her book, A Hunger So Wide and So Deep, unlike Unbearable Weight, uses psychology to focus on the social contributions to anorexia and bulimia and argues the eating practices are connected to class, racism, sexual assault, depression, and other issues unrelated to the media. Thompson explains the goal of her book when she writes,

Talking with Latina, African-American, and white women- including both heterosexual and lesbian women - reveals that the origins of eating problems have little or nothing to do with vanity or obsession with appearance. In fact, eating problems begin as survival strategiesas sensible acts of self-preservation- in response to myriad injustices including racism, sexism, homophobia, classism, the stress of acculturation, and emotional, physical, and sexual abuse. The women I interviewed for the book told me stories that starkly expose how eating 
problems often begin as an orderly and sane response to insane circumstances (1-2).

Thompson's focus is rare for the time because the cultural consensus of eating disorders in the 1990s, as explained earlier, was believed to be a problem that mostly affected white middle class girls and a problem mostly related to the media and standards of beauty. Unfortunately later works in the field of feminist theory, in focuses such as psychology, sociology, post-modernism, and cultural studies often label anorexic and bulimic women as objects affected and controlled by the media. These writings are in opposition to Bordo's claim that the women are active protesters, although unconscious protesters, who are not just objects unable to resist bodily pressures enforced by the media and other patriarchal institutions.

In the 2011 article "A Perfect Loathing: The Feminist Expulsion of the Eating Disorder" author Stephanie Houston Grey outlines the problems of dehumanization in feminist literature on eating disorders. Houston Grey explains the goal of her article when she writes that her essay,

examines the strategic negation of the eating-disordered person within this political context as the anorexic/bulimic subject was transformed into a projection of patriarchal visual codes. Finally, this work discusses the political and social ramifications of the containment strategies through which the eating-disordered person was symbolically purged as a non-woman (indeed a "non-being") and ultimately as a patriarchal tool. Only by understanding the history of the eating disorder as a product of dramatistic motive can the contours of isolation and stigma associated with these conditions be appreciated (Houston Grey).

Houston Grey argues that transforming an anorexic or bulimic woman into a projection of patriarchal influences is problematic because it is essentializes all women into having the same experiences (Houston Grey). She also argues that 
feminist theory that claims anorexic and bulimic women are acts of conscious political commentary is problematic. Because the women are treated as symbols of institutional resistance only, Houston Grey argues their own identities and experiences are erased and they become non-entities who only stand for the patriarchal control of women's bodies (Houston Grey).

The erasing of anorexics and bulimics as people is seen through groups of feminist writers who preach the dangers of Pro Anorexic and Bulimic blogs. By censoring the blogs, the actual voice of the anorexic and bulimic person is lost and all that remains is the voice of the theorist who then speaks for the community (Houston Grey). Houston Grey is not arguing that anorexic and bulimic women are never making political comments about the effects of the patriarchy, but instead is claiming the protests are unconscious and linked to the women's unique identities and lives, identities and lives which must not be silenced or essentialized.

The 1996 collection of essays Feminist Perspectives on Eating Disorders, edited by Patricia Fallon, Melanie A. Katzman, and Susan C. Wooley, represents many of Houston Grey's criticism of feminist studies' approach to anorexia and bulimia. It is important to note when overviewing feminist theory that treats anorexia and bulimia problematically, I am not claiming the writings have no value or that the media does not play a role in women developing eating disorders. The media does play an important role in the culture of anorexia and bulimia, but the media is not the only role and it does not turn women into voiceless and vulnerable objects, but to use Bordo's language, results in women's unconscious protest of patriarchal standards of femininity. Alternatively, a few essays in the collection avoid problems of 
essentializing anorexic and bulimic women into objects, but these alternative essays do not form the major focus of the book. Instead the overview and critique of certain feminist theory is to outline the limitations of theory that is only interested in the effects of the media and the implications involved in labeling anorexic and bulimic women as objects whose identity is always tied to their weight. The scope of this introduction does not allow for examinations of all the feminist theory that overvalues the media and concerns with weight, so I will only be able to point to key feminist texts that repeat these issues.

Feminist Perspectives on Eating Disorders is an important text in the history of feminist writing on eating disorders because it was one of the first of its kind. In the introduction the editors write,

It is strange, really, that this book should be among the first collections of feminist writings on eating disorders, and stranger still that it should serve as the occasion for many contributors to write their first explicitly feminist pieces. For although feminist perspectives have informed this field since its inception - commanding increasing attention in recent years- a list of published works with a feminist orientation could easily fit on the cocktail napkins used at conference receptions (ix).

Because it is one of the first edited collections of essays on anorexia and bulimia, its content needs to be addressed.

The first section of essays in the book contains essays exploring the history of eating disorders in the United States and their connection to fashion, representations of the feminine form, dieting, advertisements, fat prejudices, body image, and standards of beauty (xiii-xiv). Although a history and explanation of the media's involvement and influence of anorexia and bulimia is important by 1996, when the essays were published, this concept had already been well established. The 1996 
collection of theoretical writing on eating disorder is what is notable about the collection, not its focus on the media's contribution to disordered eating. By focusing only on the role of the media, instead of other factors or reasons women practice anorexia and bulimia, these essays again limit female identities to their bodies and label women as weak people incapable of resisting patriarchal appointed standards of beauty.

Similar to essays in Feminist Perspectives on Eating Disorders Maggie Wykes' and Barrie Gunter's The Media and Body Image: If Looks Could Kill is also focused on the role of the media and images in producing anorexia and bulimia. The introduction of the book argues that the authors will

address the lack of research on the media, body image, and eating disorders by bringing together new empirical work on both media representations and audience responses, within a broad discussion of socio-cultural change, gender politics and self-identity... [The book] investigates the contemporary 'moral panic' over the media and the body and the lack of detailed analysis of the mediated material blamed for the current health crisis by theorizing the role of the mass media in gendered discourses and analyzing textual examples from print and screen $(9-10)$.

The media's contribution to eating disorders has been repeatedly documented by feminist theory, notably by Susan Bordo and the authors of Feminist Perspectives on Eating Disorders, making the goal of the book less groundbreaking than the authors intend.

The authors also equate eating disorders to weakness when they claim anorexics and bulimics are too weak to resist damaging inscriptions placed on the body (25-33). The authors come to similar conclusions when they study body schema theory. Women with body dysmorphia often have eating disorders because they 
cannot accurately perceive their own bodies. Anorexic and bulimic women instead see their bodies through the lens of the present body, the socially represented body, and the internalized ideal body. The present body is how one currently perceives her body, which is different from the body the person actually possesses. The socially represented body is the ideal body created by the media and society and the internalized ideal body is the combination of the socially represented body and the present body (145-147). The authors' research on body schematics present valid and intriguing ways to look at disordered eating. That is not in question. What is in question is the author's singular focus that ignores other personal experiences that contribute to anorexia and bulimia and thus essentializes the anorexia and bulimic experience and does not explore how disordered eating can actually be used to resist or challenge society's control of women's bodies.

In Galya Hildesheimer's and Hemda Gur-Arie’s 2015 article “Just Modeling? The Modeling Industry, Eating Disorders and the Law", Hildesheimer and Gur-Arie examine the 2012 Israeli law that restricts weight of professional models in ads, forces models to present documentation proving they are of suitable weights, and requires commercials to air disclaimers when the image of the models' bodies are overly manipulated (105). The authors are in support of the law but claim it overlooks other areas of the media, such as celebrities, toys, beauty contests, and magazines that also can trigger disordered eating (109-110). The authors later argue that the difference between the 2010 law and 2012 are very problematic. The 2010 law not only forbids models who do not have a high enough BMI from commercials, but prohibits agencies from employing the low weight models. The law was later changed 
after models complained the law violated their personal rights and choice to have a slender body (118). The authors claim the choice to have a skinny or anorexic body is a non-existent and false choice because it is the result of the media's influence, regardless of whether the model is consciously choosing to be skinny. The models' rights to their emaciated body types is also problematic, according to Hildesheimer and Gur-Arie, because the 2012 law values the models' rights of emaciation and employment over the public's exposure to the unhealthy standards of female bodies (126). "Thus, the Modeling Act of 2012 reflects a shift from protecting the dignity of the public, and mostly women, in the positive sense to protecting the advertising and modeling industries" (126). The authors' reasoning and phrasing place all women into the position of people who need to be protected from depictions of emaciated models' bodies. Moreover, the authors objectify the models into voiceless non-entities, a common issue of feminist writing according to Houston Grey. The models in the article become symbols for the contagion of anorexia and bulimia physically through their emaciated bodies and mentally through the women's desire to remain emaciated.

In summary, the essays and books addressed in this section are not actually the problem. The body of work represents the essentialist focus on eating disorders in fields of feminist literature and the need to find new approaches that do not claim women's, or anorexics' and bulimics', entire identities are based on their appearance or their eating habits, and that women are just objects who are susceptible to the media's influences. By analyzing the representations of eating disorders in memoirs and visual texts, the problems of dehumanizing and overvaluing the role of the media in encouraging anorexia and bulimia can be avoided. Because the representations of 
anorexia in memoirs, blogs, and social media are complex texts involving character development, literary techniques, and genre conventions, the narratives of eating disorders cannot be limited to simple critiques or portrayals of the effects of the media's influence and women's failure to resist those pressures.

The later work of Foucault is focused on care of the self, truth telling, identity creation, and challenging of discursive systems' constructions of subjectivities and is useful in analyzing the role of self creation in the eating disorder memoirs and blogs and the role of subjection in the videos. By applying the later works of Foucault to memoirs, blogs, and social media videos, not only can gender studies move away from limited focuses that essentialize the anorexic and bulimic experience, but the gap between gender theory and literary criticism can be bridged.

\section{The Need to Turn to the Later Works of Foucault:}

Beginning in the 1990s with the works of Susan Bordo many feminist writers have incorporated theories of Foucault into their writings on anorexia and bulimia. Many poststructuralist and postmodern feminist writers use Foucault's theories on technologies of the self and subjectivity to ask questions regarding the struggles of the self and disordered eating under networks of power such as psychology. Paula Saukko asks if Foucault can be used to understand the limits of subjectivity imposed on anorexic and bulimic women by the psychiatric community (Saukko 17). Susan Bordo relies on Foucault to argue the false concept of a natural femininity is due to discursive powers' inscriptions and constructions of subjectivity (Bordo 98-99). Marce Burns claims anorexia and bulimia are technologies of the self that are 
practiced by women to adopt or resist social inscriptions of identity (Burns 129-130).

Other writers such as Elspeth Probyn also turn to Foucault to examine eating habits as signifiers of culture and identity that have been inscribed onto people as codes of conduct enforced by systems of power (Probyn 4).

Despite the importance of Foucault in feminist approaches to women and disordered eating the later writings in Foucault's body of work have remained mostly untouched by feminist writings allowing the chapters that follow to take up Foucault's work on care of the self, parrhēsia, and the true life. In the following chapters I use Foucault's writings on power relations and the Ancient Greeks' and Romans' use of care of the self and parrhēsia, also known as truth telling, to examine the subjects of memoirs and online communities and how they engage in parrhēsiastic conversations for self understanding and betterment. Here I outline important concepts of Foucault's work that are essential to the proceeding chapters.

\section{Power Relations, Subjectivity, and Confession}

In a 1984 interview "The Ethic of Care for the Self as a Practice of Freedom" Foucault offers a succinct account of his view of power relationships. Relations of power are between individuals and other individuals, or between individuals and social institutions such as schools or families (283). In power relations an individual or institution attempts to direct or influence the behavior of another. In the interview Foucault clearly expresses what he means by relations of power:

in human relations, whatever they involve verbal communication such as we are engaged in at this moment, or amorous, institutional, or economic relationships, a power is always present: I mean the 
relationships in which one person tries to control the conduct of the other (291-292).

Relationships of power incite the actions of others and are always present within human interactions. The relationship of power can be more intimate such as between romantic partners, or more formal such as between a teacher and a student. Or, a relationship can be between a practitioner and the church. Regardless of what type of power relation a person is in, the power relations influence individuals' behavior in various ways.

Power relations can also be challenged because "these power relations are mobile, they can be modified, they are not fixed once and for all" (292). The relationships of power do not have to be balanced or equal, as in the case of student and teacher, but even with the imbalance of power, change to the relationship is possible, even if unlikely. Because relationships of power are everywhere and are capable of being transformed, power is also not inherently good or evil and people must be free in order to resist, change, challenge, or obey the power relation (292). Because there is power, freedom is possible. By freedom Foucault means that people can respond in various ways, such as opposing or obeying the mode of power that influences their behavior (Foucault, "The Subject and Power" 342). For example, one can rebel against a teacher by not completing homework, or abide by the teacher's authority and complete the homework. Regardless of the person's behavior the subject has various options in the response to the relation of power. Power relations can then be summarized as the way individuals and social institutions aim to conduct and determine the behavior of a free subject (Foucault, "The Ethic of Care for the Self as a Practice of Freedom" 290-291). 
Because freedom is a requirement for networks of power, relationships of power are not the same as power exercised by dictators or other totalitarian systems. The type of power that prevents any type of resistance or alteration is a state of domination. In "The Ethic of Care for the Self as a Practice of Freedom" Foucault describes states of domination as when "an individual or a social group succeeds in blocking a field of power relations, immobilizing them and preventing any reversibility of movement by economic, political, or military means, one is faced with what may be called a state of domination" (283). Because there are no methods of resistance or only very unlikely possibilities to change the relationship of power, these methods of power are states of domination rather than power relations.

As a result of power relations' abilities to influence or incite the behavior of individuals or groups, the networks of power subjugate people by attempting to determine their behavior (Foucault, "The Subject and Power" 331). Foucault explains the meaning of the subject here. "There are two meanings of the word "subject": subject to someone else by control and dependence, and tied to his own identity by a conscience or self-knowledge. Both meanings suggest a form of power which subjugates and makes subject to" (331). Subjectivity or how one is made subject to a mode of power marks the individual, "with his identity and characteristics, is the product of a relation of power exercised over bodies, multiplicities, movements, desires, forces" (Foucault, "Questions on Geography" 74). To describe subjectivity in another way individuals construct themselves; or the self is constructed through and in relation of power. Foucault often uses sexuality to explain subjectivity. Individuals and society construct themselves through sexuality, a mechanism of power, by 
identifying themselves and other people through labels of sexuality such as heterosexual, homosexual, bisexual, transgendered, and so on. A truth is then produced about one's sexuality. The mode of power of sexuality determines people's behavior by determining how people recognize the so called truth of themselves and are recognized by others as sexual beings (Foucault "The Subject and Power" 327). This is shown on dating websites where one must choose a sexual preference, forcing a person to subjugate themselves through the language of subjectivity created by the website. To summarize, subjectivity, or how individuals think of or construct their sense of self, is influenced by relations of power and makes people subject to that power relation.

In "The Ethic of Care for the Self as a Practice of Freedom" Foucault clarifies that when a subject constructs him or herself as a sexual subject they are not creating the language of sexuality to use to identify themselves. The power relation has already constructed this language of sexuality. In the interview when explaining his interest in the subject he remarks "I am now interested in how the subject constitutes itself in an active fashion through practices of the self, these practices of the self, these practices are nevertheless not something invented by the individual himself. They are models that he finds in his culture and are proposed, suggested, imposed upon him by his culture, his society, and his social group" (291).

In the same interview Foucault explains that when people construct themselves as sexual subjects it is different from how people construct themselves as political subjects; how people present or establish themselves then depends on the relation of power (290). There are countless types of power relations present in 
society that affect subjectivity or how one constructs the self but Foucault often focuses on certain mechanisms of power relations. In "The Subject and Power" Foucault explains that his work has always been concerned with how people are made into subjects. Through his research he has contemplated subjection through three modes of objectification. The first mode of objectification Foucault describes is modes of inquiry through science. The subject is constituted through disciplines of science and sociology such as biology, psychology, medicine, criminology, linguistics, sexology, and other discursive modalities (326). This network of power is what Foucault often refers to as biopower (Security, Territory, Population: Lectures at the College de France, 1977-1978, 16). Within this relation of power one can construct the self as anorexic or bulimic, terms created within medicine and psychology to understand and label the eating practices. The second mode of objectification Foucault's work has been focused on, according to him, is "dividing practices". Dividing practices are the ways an individual is objectivized into categories of people and differentiated from one another such as mad versus sane, sick versus healthy, or normal versus perverse (Foucault, "The Subject and Power" 326). Within this chapter, dividing practices are how the subjects and characters of the videos construct themselves as disordered eaters versus non disordered eaters, or anorexic versus bulimic, or not recovered versus recovered. Subjectivity is constructed through a binary label. The final area of objectification Foucault explores is the focus of his final work and concerns how "a human being turns him- or herself into a subject. For example, I have chosen the domain of sexuality - how men have learned to recognize themselves as subjects of "sexuality"' (327). 
In "The Subject and Power" Foucault explains Christianity as a form of power that is "salvation-oriented (as opposed to political power)... it is individualizing (as opposed to legal power); it is coextensive and continuous with life; it is linked with a production of truth- the truth of the individual himself" (333). Foucault further argues in the article that pastoral power is about renunciation or self-sacrifice in order to acquire salvation (333). He clearly links confession to pastoral power when he writes "this form of power cannot be exercised without knowing the inside of people's minds, without exploring their souls, without making them reveal their innermost secrets" (333). Although pastoral power has lost part of its efficacy during the $18^{\text {th }}$ century, it was disturbed into the modern state (333-334) and changed to being no longer about "leading people to their salvation in the next world, but, rather, ensuring it in this world. And in this context, the world 'salvation' takes on different meanings: health, well-being (that is, sufficient wealth, standard of living), security, protection against accidents" (334). The new form of pastoral power is exercised through police, the family, schools, medicine, but also through the individual who constructs him or herself through those power relations (334-335).

\section{Parrhēsia and Care of the Self:}

In the winter of 1984 Foucault taught at the Collège de France as a public lecturer, a position he held from 1971 until his death in June of 1984 (Ewald and Fontana xi). From February $1^{\text {st }}$ to March $28^{\text {th }}$ he discussed the concept of care of the self in ancient Greek and Roman philosophy and society, the true life, and parrhēsia. Stylistically the lectures more closely resemble essays and were published in 2008 
under the title The Courage of Truth: Government of Self and Others: Lectures at the Collège de France 1983-1984 and is one of the key texts in Foucault's work on care of the self, the true life, and parrhēsia. Foucault's discussion of care of the self and parrhēsia in essays such as "What is Enlightenment", "The Subject and Power", "The Ethics of the Concern For Self as a Practice of Freedom", and "The Hermeneutics of the Subject", will also be crucial to my application of the concept of care of the self and parrhēsia to characters and subjects in eating disorder memoirs, blogs, and videos.

In "The Ethics of the Concern For Self as a Practice of Freedom" Foucault explains the Ancient Greek concept of care of the self "as knowledge [connaissance] of the self... but also knowledge of a number of rules of acceptable conduct or of principles that are both truths and regulations" (116). Care of the self is selfunderstanding by contemplating and critiquing how modes of behavior and one's subjectivity are shaped by relationships of power. Through self-knowledge, selfmastery emerges and people are able to expel influences that have a destructive effect on their lives and subjectivities (116).

Care of the self thus leads to ethos, or understood in Ancient Greece as a way of living and being that is apparent to others (117). Ethos is also the way a person forms one's self as a moral subject (Foucault, The Courage of Truth 63) and the codes and practices one lives by. In living by one's own morality, one creates the self and is not subjected by a network of power, but practices subjectivation (Gros 511). It is an art of life. In connection to care of the self, ethos is then a behavior that emerges after self-understanding, self-knowledge, and self-mastery, and is the practice of a way of 
life where harmful appetites and influences have been overcome ("The Ethics of the Concern For Self as a Practice of Freedom”, Foucault 116). Through ethos one is able to practice parrhēsia and engage in truth telling about the self, others, and society because a person lives by his or hers ethos and therefore lives what one understands to be a 'true" life. When writing about the memoirists' and bloggers' creation of a self, I am referring to their subjectivation and how the creation of self is in resistance to subjection.

Parrhēsia is the practice of telling all without holding anything back (Foucault, The Courage of Truth 9). The subject is a parrhēsiast when he or she is also not reluctant to speak the truth and speaks only what he or she believes to be the truth to a listening interlocutor (6). The interlocutor's qualification to hear the truth is not determined by an institution, it is determined by the interlocutor's own use of parrhēsia (6). The contemporary interlocutor's lack of qualifications determined by biopower for example, separates the interlocutor from the position of doctor or priest whose position and authority is regulated by biopowers. Because the parrhēsiast speaks the truth, the interlocutor always accepts what is spoken as the truth. The interlocutor does not question what the parrhēsiast says.

Truth for the Ancient Greeks, and for my work as well, does not refer to an internal truth of the individual that is unearthed. It is opposed to the idea of a universal humanism that is inherent since birth. Instead the Greek idea of truth (alēthēs) or the true life (a-lètheia) etymologically means what is not concealed or hidden, what is sincere and does not deceive. Alêthēs also means what is not supplemented or "mixed with something other than itself" (218-219). The truth is also 
straight and direct. The truth is free from twists and turns that would conceal or distort it. Lastly, alēthēs refers to "that which exists and remains beyond any change, which remains in its identity, immutability, and incorruptibility" (219). The truth is the truth because it can never be changed through manipulation or deviation (219). Because parrhēsia is truth speaking, what is spoken is free of distortion and concealment. Truth for the memoir and blogs then means when the subjects are speaking sincerely, openly, and without tools of manipulation. Although parrhēsia is not manipulation, parrhēsia is not always straightforward. Fiction and other artwork for example can be parrhēsia. In literature and even the blogs, the truth is often written or shown through literary conventions such as irony or satire and visuals such as editing, filters, and other devices. Literary, digital theory, and visual tools are then needed to understand the truth spoken through the prose. The truth is not concealed through irony, satire, or a video's editing, but astute readers are needed to comprehend how the literary and visual devices tell the truth.

The parrhēsiast must also take a risk because the truth spoken may jeopardize the parrhēsiast's relationship with the interlocutor or even jeopardize the parrhēsiast's life (11). In truth speaking the parrhēsiast takes a risk because the truth spoken has the possibility of "offending the other person, of irritating him, of making him angry and provoking him to conduct which may even be extremely violent" (11). The risk is what differentiates a parrhēsiast from a teacher, for example, teaching a truth of geometry or astrology (10-11).

It is important to not confuse parrhēsia with rhetoric. In contrast to truth telling rhetoric, is a method of persuasion where the person speaking may not even 
believe what he or she is stating. Foucault writes rhetoric is "a technique, a set of processes which enable the person speaking to say something which may not be what he thinks at all, but whose effect will be to produce convictions, induce certain conducts, or instill certain beliefs in the person" (13) he or she is speaking to. Moreover, the person listening to the rhetorician believes, through the manipulation of the rhetorician's speech, that what is spoken is the truth. Because rhetoric is not about stating a truth, there is no bond between the listener and the rhetorician. Foucault claims that no bond exists between the rhetorician and the listener, it is already destroyed through the manipulative act of rhetoric (13). Parrhēsia lacks manipulation and the desire to persuade because with parrhēsia "there is no question of saying anything other than what one thinks" (13) and therefore everything spoken is the parrhēsiast's truth. Parrhēsia is also a stance or way of life instead of being a skill one acquires as in rhetoric (14).

Although the second chapter of the dissertation will more thoroughly address the challenge of applying Ancient Greek and Roman concepts and practices to contemporary texts and videos, here I will briefly acknowledge the issue here. In the interview "On The Genealogy of Ethics: An Overview of Work in Progress” Foucault answers questions regarding the relevance of care of the self to late twentieth century life, gender and civil rights issues in Ancient Greece, and the practice and adaptation of methods of care of the self after the time of Ancient Greece and Rome.

Early in the interview Foucault explains that Ancient Greek citizens were concerned with moral conduct and following one's own ethics instead of following a moral code associated with religion or the law. Citizens were not interested in 
questions about the afterlife or the legality of their conduct. Instead one was invested in constructing an aesthetic of existence (355). This idea of morality is different than morality in Christianity that is concerned with afterlife and behaving morally in order to get into heaven. According to Foucault the common social dissociation of ethics with religion and the law resembles the then, the interview is from 1983, current state of life. Foucault comments

I wonder if our problem nowadays is not, in a way, similar to this one, since most of us no longer believe that ethics is founded in religion, nor do we want a legal system to intervene in our moral, personal, private life. Recent liberation movements suffer from the fact that they cannot find any practice on which to base the elaboration of a new ethics. They need an ethics, but they cannot find any other ethics than an ethics founded on so-called scientific knowledge of what the self is, what desire is, what the unconscious is, and so on. I am struck by this similarity of problems (355-356).

Late twentieth century life is related to the ancient Greeks in that, like Greek citizens, people want an ethical way of life to understand their desires and other aspects of the self. Although Christianity is no longer the dominant power relation that one uses in order to understand the self, scientific knowledge has become the dominant power to understand the self, despite peoples' attempts to understand the self through new ethics. The current desire to understand one's self through a moral code that is not associated with religion, the law, or science is a desire to care for the self and develop an ethos.

Foucault is not suggesting that society should return to Ancient Greece or that it is even possible to return to former historic periods. He directly states this in the interview when he explains that contemporary problems cannot be solved by recreating a past historic moment and uses the exact tools people once used to solve a 
similar problem (256-2559). Foucault further suggests that Ancient Greece is not a time period current day citizens would desire to return to due to societal sexism and slavery (256). Instead, Foucault is arguing that society's desire to understand the self and create a way of life is similar to the Ancient Greeks' desire to live a life of truth. "We don't have to choose between our world and the Greek world. But since we can see very well that some of the main principles of our ethics have been related at a certain moment to an aesthetics of existence, I think that this kind of historical analysis can be useful" (261). By understanding care of the self in Ancient Greek culture, one can adapt the technique to current times and change it to better fit in the contemporary world. Throughout history methods of attending to the self have resurfaced and been altered by the historic period. For example, Foucault clarifies that during the Renaissance groups, of people resisted the Church and attempted to find their own way of life (278). As Foucault points out then, we "can see, therefore, a reappearance, up to a certain point, not of the culture of the self, which had never disappeared, but a reaffirmation of its autonomy" (278). I will argue that the genres of the memoir are blogs are contemporary altered tools of care of the self. By altering the method of care of the self to contemporary life, one is not recreating a way of life through the Ancient Greek practices, but is creating a way of life that is unique to the late $20^{\text {th }}$ and are early $21^{\text {st }}$ century and is akin with the Greeks' desire to create an aesthetics of existence. The current day methods of care of the self can be practiced by women and thus adapted and not limited by the sexism and classism that existed in Ancient Greece. 
Through anorexia and bulimia, the YouTube video creators use anorexia and bulimia to confess their disordered eating ways and are thus made subject to pastoral powers. The memoirists and bloggers use disordered eating to understand their subjectivity and then care for the self by knowing the self, mastering the self, and bettering the self. Care of the self leads to the memoir and blog subjects' self-mastery and agency. Through self-mastery the subject resist networks of power that subjugate and produce ways of life, as well as other self-destructive behaviors. The bulimic and anorexic subjects of the blogs and memoirs engage in subjectivation, in contrast to the subjects of YouTube who are subjugated. The eating practices in the memoirs and blogs temporarily become the memoir and blog subjects' mode of behavior and a way of life that is visibly reflected through the subjects' choices and bodies.

In my chapters the memoirists and bloggers illustrate the process of care of the self, ethos, and parrhēsia. The first chapter will focus on the genre of the "My Eating Disorder Story" on YouTube and the video creators' use of the medium of YouTube, social media, and branding as a means of confession. This chapter will argue that these subjectifying narratives are in opposition to the narratives of the memoirs and the bloggers where the writers attempt to create personhoods in opposition to systems of power. My second chapter will explore Wasted and the author Marya Hornbacher's contemplation, alteration, and creation of a self under networks of power such as family, school, gender, and the medical community. For my third and fourth chapters I focus on texts that feature subjects that begin to care for the self, develop an ethos, and then speak truths to their collective of readers. In the third chapter I argue the Pro Eating Disorder bloggers' writing is a modernization 
of the Ancient Greek use hupomnematas. Through the act of disordered eating and blogging, the bloggers gain knowledge of the self and attempt to better the self. The fourth chapter on Dana Lise Shavin's memoir The Body Tourist proposes that the memoir is a parrhēsiastic narrative of recovery that challenges cultural notions of what recovery means and how one becomes recovered. 


\section{Works Cited}

American Psychiatric Association: DSM III-R: Diagnostic and Statistical Manuel of Mental Disorders. Brunner, 1987.

Bordo, Susan: Unbearable Weight: Feminism, Western Culture, and the Body. University of California Press, 1993.

Bruch, Hilde. Eating Disorders: Obesity, Anorexia Nervosa, and the Person Within. Basic Books, 1973.

Burns, Marce. "Bodies as (im)material? Bulimia and Body Image Discourse." Critical Feminist Approaches to Eating Dis/orders, edited by Helen Malson, Routledge, 2009, pp. 124-134.

Ewald, Francois and Fontana, Alessandro. "Foreword." The Courage of Truth: The Government of Self and Others II Lectures at the College De France 19831984. Translated by Graham Burchell, Palgrave Macmillan, 2008, pp. xi-xvi.

Fallon, Melanie A. Katzman, and Susan C. Wooley "Introduction." Feminist Perspectives on Eating Disorders, edited by Patricia Fallon, Melanie A. Katzman, and Susan C. Wooley, Guilford Press, 1996, pp. ix-xiv.

Foucault, Michel. The Courage of Truth: The Government of Self and Others II Lectures at the College De France 1983-1984. Translated by Graham Burchell, Palgrave Macmillan, 2008.

---. "The Ethics of the Concern For Self as a Practice of Freedom." Ethics Subjectivity and Truth. Translated by Robert Hurley and Others, The New Press, 1994, pp. 281-302.

---. "Hermeneutics of the Subject." Ethics Subjectivity and Truth. Translated by Robert Hurley and Others, The New Press, 1994, pp. 93-106.

---. "On The Genealogy of Ethics: An Overview of Work in Progress." Ethics, Subjectivity, and Truth, edited by Paul Rainbow. Translated by Robert Hurley, Penguin Books, 1997, pp. 253-280.

---. "Questions on Geography." Power/Knowledge: Selected Interviews and Others Writings: 1972-1977. Translated by Colin Gordon, Pantheon, 1980, pp. 6378.

---. Security, Territory, Population: Lectures at the College de France, 1977-1978. Edited by Michel Senellart. Translated by Graham Burchell, palgrave macmillan, 2004. 
---. "The Subject and Power." Power. Translated by Robert Hurley and Others, The New Press, 1994, pp. 326-348.

---. “What is Enlightenment?" Ethics Subjectivity and Truth. Translated by Robert Hurley and Others, The New Press, 1994, pp. 303-320.

Gros, Frédéric. "Course Context." The Hermeneutics of the Subject: Lectures at the College de France 1981-1982, Translated by Graham Burchell, Picador, edited by Frédéric Gros. 2005, pp. 507-550.

Hess, Amanda. "Let them Blog: The Panic Over Pro-Anorexia Websites and Social Media isn't Healthy." Slate, The Slate Group, 14 Jul. 2016, http://www.slate.com/articles/technology/users/2015/07/pro_anorexia a nd_pro_bulimia_websites_blogs_and_social_media_moral_panic.html. Accessed 10 Feb. 2016.

Hildesheimer, Galya and Gur-Arie, Hemda. "Just Modeling? The Modeling Industry, Eating Disorders and the Law." International Journal of Feminist Approaches to Bioethics vol. 8, no. 2, 2015, pp. 103-138, JSTOR, http://www.jstor.org/stable/10.3138/intjfemappbio.8.2.103. Accessed Feb. 10 2016.

Houston Grey, Stephanie. "A Perfect Loathing: The Feminist Expulsion of the Eating Disorder." Journal of the Kenneth Burke Society vol. 7. no. 2, 2011, pp. 10, http://kbjournal.org/grey. Accessed Feb. 2016.

James. “AboutPrettyThin.” PrettyThin. WordPress, 15 Jun. 2015, http://www.prettythin.cm/. Accessed 30 Sept. 2015.

Probyn, Elspeth: Carnal Appetites Food Sex Identities. Routledge, 2000.

Saukko, Paula. The Anorexic Self: A Personal Analysis of Diagnostic Discourse. State University of New York Press, 2008.

Seber, Emma. "Reading Disorders: Pro-Eating Disorder Rhetoric and Anorexia LifeWriting." John Hopkins University Press, vol. 34, no. 2, Fall 2016, pp. 484508, http://doi.org/10.1353/1m.2016.0023. Accessed 16 Oct. 2017.

Seid, Roberta P. "Too 'Close to the Bone': The Historical Context form Women's Obsession with Slenderness." Feminist Perspectives on Eating Disorders, edited by Patricia Fallon, Melanie A. Katzman, and Susan C. Wooley, Guilford Press, 1996, pp. 3-16.

Thompson, Becky W. A Hunger So Wide and So Deep. University of Minnesota Press: Minneapolis, 1994. 
Vandereychken, Walter and van Deth, Roth. From Fasting Saints to Anorexic Girls. University Press, 1990.

Wykes, Maggie and Gunter, Barrie. The Media and Body Image: If Looks Could Kill, Sage Publications, 2005. 


\section{Chapter 1: \\ Confession, Branding of Anorexia and Bulimia, and the YouTube Subject in My Eating Disorder Story Videos}

On 22 January 2016 Cassey Ho fitness YouTube Celebrity and creator of blogilates posted a 15-minute long video on her YouTube channel called "Why I will NEVER DIET Again.” The video starts with a fake infomercial for an unnamed diet product where a spokesperson, played by Ho in a wig, promises magical weight loss and the chance to have a fit celebrity body. As the video continues Ho explains that between 2012 and 2013 she developed the eating disorder of orthorexia in response to the guidelines of a personal trainer and the strict diet she was on when she competed in a bikini contest. Ho claims that she wants to be honest with her self and YouTube community in order to help others avoid her own experience with disordered eating, as well as reject the harmful influences that made her develop orthorexia in the first place (blogilates).

The video has been watched over 1 million times and has been featured on online health and celebrity culture sites such as HelloGiggles, health.com, DailyMail, MSN, and others. When Googled the video has over 500,000 results concerning blogs and other news sites that have featured and discussed the video.

The video and the sensation the video caused on the Internet represents the growing popularity of the My Anorexia and Bulimia Story videos, but also Ho's rebranding of her YouTube channel and self into a subject of eating disorders and a subject of the mechanisms to present narratives of disordered eating on YouTube. Ho's video follows the codes and conventions of the My Eating Disorder Story genre. Although the beginning of the video is a recreation of an infomercial, the rest of the 
video in contrast is simply framed and features a stationary camera on Ho as she sits in her living room and talks directly into the camera. The rest of the video is composed of intercuts of photographs of Ho as she struggled with her weight, jumpcuts, stills of the word truth over photographs of diet products, text, zooms, photograph advertisements for blogilates, and muted clips from an anti dieting Lean Cuisine commercial. All of these traits are repeatedly found in the My Eating Disorder Story genre on YouTube.

Besides the videos' aesthetics and composition, the content and tone also mirrors the disordered eating story genre of videos. Like the other videos, Ho discusses a former type of eating disorder, features scrolling or frozen text concerning disordered eating and recovery, discusses her sense of self and its connection to disordered eating, rejects negative influences on her sense of self, and features moments of self contemplation. The video and other My Eating Disorder Story videos are then about being incited by the medium of YouTube and aesthetics and conventions of the My Eating Disorder Story genre where one confesses one's narrative of disordered eating.

In the videos the uploaders are also depicted as subjects of YouTube and other systems of power. Ho's dialogue and the medium of YouTube are all rooted in language and ideology that is about essentialist modes of classification that divide subjects. For example, in the video Ho says, "I was working out for all the wrong reasons" and "I want us all to live a healthy and fulfilled life that is not based around the way that we look" (Ho). Wanting individuals to find value outside of their appearances is not a bad idea, but her use of the world healthy and the rest of the 
statement suggests that one cannot be fulfilled by one's appearance, so there is a certain way to then be "healthy" and find "happiness". There is thus "healthy" and "sick". She does not define what "health" or "happiness" means, or what the right reason to work out is, but based on her pledge not to diet and the content of the rest of her channel, health and happiness occur by following her Cheap Clean Eats guidelines and working out for reasons other than being skinny.

In the video Ho also links to a Lean Cuisine video marketing their gadget that monitors how often the word diet is used online. Although the linked website is not selling the "Weigh This Diet Filter", it is a company that sells diet food, so not only is Ho's pledge to not diet contradicted by her endorsement of a Lean Cuisine product, but is linking to another site that is instructing people that there is a certain way to eat healthy, which is eating Lean Cuisine. Ho's video is also engrossed in the essentialist ideology and culture of branding on YouTube. Because YouTube is a business that profits from the success of YouTube personalities, the more popular a personality the more revenue YouTube will earn from views and advertisements. And because YouTube is about the "You" of the video by showing the "You" through the actual appearance of the YouTuber in the video or the appearance of the YouTuber through the personality of the videos and channel, YouTube is about creating a specific personality or brand, where the self is what is branded and sold to the public. Once a certain YouTube brand is popular others will often copy this brand. For example a 2015 study explains how the most popular YouTubers all speak in similar casual linguistic styles that make the uploaders appear more personable. Julie Beck suggests the linguistic similarities between the way popular uploaders speak have likely 
influenced other YouTubers to mimic, perhaps unconsciously, the style of the YouTubers (Beck). This similar content is also seen through gaming channels that have copied the personable and comedic style of YouTube millionaire ihascupquake, the similar structure, aesthetics, and time length of exercise videos, as well as the genre of My Eating Disorder Story and how all the videos resemble each other. YouTube is a power relation that makes one a subject to a specific style and brand on YouTube. The person and content of the YouTube channel becomes a brand, such as the brand of fitness instructor, gamer, or storyteller of eating disorders. The brands or narratives on personal topics such as eating disorders are presented in identical ways, whether consciously or unconsciously by the YouTubers, which then presents disordered eating in an essentialist way and therefore brand. By presenting the stories in an essentialist way or brand, the similar narratives of disordered eating suggest that there is one way to tell the story of one's eating disorder, imposing a truth in what it means to be anorexic and bulimic, and how one chronicles that experience.

My comments are not meant to condemn Ho or refute her advice, but to point out how her language as well as her use of YouTube and the conventions of the My Eating Disorder Story video suggest that there is a correct way to exercise, find happiness, eat, and most importantly for this chapter, that there is a correct way to tell one's disordered eating story. Ho's video may then attempt to challenge standards of beauty associated with weight, but the video still engages in a rhetoric of subjection by following the standard conventions of how YouTube frames narratives of disordered eating. Through the video Ho is then a subject of YouTube's genre of My Eating Disorder Story. 
This chapter will argue that YouTube and specifically the genre of My Eating Disorder Story on YouTube are ways for YouTubers to tell their story of disordered eating in a medium that is easy to use and share with others. But, because the videos all follow the same genre conventions and are engaged in language of system of powers that mark them as subjects, the videos essentialize the experience of disordered eating into a uniformed experience that categorizes the uploaders. The videos all involve the act of confessing one's disordered eating, but also usually use a cinematic language of confession by speaking directly to the camera. The aesthetics of the videos are similar to each other and make the face the central focus of the screen, and use scrolling text, photographs, editing, and music to dramatize and create suspense regarding the words of confession. Because the YouTubers use the act of confession and language of the medical community and Christianity, the videos also then mark the YouTubers as subjects of those networks of power.

It is important to note that I am not problematizing YouTube as a medium of and for confessional storytelling. Instead I am problematizing the confessional genre that normalizes the experience of disordered eating and equates the eating habits with something that one must confess and be ashamed of. YouTube is just a medium of confessional story telling and another example of how one is made subject. There are many other stories being told through YouTube than what I write about in this chapter, so my problematization of this genre of YouTube does not represent all the narratives told through the platform.

Unlike the chapters that follow, this chapter explores how the videos are about the subjection of disordered eating, YouTube and other relations of power, rather than 
subjectivation and rebellion through anorexia, bulimia, and memoir and blog writing. It is important to analyze the narratives of disordered eating told on YouTube, and how they differ from the narratives of disordered eating that occur in the memoirs and blogs. The videos also represent the typical narrative of disordered eating that is found in made for television movies, interviews with celebrities, criticism of the fashion industry and standards of beauty, and narratives about Karen Carpenter. The videos are part of the culture of disordered eating that is written about in the introduction. In the videos disordered eating is associated with shame, secrecy, embarrassment, isolation and a part of the YouTuber's self and life that he or she must renounce in order to find happiness and salvation. In contrast, disordered eating in the memoirs and blogs becomes the inspiration and method the authors use to create a self, rather than being subjected, and are eating habits that bring anorexics and bulimics together, and eating habits to be proud of and even worship.

In what follows I will outline the history of My Eating Disorder Story genre of videos and how YouTube resembles Foucault's concept of dividing powers.

\section{Aesthetics of My Eating Disorder Story Videos and Shame:}

Disordered eating narratives are part of a larger genre on YouTube called “illness narratives” (Holmes 6). The genre consists of videos concerning teenage suffering and are focused on topics involving bullying, self harm, and disordered eating (6). The genre of videos has also been referred to as "pain memes". Amy Shields Dobson explains that the videos all have similar aesthetics, star young girls or boys, and use written text and emotional music to convey their suffering and grief (1). 
Su Holmes further defines the genre of disordered eating narratives as ranging from about 3.5 minutes to 11.5 minutes (Holmes 6), although I will include videos that are slightly over 15 minutes long. The majority of the videos are also represented by white young girls between the ages of 13 and 19 and are native English speakers (6), although I will also consider videos created by people who identify as male and who are older then the average age range. Due to the abundance of the videos on YouTube, as well as the website's inability to search from reverse upload date, it is difficult to locate a date when the videos first began to be uploaded onto YouTube. The oldest video I found was posted on February $7^{\text {th }}, 2007$ by Charlxttte, and is called "My Anorexic Story." The newest videos were posted as recent as an hour ago, suggesting that the videos have been popular since the early years of YouTube and will continue to be popular in the future.

The My Eating Disorder Story narratives have seen some attention in academia and the Internet. Two peer reviewed articles have been written about the videos since 2013. They include the 2013 "Misleading Health-Related Information Promoted Through Video-Based Social Media: Anorexia on YouTube" by 12 researchers in various departments, and the 2016 article written by Su Holmes called “"My anorexia story:' girls constructing narratives of identity on YouTube". In the online eating disorder community some pro-Ana and Mia forums have discussed the videos as recent as 2014 (EmilytheSlayer). The majority of other blogs or sites that discuss the YouTube eating disorder videos are focused on celebrity YouTubers like Ho and their YouTube discussions of their former disordered eating habits (Lodi). Despite the popularity of the videos, little has been written about them. 
There are two types of My Eating Disorder Story videos, a slideshow style video of text and images, and the confessional style of video where the YouTuber is on screen and talks into the camera. The slideshow style of the videos feature only selfies, title cards of text, music, and sometimes old videos of the uploaders. The current day uploader is never seen by a moving camera and no cinematography occurs because the video usually consists only of photographs. Confessional style videos also consist of photographs, text, and music, but feature the uploader talking directly to the camera or webcam. In these videos filters are often used, jumpcuts occur, and the backgrounds of the uploaders' bedroom or other spaces can be seen. The videos can be professionally produced like Ho's video; these videos use a high quality camera and lighting, or, as is more common, are produced by nonprofessional filmmakers who just use a webcam to make the videos.

Regardless of the type of My Eating Disorder Story video, the face, body, and words or confession of the subject are always the central focus of the video, calling attention to the act of confession. In the slide show style of the videos the aesthetics are simple and non professional, but through their lack of flash and other professional filmmaking techniques, the self of the video is called attention to. Because the video techniques lack complexities there are no distractions and the audience is forced to pay attention to the text, editing, and photograps because no other visuals occur. For example, in Charlxttte's video "My Anorexic Story", the 3:15 minute long video features nothing but two selfies, colored texts on title cards, dissolves, a lullaby style song, and zooms into the photographs. Text from the title card includes "anorexia, the Dream Never dies [dissolve edit] and just because I can cope doesn't mean its gone 
[dissolve] one day I saw the people around me suffer [dissolve] they knew.. the farther I'd go, the harder to stop [dissolve] but I never thought it would nearly kill me" (Charlxttte). The dissolves during beats of the song further emphasize the words and create a sense of fluidity between the words by using a soothing style of editing instead of an abrupt or harsh hard cut. Also, as each title card dissolves into the other, certain words change colors highlighting them. For example, in the last line to the quoted text, kill turns from yellow to red during the dissolve, once again simply calling attention to the serious tone of the video and the uploader's desire to call attention to the painful and deadly consequences of disordered eating. Because the video lacks technical complexities, the story of the disordered eating becomes the entire focus of the video.

In the confessional style videos the uploader largely use webcams to film themselves as they discuss their eating disorder story directly to the viewer or camera, also making the face the center of attention. This occurs in rocket girl's "MY ANOREXIA STORY TRIGGER WARNING". In the video rocket girl is in front of a plain white wall and the entire video consists of her talking to the camera. She is in the center of the frame during the entire video and the viewers see her exclusively from her chest to the top of her hairline because the top of her head is cut off. The video is unprofessional in that she is talking to a camera, and the only types of edits that occur are jumpcuts. The framing is also in contrast to traditional cinema in that she does not follow the rule of thirds or leave headroom. The top of her head is cut off by the frame and because she is in the center of a plain white wall, no depth of field can occur. Her face is the only visual interest in the frame and is the central 
focus of the video. This is reinforced by certain jumpcuts in the video that cut her off in mid sentence. These jumpcuts do not undermine rocket girl as a speaker, but the visuals and audio once again draw attention to the self on screen. Jumpcuts are also a type of cut that is often attributed to experimental cinema and French New Wave where the edit is used to draw attention to the medium of film due to the jarring effect of the non continuity edit. Here the jumpcuts are less abrupt because the angles are all identical, only the position of rocket girl's head changes, but because the jumpcuts break up the continuity of the video, often when she is speaking, the medium of the YouTube is called attention to. Because YouTube is about the "You" of the video the face of rocket girl once more becomes the video's focus. Her words are not always then the focus, but her face is. The use of multiple long takes in the video also further draws attention to her face, because the camera remains on rocket girl uninterrupted for long periods of time.

Other videos such as NikkiPhillippi’s “My Eating Disorder” uses a webcam that also draws attention to her self. In her video she uses jumpcuts and speaks directly into the camera, but she uses other technical features such as slow motion, voice filters, and sound effects. In the beginning of the video she starts by singing “Testing, testing, 1,2,3" through a high pitch voice filter and a cinematic filter that makes the image appear as if it has wavy lines like a vintage television. In another moment she uses a slow motion effect to repeat the words "eating disorder", and when she compares herself to Olive from the Popeye cartoon, she edits her snapping fingers with a sound effect that is in time with the popup of an image of Olive. The use of slow motion and sound filters make her the center of attention by giving her a 
strange voice and slowing down time so her words and her corresponding facial movements are exaggerated and last longer. The video is edited to focus longer on her face. She is also always in the center of the frame and only jumpcuts, slow motions, and insertions of photographs on the side of the screen occur. She never leaves the frame. These visuals that call attention to the self setup the act of confession by creating aesthetics that highlight the self and the words spoken by the uploader.

The verbal or written content of the videos are similar. Most of the confessional style videos start off with introductory remarks to the audience, explaining that the videos will be about the uploader's former use of disordered eating. Often the YouTuber's former use of disordered eating is presented as a reveal though, even though the title usually makes the reveal obvious, and a truth that must be spoken if the YouTuber is going to remain honest with his or her YouTube community. Sometimes the YouTuber, such as Ho, will dramatize the reveal of her use of disordered eating and explain how it may come as a surprise to her viewers that she once had an eating disorder. In the video Ho states,

Today in this video I want to share with you something that I've been really ashamed of, and I didn't want to tell you for a really long time, in fact for like three years, because I didn't want to admit to myself that I had a problem, and this is going to be a very emotional, I think video, and I never talked about it publicly, and like I said, I refrained from doing that because I felt like it could be controversial, or could be, a lot of people could judge me for it, but, you know what, I want to be super honest with you (blogilates).

Ho then goes on to state that when she trained for a bikini contest, she developed an eating disorder. The video then cuts to a title card that states "Time to get real." (blogilates), before she chronicles what lead to her disordered eating. Stating that she 
never revealed her disordered eating past before and was ashamed of her disordered eating suggests that not only are eating disorders something to be embarrassed about, but something that must be confessed. The eating disorders cannot be kept to an individual, but must be confessed to the public. Ho must be honest or "get real" (blogilates).

NikkiPhillippi starts her video in a similar way by stating that "Today I am going to talk about and address something that I never blatantly talked about or made a sole video about on this channel" (NikkiPhillippi). When she finally states that what she never talked about before is her eating disorder, NikkiPhillippi uses a slow motion voice effect to slow down "my eating disorder" so the reveal becomes dramatized and the words are exaggerated. Similar to Ho, NikkiPhillippi also clarifies that she no longer has an eating disorder. Like Ho, she then also goes into the story of how she developed an eating disorder. NikkiPhillippi's use of the statement "I never blatantly talked about or made a soul video about" (NikkiPhillippi) is similar to Ho's language of confession and secrecy. Her disordered eating was something she previously hid and now is finally confessing to her audience about her obsessive thoughts concerning her weight and eating habits. Similar to Ho, the language of confession and declaration that she no longer has an eating disorder further places disordered eating into a category of shame, because it is something one must shed in order to get to the stage of confessing.

In Izzy D's video "I blamed Blogilates for my exercise addiction" she is framed similarly to rocket girl's video where the later speaks directly to the camera, is in the center of the frame, and the shot has cut off the top of her head. She is outside, 
but the background of trees also distorts the sense of space, making the scenery all blend together. The visuals then are similar to the other videos and call attention to the self. In the video she states "I" before pausing and leaning closer to the camera and then back again, as if getting ready to tell a secret, and then states "used to be obsessed and addicted to exercise" (Izzy D). The gesture of turning to and away from the camera and pausing sets up the statement of being obsessed with exercise as a revelation and something to confess. As the video continues, she analyzes blogilates and Ho in her attempt to explain how she once obsessively watched the videos and then mistakenly blamed the videos for her eating disorder. Her analysis of Ho occurs when she comments "I thought blogilates, Cassey herself, and anyone else who followed blogilates, must also have this unhealthy weird relationship with exercise" (Izzy D). Although in the video she says she was incorrect to associate blogilates with her own eating disorder and to assume Ho had an eating disorder, she contradicts herself by embedding a link to her reaction video to Ho's "Why I will NEVER DIET Again". The embedded link says "and I was right!!! :o" (Izzy D) and links to her reaction video titled "Blogilates admits to ED \& I am blocked on her instagram :( Response from comments". The use of the title "Blogilates admits to ED" and writing “and I was right!!! :o" (Izzy D) further emphasizes that in the videos disordered eating is something one should be ashamed of and hide at first, because it is something one has to admit, but also something that others are actively trying to figure out, and then out the person for having an eating disorder. And again, Izzy D presents herself as someone who no longer practices disordered eating or mistakenly associates blogilates with disordered eating, which is contradicted by making a 
reaction video about Ho's disordered eating. Regardless of the contradiction, she is presenting her self as someone who does not practice disordered eating any more, and therefore is capable of confessing her story. The video, as well as Ho's and NikkiPhillippi's videos, suggest that eating disorders can only be confessed, when they are no longer being practiced. The aesthetics that call attention to the self highlight the act of confessing and expelling a truth of one's self, a truth that needs to be expelled in order for the uploader to become honest or real.

Other confessional style videos more directly turn the video into a confession:

I can't live my life without telling you guys, cuz you guys are so important to me, and I just want to make something clear right now... Recently I've been feeling like I've been living in two worlds, this one perfect YouTube life, and I was so happy and I love you guys and everything seems so perfect. Perfect family, perfect room, perfect like makeup, outfit, everything, that is not the truth, at all, not even close (Megan Hylands).

Through her language the video is linked to confession and an urgency of confession by words and phrases such as "I can't live my life without telling you guys", "that is not the truth" (Megan Hylands), suggesting that her disordered eating past is her truth, and the truth that she must confess or produced in order to stop living the lie of being a perfect YouTuber. This use of language is similar to the language Ho uses when she uses a title card that states "Time to get real" (blogilates). Again, the representation of anorexia through Hylands' video suggests it is something one is obligated to confess in order to be real or truthful.

The confessional style videos are also linked to confession through the use of the webcam. By calling the videos confessional style videos, I am calling attention to the connotations of the webcam or stationary unmanned cameras that create a similar 
effect as the webcam. The confession cam became popularized by reality television that began in the early 90s in shows such as The Real World. Often called the confession cam by participants on the reality show, the confession cam is a camera mounted on a tripod or embedded into a wall that reality show participants confess to. Usually the confessions are about being annoyed by other housemates or contestants on the television show. The confession cam films the individual without any movement, and usually the editors use limited cuts when editing the confessional scene. This style is replicated in the My Eating Disorder Story videos when, like a reality show participant, the YouTuber just sits in front of the camera and confesses his or her eating disorder. Just through the use of a webcam or stationary camera, the videos are associated with confession.

In the slideshow style of the My Eating Disorder Story genre, the videos also begin with a confession of disordered eating, but are usually more direct about it and state they had an eating disorder through text in the first frame or slide of the video. For example the first two slides of indiefox187's video state "My name is Claire" and then, "I'm 16 years old and recovering from anorexia" (indiefox187), and Elizabeth Mitchell's video begins with the slide "This is My Anorexia Story" (Elizabeth Mitchell). Despite usually directly addressing their eating disorder instead of introducing the video and then confessing about their disordered eating past, the slideshow videos still use a language of confession and create suspense regarding the disordered eating. In Elizabeth Mitchell's video after the first slide a series of title cards are used that state "I was healthy and I had a lot of friends/ I laughed, I smiled, \& talked all the time/ I was happy, really happy/ But then things changed/ I was more 
self-conscious of my body/ I was slowly changing” (Elizabeth Mitchell). Between each title card Mitchell dissolves to photographs of herself with friends, and after she states "But then things changed/ I was more self-conscious of my body/ I was slowly changing" (Mitchell) the photographs now show her weight loss before dissolving to a picture of her in a hospital after what one assumes to be losing too much weight. Similar to how Ho, NikkiPhillippi, and Izzy D wait several minutes into the video to reveal their disordered eating, the way the slides are edited in Mitchell's video make it seem like she is revealing her disordered eating in a dramatic and confessional way. Despite stating in the first slide that the video is about her disordered eating, she has to build up to showing pictures of her disordered eating self and eventually stating that she was "sick, physically, mentally, \& emotionally" (Elizabeth Mitchell).

There is a similar theme of confession in indiefox 187's video, but she uses a song to create this effect. As title cards and selfies are played throughout the video, John Meyer's song "War of My Life" is used. The title is of course important and will be explored shortly in this chapter, but the lyrics are what suggest indiefox 187 is confessing her disordered eating to the YouTube audience. The lyrics state "Come out angels/Come out ghosts/ Come out darkness/ Bring everyone you know/ I'm not running/ And I'm not scared/ I am waiting and well prepared/ I'm in the war of my life/ At the door of my life/ Out of time and there's no where to run away" (Meyer). The song is about facing one's addictions or demons and fighting the war within one's self, and for indiefox 187 to face her demons, she must first confess her anorexia and come out of the darkness to move on or go through the door of one's life and start over. 
AdamJernberg uses a song in a similar way. In his video "My Anorexia Story (Through Pictures)", he plays Goo Goo Dolls' song "Iris". The song is about a narrator attempting to connect with a female lover, and the conflict in his desire to hide aspects of himself from everyone but her. The chorus of the song states "And I don't want the world to see me/ 'Cause I don't think that they'd understand/ When everything made to be broken/ I just want you to know who I am” (Goo Goo Dolls). Through the video AdamJernberg is telling the YouTube community who he is through text and pictures of his former anorexic self. Again, he is confessing.

The idea that anorexia, bulimia, and other types of disordered eating habits are something that need to be confessed in order for one to move on, equates disordered eating with shame and something one should at first hide because it is too unpleasant or controversial for one to discuss openly. Ho directly equates disordered eating with embarrassment and the sensational when she states that she was ashamed of her disordered eating and that discussing her disordered eating is controversial. She also confirms that while she had orthorexia, she was obsessed with how she looked, and that now looking back she thinks of herself as being vain and superficial for being happy over her slender body (blogilates). In Ho's video then, orthorexia or other types of disordered eating are not just shameful, but are linked to one's vanity, which further places shame onto disordered eating.

Psychologists have also written about the presence of both shame and pride in anorexic women. In his article "Shame and Pride in Anorexia Nervosa: A Qualitative Descriptive Study", the author Finn Skarderud explores the presence of the contradictory emotions in anorexic patients. In his study, female anorexic patients 
were interviewed by the author and asked various questions, some which concerned shame. In his results he found that a large portion of the anorexic people interviewed expressed shame over being vain and wanting to lose weight, shame of not living up to one's ambitions, shame in having an eating disorder when others' have to live with more serious problem like war, shame in being sick, and disgust of their bodies and eating (7-12). But others interviewed also explained their pride in being able to starve their bodies and be anorexic while others fail, the pride in being different from others by being exceptionally thin, and the pride felt when a person commented on their slender body (12-13). According to the author, shame and pride co-existing in anorexic patients conveys the complexity of the eating habits (14). The paper concludes by expressing the importance of patients openly discussing what they are ashamed of in order to end silence associated with shame that then prevents the patients from opening up and talking to their therapists about taboo or uncomfortable topics (15).

In Elspeth Probyn's book Carnal Appetites: Food, Sex, Identities, a chapter is focused on shame, disgust, and eating. In that chapter she starts with a story of her own disordered eating past.

Like many, I spent much of my childhood feeling disgusting. However, any evidence of that time is scant. Of the series of photographs that document my childhood, there is an absence that occurs about the time that I was severely anorexic. The reason for the lack of previous documentation is simple: why or how could such a sight be documented? Even now my eyes turn in aversion from memories tinged with a mixture of shame, disgust, and guilt. At the same time, I do remember the splinters of pride that accompanied the disgust; pride at the beautifully prominent set of ribs, the pelvic bones that stood in stark relief, causing shadows to fall on a perfectly concave stomach. Looking back at my experience, I wonder at the 
forces of pride and shame doing battle in a body that know itself to be disgusting (125).

The quote emphasizes the contradicting thoughts regarding disordered eating. It is something both shameful and disgusting, yet something to be proud of. She also questions how the sight of anorexia can or should be documented, if one is both proud yet ashamed of one's former disordered eating.

As the chapter advances Probyn analyzes the meanings of shame, pride, and disgust, as well as representations of body acceptance movements in photographs. The first photographs she analyzes are a series of pictures that showcase an obese body and then an emaciated body. In the obese photograph the body is covered in rolls of fat and in the anorexic photograph the model has sharp bones that jut out. In both pictures the identities of the models are hidden by framings that cut off the models' faces, and the photographs end with information on fat acceptance groups and anorexia support groups (126). Probyn explains that the photographs force the viewer to at first be disgusted but then to feel shame about the former feeling of disgust when first looking at the photographs. Shame of one's disgust then leads the viewer to possibly learning how to accept the obese and emaciated bodies that have been othered by the photographs (126-127). As the chapter continues, Probyn explains that the former disgust over different bodies or people, like obese and anorexic bodies, often is transferred into guilt (129).

Although Probyn's chapter focuses on the disgust and shame experienced by the viewer when looking at obese or emaciated bodies, her argument can be applied to the evocations of disgust, shame, and pride of the creators and videos in the My Eating Disorder Story genre. In the videos though, shame is associated with one's 
disgust over one's former emaciated body, but also one's disgust with his or her former pride over the emaciated body and the effect the eating disorder had on the uploader's family. As explained above, Ho states that she now feels like it was superficial to enjoy and be proud of her more slender body while she was training for the bikini contest (blogilates). Her former pride over her orthorexia, as well as the orthorexia itself, can then be inferred to be what she means when she states that she was ashamed of her disordered eating past. Like in Probyn's argument, Ho's former disgust over her body and superficiality turns to about wasting time on such trivial thoughts as one's appearance.

It is notable that Ho says in in her video that she wants "to share with you something that I've been really ashamed of, and I didn't want to tell you for a really long time" (blogilates), indicating that she is no longer ashamed of the disordered eating, but just ashamed of her vain enjoyment of losing weight. The video then suggests that disordered eating is something one should be ashamed of because it leads one to becoming superficial, but it is also something that one needs to confess in order to be honest. Once one confesses or is ready to confess, then the shame disappears and is replaced with the cathartic experience of confessing. This idea relates to Skarderud's article that ends by stating the importance of patients' discussing what they are ashamed of in order for therapy to be successful and remove the stigma of shame (15). Like the uploaders, the patients needed to confess their shame.

The depiction of disgust and pride is more complicated in the slideshow style of videos. Through the use of photographs, editing, and music, the uploaders' intent 
seems to be to showcase their emaciated bodies as sites of pain and disgust. The shame is also present through the texts of the videos that highlights how the uploaders felt guilty for hurting their families by practicing disordered eating. But, the uploaders' use photographs from when they were anorexic and therefore were taken when the uploader's intent was to showcase or exaggerate their weight loss as an achievement or source of pride.

The intent to evoke disgust through pictures of emaciation is most apparent in AdamJernberg's video. After explaining how anorexia lead to a foggy mental state and his fingernails turning blue, at 3:29 AdamJernberg cuts to a selfie of just his ribs and torso. The angle cuts off his face and legs, and the blanket he is under outlines his jutting ribcage. The video then quickly cuts to a slide that asks "IS THIS BEAUTIFUL?" (AdamJernberg). Through the title card, and earlier title cards that described his blue fingernails, AdamJernberg is relating the image of his ribs to disgust, by questioning how anyone could view the image as beautiful. In other moments in the video AdamJernberg associates his disordered eating with shame by stating that he was "HURTING EVERYONE [HE] LOVED" (AdamJernberg). By linking disordered eating to hurting his family, he is making disordered eating a shameful act because besides making his body disgusting, it negatively affected his loved ones.

The video is full of other similar selfies that cut off his face and feature his slender frame, but this is the only moment where AdamJernberg directly questions his motives in desiring to lose weight. Most of the other selfies of his emaciated body are used in between slides that explain how he cut calories in order to gain control of his 
body during a traumatic time, but also that during that time he found his emaciated body attractive. AdamJernberg writes in one slide at 6:24, "I THOUGHT I WAS FAT.. I THOUGHT THIS WAS ATTRACTIVE" (AdamJernberg), before cutting to a series of selfies that showcase his slender ribcage, his slim face, and a scale showing his weight. The title card functions similarly to the other slide by associating disgust with his anorexic body, but the title card also reveals that like Ho, he once found his anorexic body attractive. The framings of the photographs exaggerate his weight loss by using angles to show off the bones of his ribs and face, and the framing makes his body look smaller by isolating the body parts from the rest of his body by cutting out his face or torso from the photographs. Without talking to AdamJernberg is it impossible to know if he felt pride over his slender body, but because he writes that he found his body attractive, and then took pictures of that attractive body, he valued or had pride over those slender body parts initially, until he recovered and then found them disgusting.

The suggestion of pride created by the selfies is similar to the pride Probyn remembers while thinking back on her own time as an anorexic. "I do remember the splinters of pride that accompanied the disgust; pride at the beautifully prominent set of ribs, the pelvic bones that stood in stark relief, causing shadows to fall on a perfectly concave stomach" (125). The mixture of pride and disgust is also shown in AdamJernberg's video when he writes "I THOUGHT I WAS FAT.. I THOUGHT THIS WAS ATTRACTIVE" (AdamJernberg). The statement is contradictory because it states that he felt fat, something he desperately was trying to shed; on the other hand he thinks he is emaciated and therefore attractive. 
The back and forth between feeling pride, disgust, and shame that Probyn refers to is perhaps why she questions "why or how could such a sight [anorexia] be documented" (125)? The videos suggest that anorexia or other disordered eating habits can only be documented once the uploaders admit and confess their disordered eating habits and view their former disordered eating bodies as disgusting, and the desire to lose weight as something shameful.

The styles of the video are linked to confession and, by implication linked to Christianity and pastoral power. The videos are also linked to branding through their existence of YouTube, so the uploaders are not just subject to Christianity, but are subject to branding and YouTube as a system of power. In what follows I will analyze YouTube and the brand of YouTube and My Eating Disorder Story as a relation of power.

\section{The Subject of YouTube:}

As explained earlier, the language, aesthetics, and goals of the My Eating Disorder Story videos are linked to confession through the uploaders' declarations that they need to finally be honest, the videos' editing that dramatizes the reveal of images of disordered eating, and the use of a webcam that is connected to a language of confession due to its history of use in reality television. These aspects clearly connect the videos to pastoral powers. The uploaders feel like the must be honest or get real to confess inner truths of themselves, which is the inner truth that they once had an eating disorder. The act of confessing is an act or renunciation because the uploaders state how earlier they attempted to hide the truth of their disordered eating 
and were ashamed of their disordered eating past. But, in order to be honest with the YouTube community, which is repeatedly stated to be very important to the YouTubers, they must confess their innermost secret. Only through confession can the YouTuber finally be honest and move on from his or hers disordered eating past to find salvation. The YouTubers are actively using a language of salvation even if most of them are likely unaware of Foucault's writing on pastoral power and may not identify as Christian or as someone using a Christian practice of confession. The YouTubers are also then subject to the redistribution of pastoral powers in the modern state.

The YouTubers identify themselves through the language of systems of power such as psychology and by explaining that they only got better, or acquired salvation, when they admitted to having a disorder or accepted medical help in order to get healthy. Ho never was hospitalized or officially diagnosed as having an eating disorder, or at least she does not reveal this in the video, but does explain how she became healthy. She first explains that when she developed orthorexia, she initially “didn't want to admit to [herself] that [she] had a problem" (blogilates), but once she got fed up with her obsessive dieting and gaining weight even while working out and only eating "clean", she decides to start eating "healthy and normal again" (blogialtes). Eating normally then lead to her being "at peace" and a "state of balance in [her] mind and in [her] body" (blogilates). According to the video, to Ho clean must mean only eating plain chicken breast, plain broccoli, plain lettuce, and plain tilapia, and one squeeze of lemon juice, the food she was allowed to eat while on her bikini training diet. She does not define what healthy or normal means, so it can be 
assumed it means eating anything else. Regardless what she means exactly by health, health is what lead to her salvation and finally being content and at peace with herself. Through her use of language Ho also then becomes a subject of not just religion, but dividing practices where "the subject is either divided inside himself or divided from others" (Foucault, "The Subject and Power" 326). Ho is divided in herself by creating a binary between healthy and unhealthy, eating normally and not eating normally, and orthorexic and not orthorexic. Ho's conscious or unconscious use of language of division further highlights her subjecthood.

Ho's salvation is also similar to the salvation acquired through getting healthy that occurs in other videos. Most of the slideshow videos start with title cards and pictures of the time before they were anorexic, and therefore a time when they were healthy and happy. Mitchell states this explicitly in her video through the title cards. "I was healthy and I had a lot of friends/ I laughed, I smiled, \& talked all the time/ I was happy, really happy/ But then things changed/ I was more self-conscious of my body" (Elizabeth Mitchell). In between these slides are pictures of Mitchell's pre anorexic self, and show her smiling and interacting with friends. The photographs showing her anorexia are in contrast images of her alone and often without any expression. Once Mitchell begins to recover, the photographs change and again showcase the happiness she has after she stopped being anorexic (Elizabeth Mitchell). Happiness is something one is then rewarded or is a salvation one acquires by renouncing disordered eating.

Other YouTubers also use language of dividing practices to tell their stories and link the idea of happiness to the concept of healthy. In AdamJernberg's video, 
halfway through the video he writes that at 145 pounds he was not healthy, and at that lowest weight when the paramedics had to be called for him, it was then that he decided to begin his "JOURNEY TO FIND HAPPINESS" (AdamJernberg). As the video continues he uses pictures and title cards to illustrate and explain how once he stopped practicing anorexia, he was able to gain happiness and find himself. This section of the video also changes to an upbeat song that matches AdamJernberg's happy expression in the photographs and the energy he displays in the embedded videos of the cheerleading competitions he participated in. The video then ends with title cards that states he would never have recovered without the help of his friends. Because the video ends with AdamJernberg finding happiness through recovery, a psychological term, he is equating happiness with finding salvation through psychological concepts of recovery. Because he does not explain what recovery means, similar to how Ho does not explain what healthy means, it can be assumed that he means recovery in a binary way. One is either sick and anorexic, or healthy and recovered. Even though AdamJernberg states that his friends, family, and his own motivation are what lead to his recovery, rather than an eating disorder rehabilitation center, because the meaning of the word recovery is linked to recovery in the medical world, he is engrossing himself and his video in the language of psychology, and therefore is a subject of psychology.

A similar effect occurs through the use of the terms anorexia, bulimia, orthorexic, and disordered eating in the My Eating Disorder Story genre. As conveyed in the introduction, the terms are from psychology, and imply that there is a correct way to eat, which is not being anorexic. These terms then create a truth of the 
proper way to eat or behave, which means one then needs to be corrected in order to reach salvation and find happiness. By explaining the terms' of disordered eating connection to the system of power of psychology, it is not to argue that the psychological community is wrong in how they treat and label anorexic people, but is to point out how the use of a uniform language to tell the stories of disordered eating is rooted in systems of power. The uploaders then can only understand themselves and their past disordered eating behavior by using language that subjugates them into subjects of psychology and disordered eating. The use of the phrase My Anorexic/Bulimic/ Eating Disorder Story title for all of the videos further highlights how the uploaders must use language of a power relation to present themselves through YouTube. But the subjects of the videos are also constructing themselves through the language of YouTube.

\section{History, Medium, and Branding of YouTube and My Eating Disorder Story Genre:}

YouTube first began in 2005 as a site where individuals could easily upload videos, watch videos, store content, and comment and follow others' YouTube uploads (Banet-Weiser 278). The ideology of YouTube as a user friendly site available to everyone, as well as a site about communicating with others, is noted through YouTube's early use of the slogan "Broadcast Your Self" as well as the name YouTube, a play on words joining You with Tube, a slang for television.

The ideology of YouTube changed in 2006 after Google bought the site and YouTube then became about profiting from "You" instead of just a website about 
broadcasting "You". Authors Patrick Vonderau and Pelle Snickars explain in the introduction to their book The YouTube Reader, that after the buyout, Google eventually allowed advertisements to be placed in front of videos, increased competition with platforms such as Hulu, and uploads of content of music and films became more frequent. YouTube's goal changed to profit and became focused on increasing economic gains, shown through the creation of content designed to generate more views so more advertisement deals with corporations would occur. At the same time amateur video uploads continued to be popular, but those videos also usually featured advertisements before the video or embedded advertisements on the bottom of the video (10-11).

In order to make profits from "You", the website became similar to a video store, where through meta information a viewer's interest can be monitored, and then targeted in order to get that viewer to watch more videos, which results in YouTube making more money from advertisements. As defined by Frank Kessler and Mirko Tobias Schafer in "Navigating YouTube: Constituting a Hybrid Information Management System", meta-information are the key words, titles, and info boxes uploaders use to describe their videos, and the key words, titles, and phrases users type while searching for videos (281). Popular searches and keywords become saved by the system, so if one searches for "Cassey Ho diet" YouTube can suggest her video titled "Why I will NEVER DIET Again" based on others who used the phrase earlier to find the video (284). YouTube then uses this information to perform the viewer's interest and offer him or her categories to choose from that matches the person's previous videos and interests, which results in more views and money for 
YouTube if people watch the videos they are recommended. Because YouTubers also want more views, for money or just to have an interactive YouTube community, they also have to perform viewers' interest or become a specific brand.

The uploaders can also use other social media platforms to promote and categorize their YouTube brand and videos. On other social media platforms such as Twitter and Instagram users can tag their posts themselves creating a personal categorizing system that functions as a form of data structuring (Cocq 275). By linking to their own YouTube videos on Twitter and other platforms, the YouTubers create categories and keywords to label and identify their YouTube content. In "Indigenous Voices on the Web: Folksonomies and Endangered Languages" Coppélie Cocq explains that hashtags on Twitter "function as keywords: they are a way to filter, categorize, share, and organize" (275). Although the uploaders do not control the metadata system YouTube uses to monitor and categorize viewers' interests to then suggest other videos to watch, the use of keywords to describe their videos on other platforms results in user controlled keywords. Other people can also link to the videos through Twitter or other platforms and then create their own keywords and hashtags to mark the YouTube content. This style of a collaborate classification system is known as folksonomy. Cocq describes folksonomy as "a usergenerated taxonomy" (275). Folksonomy was coined in 2004 by Van der Val and refers to any type of tag or label that indexes online content to make it easy for others to catalogue and find. Hashtags and other styles of folksonomy grant the tagger the ability to organize content around specific interests and identities (Salazar 17). When YouTubers use hashtags on Twitter to link to their videos they are not just publicizing 
their videos and channels, but they are devising their own classification system. The taggers' use of the keywords sires a brand of various interests to associate the videos with. When other people re-tweet the video the previous tags are repeated and the retweeters can also add their own tags, creating a cycle of keywords that advertise the content of the video in certain ways and continues to brand the videos. Through the synergy of folksonomy the video creators and viewers control the brand of the YouTube videos and channels.

Branding can be used to just create a YouTube personality to attract others with similar interests of that YouTube personality. Sarah Banet-Weiser writes on branding in her article "Branding the Post-Feminist Self: Girls' Video Production and YouTube", and states that due to the structure of YouTube and "the site's dynamic capacity for individual public performances and viewers' comments and feedback, it has become an ideal space to craft a self-brand" (278). Self-branding occurs through YouTube because the platform allows one to create a personality through the performance of the videos, or brand, to then form and interact with a community. By performance I mean the design of the videos, personality of the uploader, subject or genre of the videos, how the uploader interacts with his or her community, and the aesthetic of the YouTube channel. Performance is related to the entire content of the YouTube channel, videos, and community.

And as expressed before, the brand can be commerce based or amateur, so corporations and casual YouTubers can create a brand. For example Ho created the original pilates YouTube channel, blogilates, that uses pop songs in the workout. Her performance is her role as pilates instructor, use of pop songs in her workouts, unique 
pilates moves, and friendly, supportive, and bubbly personality. Through these performances Ho quickly developed the brand of blogilates into a YouTube channel where one could find original pilates workouts, contemporary music, and an encouraging and engaging instructor. Her unique personality/brand is also showcased through the design of her YouTube page that is decorated in pink texts, contains a pink heart and an image of her jumping from her icon, and videos that often begin with the blogilates' logo covered in colorful electronic glitter. The aesthetics of the videos and channel match the lively personality of Ho. Eventually blogilates became so popular that Ho was able to transform her loyal followers, called Popsters, into customers by selling her workout clothes, book, and real life meet ups through her channel. Her branding was successful and she now currently has 3.1 million subscribers (blogilates). Although Ho never states that her videos are professionally made by a friend or hired filmmaker, the quality of the videos have drastically changed since she first started, suggesting that the videos were originally self produced but were later likely created by professional video makers. Because she states that she creates the workouts, designs her own clothes, and writes her motivation slogans, Ho still presents herself as controlling and creating the performance of herself and blogilates, making the people or company that likely creates her videos unimportant. Instead, the brand that she has created is not just about the content of her videos and the aesthetics of her channel, but is about her as a lone and individual performer.

But not all brands on YouTube are used as a platform for a business, but the subjects of the videos are still subject to the effects of branding. For example, 
AdamJernberg has a YouTube channel that is about his jump roping competitions, queer identity, and other fitness and lifestyle related posts. Although he has just under 15,000 subscribers, compared to the 3.1 million of Ho, he has a clear YouTube personality and brand that has attracted a community (AdamJernberg). His branding is seen through the color schemes of his videos and fonts. Under his video page on his YouTube channels the thumbnails of his videos are often overlaid with colored fonts, images or cartoons, and captions all in white, giving his channel a specific aesthetic. Although AdamJernberg likely only makes a small profit from his videos, his YouTube personality is a brand that is selling his personality and videos as products to attract more views and build a community. AdamJernberg likely does not think of himself as a brand, and Ho may likely only think of her channel as a brand, but he and Ho still do become brands of YouTube, because their faces and narratives are part of the experience of their channel. Both Ho's and AdamJernberg's videos and channels are also located in the brand of disordered eating video. Although Ho and AdamJernberg just have single or few videos about their disordered eating history, because the videos follow the genre conventions of My Eating Disorder Stories, they are part of the brand of eating disorder narratives on YouTube.

Brands of YouTube are types of subjection under YouTube because the brands create an essentialist view of the YouTuber, and puts the YouTuber into a category of gamer, exercise instructor, eating disorder confessor, or another label. These brands and categories are how one finds these videos through the site's home page that recommends different types of videos, and through the meta information 
that tracks the interests of the person visiting YouTube. YouTube is a dividing practice that categorizes "You".

The idea of YouTubers being brands and subjects of YouTube is clear when one compares Banet-Weiser's writing on branding to Foucault's writing on modes' of powers effects on the individual. Banet-Wesier states that branding "creates a context within which consumer participation is not simply (or even most importantly) indicated by purchases, but by brand loyalty and affiliation, linking brands to lifestyles, politics, and social activism. Developing a self-brand on commercial social networking sites, such as YouTube, means that girls reference brands not simply as commodities, but as the context for everyday living" (13). Branding is not just what one buys, but how one lives one's life and how one presents his or herself to the world. Foucault writes in "The Subject and Power" that power "applies itself to immediate everyday life, categorizes the individual, marks him by his own identity, imposes a law of truth on him that he must recognize and others have to recognize in him. It is a form of power that makes individuals subjects" (331). Similar to the culture of branding that has not only affected what one buys, but is part of one's lifestyle, Foucault's concept of subjectivity involves power relations using language and other methods to place individuals into categories, which then become the categories one uses to recognize one's self. The brands of YouTube are how the YouTubers present the self to others and how the YouTubers use that brand or truth of one's self to attract and create a community.

Because the My Eating Disorder Story videos are mostly identical, the uniformity of the videos not only creates an essentialist narrative of disordered eating, 
but also imposes a truth of disordered eating. The videos are also mostly identical through the use of tone, photographs, and music. The confessional style of the videos is usually more upbeat because the videos mostly consist of the uploader talking directly to the camera. Although music is often used, it is used as a piece of background and the sound is leveled down in order to make sure the speaker can be heard. The uploader is also usually smiling and welcomes the viewers. Even though the uploader is serious and often shows emaciated pictures of themselves when they practiced disordered eating, the nature of the videos largely feel like a friendly conversation between the uploader and the viewer, making the videos' tone light even if the content of the video is discussing an unpleasant part of his or her life.

The tones of the slideshow videos in contrast are much darker and use editing, music, and photography to depict the period of disordered eating as a traumatic moment in the uploader's life. This is not to suggest that the period of disordered eating was not tragic for the subject of the confessional style videos, but because those subjects are almost always happily and calmly discussing their disordered eating past, the past use of disordered eating is presented in a less traumatic way.

The isolating effect of disordered eating is shown through the use of selfies and photographs. This is seen in indiefox 187's video "My Anorexia Story”, which consists of edits between title cards and photographs, which are shown as the Meyer song "War of My Life" plays. These photographs, edits, title cards, and sound draw attention to indiefox 187 's emaciated body and anorexia's alienating and fragmenting effect on her. For example, the selfie that occurs at the 1:54 minute mark features indiefox 187 in what appears to be a hallway. Due to the high angle of the camera, her 
full body, minus her left arm, is the only element that is actually discernable in the frame. The white wall that is on the left side of the screen as well as the right side of the frame that ends with indiefox187's body encloses her into the frame. At 1:23 indiefox187 includes a photograph that appears to be picture of the uploader with a group of friends on their way to a school dance. The picture is clearly cropped to edit out the friends that were on the right and left side of indiefox 187 . The result is a claustrophobic image where indiefox 187 is again incased in the photograph, but also the black screen that fills the rest of the YouTube video player, and the frame of the television, phone, or computer the video is playing from. Her self is all that there is to look at, and she is alone. The framing of the photographs can be argued to illustrate her obsessive thoughts concerning her body and how anorexia consumed her both physically and symbolically through the claustrophobic photographs, which lead to her isolation from her peers. This isolation from her peers is most notably seen in the photograph where indiefox187 cropped out the friends around her.

In other photographs she does not crop her friends out, but those moments occur when she is attempting to recover and is the process of gaining weight, moments when her disordered eating did not alienate her. The only photograph that does not crop out others and is not during one of her phases of recovery is the photograph at 1:37. In that photograph she is sitting on a bench between several football players during a game. By not cropping out the much older and bigger men, her small disappearing frame is further called attention to, making her an outsider in the picture despite everyone's smiling and welcoming expressions. 
Her painful time as an anorexic is further highlighted by the use of the song, "War of My Life", which as explained earlier is about facing one's demons to start over. But, the song is called "War of My Life", so even though the song has an upbeat melody and is about actively taking charge of one's life, the title suggests that taking charge of one's life will be hard, like war.

Charlxttte's video creates similar dark tones. Charlxttte's video starts with a title card that reads " $\mathrm{i}$ used to be like you" before cutting to a selfie and then a second title card that reads "anorexic", dividing herself from the viewers. The use of photographs are used similarly as indiefox 187 uses them, and again isolates and highlights the emaciated body of the uploader. In contrast to indie187, Charlxttte uses a much more ominous sounding song and only a few photographs, which seem to be stock photographs found online, rather than actual photographs of her, further highlighting her distance and alienation from the world as anorexic by not showing her actual body. The song is called "My Silent Undoing” by Queen Adreena. The song is sung in a breathy voice that is hard to understand, over a haunting melody that resembles a lullaby through the use of xylophones and chimes. The song is also very slow paced and contains lyrics such as "protruding hips and skull, and spine/ ribcage cuts/a clear outline/ oh oh/ all roped up and pinching in/ distorted and disfiguring" (Queen Adreena). Because the song is about an emaciated body, the absence of selfies and photographs in the video does not change the effect of the video, because the song is effective in conveying the pain and isolation created by anorexia. The song also infantilizes anorexia through the lullaby melody. This can connect back to the uploaders' rejection of disordered eating in order to acquire salvation. Besides Ho, 
all of the uploaders are either teens, or explain that they were a teenager or young adult when they practiced disordered eating, suggesting that disordered eating is usually something one engages in a teen or young adult, and is something one must then shed to move on and become a healthy adult.

Although the camera angle creates intimacy between Ho and the viewer, she distances herself from the problematic she is discussing by referring to it as something she has overcome. We learned that Ho's disordered eating is something that she faced alone in the past. This is true for the other confessional style videos that also refer to the eating disorders in the past. Like the association of disordered eating to alienation in the slideshow videos, the confessional style videos also depict disordered eating as alienating times of one's life.

Despite that the videos can have different tones where the confessional style videos are more personable due to the presence of the uploader, and the slideshow style of the videos draw more attention to the uploader's isolation, because the videos are generally identical to each other, the videos essentialize the narrative of disordered eating. Because the videos are all similar, the uploaders are actively constructing their videos to follow the genre conventions, and thus the brand of disordered eating. The YouTubers are constructing themselves as subjects of YouTube through the language of YouTube then is about branding one's self into a specific category that is then easy to market, but a market that also is suggesting that these styles of videos are how one presents themselves as a former sufferer of disordered eating. Notably, due to the removal of videos and identical titles, it is impossible to search for the original My Eating Disorder Story video on YouTube 
that started the trend of using slideshows, the confessional camera, and other devices, suggesting that the language of the My Eating Disorder Story video already existed elsewhere and was earlier imposed onto subjects by a culture of disordered eating as a truth in how to construct one's sense of self.

\section{Conclusion:}

Although online social spaces such as blogs and chat rooms have existed since the beginning of the Internet, in the early 2000s YouTube provided a new and seemingly more personal method of connecting to others by bringing the "You" of YouTube into people's computer screens and thus lives. Through video making programs people were more easily able to visually document their lives through webcams, upload home movies and photographs, create YouTube channels to express their personalities, and to broadcast their stories through filmmaking techniques rather than just through writing. Branding through YouTube became not just a way to possibly make money, but also a way for uploaders to create a self by visualizing one's life, past, interests, and online friendships.

Despite YouTube's ability to allow people to easily tell or broadcast their stories to connect with others, YouTube's ideology of branding through metadata and channel design helped lead to the creation of video genre systems and the identical presentation of what it means to experience disordered eating. Along with one's channel and online personality, the use of certain genre conventions become one's brand. Although the genre conventions or brand of The My Eating Disorder Story Videos cannot be traced to a single origin and seem to have always magically existed 
to inspire creation of the identical videos, the genre or brand exists because YouTubers copy the style of anorexic and bulimic storytelling they encounter when YouTube recommends disordered eating videos. The YouTube brand of disordered eating is characterized by secrecy, shame, disgust, and confession. By associating disordered eating with secrecy, shame, disgust, and eating habits that must be confessed, the videos create a contradictory rhetoric that tells audiences that they must be ashamed of disordered eating but also proudly confess disordered eating at the same time. This confusing rhetoric furthers stigmatizes anorexia and bulimia into controversial and taboo topics that are apparently very embarrassing, totalizing, and difficult to talk about. The stigmatization could lead to more people hiding disordered eating and not seeking help or treatment because of the shame associated with the eating habits. Through the uniform branding of the experience of disordered eating the videos also create an isolating depiction of disordered eating that silences others whose experiences differ from YouTube's brand of disordered eating. Although the videos express the desire to help others with disordered eating, because the videos present anorexia and bulimia in identical ways, people who have alternative narratives of disordered eating do not have a system or brand to tell their "unique" stories. Alternative narrations of disordered eating then are isolated, similar to indie187fox's isolation in her photographs. One can find narratives of disordered eating on YouTube that chronicle the experience in different ways than the My Eating Disorder Story genre, but because of YouTube's use of metadata to create their search system, these counter narratives are hard to find. Instead when one searches for eating disorder stories on YouTube one is presented with the ubiquitous My Eating Disorder 
Story videos that all have the same or very similar titles, and all tell stories of anorexia and bulimia in the same way. YouTube may allow anyone to broadcast themselves, but the "You" easily found and accessible on the site will always be a branded YouTube version of "You" -- a manufactured "You" of disordered eating that through confession feels both stigmatized and proud.

In the memoirs and blogs it is disordered eating that leads to selfunderstanding and a way of life and anorexia and bulimia are not diseases that must be expelled or renounced in order to save the self. In the next chapter I will argue that in Marya Hornbacher's Wasted the author creates a self through memoir writing by being guided and inspired by the culture of disordered eating, a culture that is similar to the culture that inspired the tone and content of the YouTube videos. Through disordered eating Marya gains self-understanding to care for the self and thus refigures anorexia and bulimia into tools needed to care for the self, instead of eating habits one must renounce in order to be saved. In the book Marya is then rewriting the culture of disordered eating that inspired the videos, into a practice that leads to self-understanding and a creation of self. 


\section{Works Cited}

Banet-Weiser, Sarah. "Branding the Post-Feminist Self: Girls' Video Production and YouTube."Mediated Girlhoods: New Explorations of Girls' Media Culture (Mediated Youth), edited by Sharon R Mazzarella, Peter Lang, 2011, pp. 277294.

Beck, Julie. "The Linguistics off 'YouTube Voice."” The Atlantic, The Atlantic.com, 7 Dec. 2015, https:/www.theatlantic.com/technology/archive/2015/12/thelinguistics-of-youtube-voice/418962/. Accessed 21 Oct. 2017.

blogilates. Blogilates, 2017, http://www.blogilates.com/. Accessed 3 Mar. 2017

"Blogilates admits to ED \& I am blocked on her instagram :( Response from comments". YouTube, uploaded by Izzy D, 2 Feb 2016, https://www.youtube.com/watch?v=ejRmJAd-z8U\&list=PLaYZ_A9ig4CKIr_IqI5aSGRhHms8HqBF\&index=8\&t=1s. Accessed 3 Mar. 2017.

Cocq, Coppélie. "Indigenous Voices on the Web: Folksonomies and Endangered Languages." The Journal of American Folklore, vol. 128, no. 509, 2-15, pp. 273-285. JSTOR, http:www.jstor.org/stable/10.5406/jamerfolk.128.509.0273. Accessed 10 Mar. 2017.

Dobson, Amy. 'Girls' 'pain memes' on YouTube: The production of pain and femininity in a digital network." Youth Cultures and Subcultures: Australian Perspectives, edited by Sarah Baker, Brady Robards, and Bob Buttigieg, Routledge, 2015, pp. 1-16.

Emilytheslayer. "Those Anorexia stories on YouTube...." mpa. 13 Jun. 2014, http://www.myproana.com/index.php/topic/208694-those-anorexia-storieson-youtube/. Accessed 10 Mar. 2017.

Foucault, Michel. "The Subject and Power." Power. Translated by Robert Hurley and Others, The New Press, 1994, pp. 326-348.

Goo Goo Dolls. "Iris.” City of Angles, Reprise Records, 1998.

Holmes, Su. “'My anorexia story': girls constructing narrative of identity on YouTube." Routledge Taylor Francis Online, 2016, pp. 1-23. http://www.tandfonline.com/doi/full/10.1080/09502386.2016.1138978. Accessed Jul 182016.

"I blamed Blogilates for my exercise addiction." YouTube, uploaded by Izzy D, 2 Dec 2015, https://www.youtube.com/watch? $\mathrm{v}=\mathrm{Rf} 8 \mathrm{oX} 30 \mathrm{no} 2 \mathrm{Y}$. Accessed 3 Mar. 2017. 
Kessler, Frank and Tobias Schafer, Mirko. "Navigating YouTube: Constructing a Hybrid Infromation Management System." The YouTube Reader, edited by Pelle Snickars and Patrick Vonderau, MEDIEHISTORISKT, 2009, pp. 275291.

Lodi, Marie. "Fitness queen Cassey Ho opens up about her eating disorder." Hello Giggles. People. 24 Jun 2016, http://hellogiggles.com/fitness-queen-casseyho-opens-eating-disorder/. Accessed 2 Mar. 2017.

Meyer, John. "War of My Life.” Battle Studies, Columbia, 2009.

"My Anorexia Story." YouTube, uploaded by Elizabeth Mitchell, 10 Nov. 2014, https://www.youtube.com/watch?v=DLs7dtBGsaA\&list=PLaYZ A9ig4CKIr_IqI5aSGRhHms8HqBF\&index=6. Accessed 3 Mar. 2017.

"My Anorexia Story." YouTube, uploaded by indiefox187, 1 Dec 2013, https://www.youtube.com/watch?v=LxtdK2qVM8A\&list=PLaYZ_A9ig4CKIr_IqI5aSGRhHms8HqBF\&index=5\&t=98s. Accessed 3 Mar. 2017.

"My Anorexia Story (Through Pictures)." YouTube, uploaded by AdamJernberg, 12 Feb. 2015, video removed.

"MY ANOREXIA STORY TRIGGER WARNING." YouTube, uploaded by rocket girl, 19 Dec 2015, https://www.youtube.com/watch?v=qWAJaUBgcIw\&list=PLaYZ A9ig4CKIr_IqI5aSGRhHms8HqBF\&index=10\&t=2s. Accessed 3 Mar. 2017.

"My Anorexic Story." YouTube, uploaded by Charlxttte, 7 Feb 2007, https://www.youtube.com/watch?v=a36gHdehgxw\&list=PLaYZ_A9ig4CKIr_IqI5aSGRhHms8HqBF\&index=19\&t=76s. Accessed 3 Mar. 2017.

"My Eating Disorder." YouTube, uploaded by NikkiPhillippi, 4 Jan. 2014, https://www.youtube.com/watch?v=Gxm8jJE3AqI\&list=PLaYZ_A9ig4CKIr_IqI5aSGRhHms8HqBF\&index=9\&t=140s. Accessed 3 Mar. 2017.

"My Eating Disorder Story." YouTube, uploaded by Hylands, 12 Nov. 2014, video removed.

Probyn, Elspeth. Carnal Appetites: Food, Sex, Identities, Routledge, 2000.

Queen Adreena. “My Silent Undoing.” Drink Me, Rough Trade Records, 2002.

Salazar, Edurado. "Hastags 2.0 - An Annotated History of the Hashtag and a Window to its Future." Icono 14, vol. 15, 2017, pp. 16-54. DOAJ Directory of Open Access Journals, doi: 10.7195/ri14.v15i2.1091. Accessed 19 Sept. 2017. 
Skarderud, Finn. "Shame and Pride in Anorexia Nervosa: A Qualitative Descriptive Study." European Eating Disorders Review, 2007, pp. 1-17. Wiley Online, doi:10.1002/erv.774. Accessed 3 Mar. 2017.

Snickars, Pelle and Vonderau, Patrick. "Introduction." The YouTube Reader, edited by Pelle Snickars and Patrick Vonderau, MEDIEHISTORISKT, 2009, pp. 921.

Syed-Abdul, Shabbir, Fernandez-Luque, Luis, Wen-Shan, Jian, Li, Yu-Chuan, Crain, Steven, Hsu, Min-Huei, Wang, Yao-Chin, Khandregzen, Dorjsuren, Chuluunbaatar, Enkhzaya, Nguyen, Phung Anh, and Liou, Der-Ming. "Misleading Health-Related Information Promoted Through Video-Based Social Media: Anorexia on YouTube." Journal of Medical Internet Research, vol. 15, no. 2, 2013, pp. JSTOR, https://creativecommons.org/licenses/by/2.0/. Accessed 3 Mar. 2017.

"Why I will NEVER DIET Again." YouTube, uploaded by blogilates, 22 Jan 2016, https://www.youtube.com/watch?v=iZGL6rCDyXo. Accessed 3 Mar. 2017. 


\section{Chapter 2}

\section{Creation of Self Through Eating Disorders and Memoir Writing in Wasted}

In her 1998 memoir Wasted: A Memoir of Anorexia and Bulimia, Marya

Hornbacher argues with a doctor regarding the correct pronunciation of her name.

The scene occurs a fourth of the way through the memoir shortly after her parents learn she is using drugs and have forced her to visit her mother's psychiatrist, referred to as 'Dokter Freud' by the adolescent Marya. While first meeting with the doctor, he calls her Mayra and Maria by mistake and continues to mispronounce her name after she aggressively corrects him.

He leaned back in his chair. It creaked. 'Mayra,' he said, contemplatively.

'Marya.'

'Pardon?'

'Marya. My name is Marya. Not Mayra. M-A-R-Y-A.'

'Ah,' he said. 'Maria-'

'MARYA. MAR-YA. Two syllables. Not Maria. Not Myra, not Mayra, not Mara. Marya.'

'Does it bother you when people mispronounce your name?'

'YES' (79).

A few seconds later the doctor calls her Maria again, resulting in an aggravated Marya yelling "MARYA! MY NAME IS MARYA, you FUCK”! (80). The doctor's disregard for Marya's claim to herself through his repeated mispronunciation of her name and her repeated affirmation of the correct way to say her name, questions Marya's right and agency over her sense of self. He disregards the condescending and invasive implications of calling Marya by a different name, whether accidently or on purpose, and is unaware of or unconcerned about how his mistake is connected to a larger lack of control Marya is facing regarding her journey to owning and creating a sense of self in a world that dictates her conduct and often eliminates Marya's sense 
of an autonomous self by failing to acknowledge her existence. Her name is not just representative of the self Marya is attempting to determine for herself, but is representative of her desire for autonomy to be acknowledged, heard, and seen by others.

The conversation where Dokter Freud unknowingly dismisses Marya's sense of self is one of many moments where an authority figure decides and dictates what and who Marya is or should be. Most of these moments result in an enraged Marya affirming her own sense of self and demanding that she knows best regarding her body and psyche. For example, a similar conversation occurs later in the memoir when a seventeen-year-old Marya is confronted by her father after he finds condoms in her room. Marya is shamed and lectured about being too young to have sex and breaking his rules, verbally setting limits with Marya's body as if it were his own. This conversation results in a screaming match between Marya and her father as she argues he has invaded her privacy by raiding her room and being overly protective. During another moment in the memoir, Marya is persuaded by her doctors in the mental institution to confess about being sexually abused as a child, an event that never happened. Marya's past is claimed by the medical community who insist they know Marya's history and the root of her anorexia better than she does. After Marya considers herself recovered, her state of existence is completely ignored during a routine wisdom teeth surgery. Before the surgery Marya warns her doctor about the dangers of anesthesia due to her weak heart condition, a side effect of her years of anorexia and bulimia, but because the doctor fails to see Marya afflicted with an eating disordered body now that she is no longer emaciated, her state of being and 
existence is totally overlooked. She is not treated as a person. Lastly and perhaps the most notable relationship that indicates Marya is a subject to others, is her relationship with her parents. Early in the memoir Marya explains that due to unhappiness, her parents often used their daughter as a tool of competition to determine who was the best parent and most loved by Marya. By aligning with the child, the parents are able to manage the absence of a healthy marital union. Therefore Marya's function in her family was to compensate for others' insecurities, identity crises, and marital problems.

This chapter argues that Hornbacher develops a way of life through the culture of eating disorders and the act of memoir writing in order to create a self in resistance to subjugation. Through the genre of memoir writing Hornbacher informs the reader of her past self's lack of a sense of an autonomous selfhood, before she was anorexic and bulimic, explains the cultural artifacts and people that instructed her how to better herself through controlled dieting and not eating, and chronicles her declaration of self through anorexia and bulimia. In the act of memoir writing and its focus on disordered eating Hornbacher creates a personhood. The writing and structure of Wasted is a crafting of Hornbacher's literary self as the past representation of Marya crafts her body through anorexia.

By the culture of eating disorders I mean cultural artifacts referenced in Wasted such as the magazines and books that tell narratives of girls' and women's creation of a new and better self through disordered eating habits. The culture of eating disorders exists outside of Wasted, but for this chapter I will mostly focus on how the culture of anorexia and bulimia is present within the memoir. The narratives 
in the culture of eating disorders that directly depict anorexia and bulimia always end in recovery, but even though the disordered eating habits are no longer practiced by the female at the center of the story, she still is only able to understand the self and create a sense of self through her anorexia or bulimia. In Wasted the culture of disordered eating is also expressed through people in Marya's life, instead of just the media, who indirectly encourage the creation of a happier self through disordered eating habits by instructing her and other girls to engage in dieting rather than specifically encouraging anorexia or bulimia. It is through the culture of disordered eating that Marya is taught how to better understand herself and craft a sense of self through her anorexia and bulimia. The culture of disordered eating depicted in Wasted is a contemporary version of the ancient culture of care of the self. Arguably Hornbacher uses anorexia and bulimia to understand herself and her place in society, develop an ethos, and then construct a self through the act of memoir writing. With the creation of self through the genre of memoir, Wasted itself then becomes part of the culture of eating disorders.

Before moving on I first need to clarify my use of Marya versus my use of Hornbacher and the distinction between the subject of the memoir and the present day author of the memoir. Throughout the memoir there is a transition between the current day Hornbacher who is in the act of writing the book and the past Marya who is the subject of the book. The current day Hornbacher addresses the act of memoir writing, mostly uses the past tense, and often refers to the culture of eating disorders by addressing readers who have also engaged in practices of disordered eating. The subject of the memoir Marya uses first person and is unable to reflect on her narrative 
of disordered eating because she is living it instead of writing it. Hornbacher has an advantage of being able to reflect on her past and therefore better understand the actions of her past. I will use Marya to stand for the subject of the memoir, and Hornbacher to stand for the author.

In what follows I will first outline Foucault's writing on care of the self in Antiquity and how the culture of disordered eating is similar. Before explaining Foucault's own thoughts of the relationship between the Ancient culture of self care to contemporary times I explain how Marya is subjectified. I then argue that through the structure, content, and genre of the memoir, Hornbacher develops an ethos through an examination of Marya's use of disordered eating and then crafts a self through the genre of memoir writing. The memoir itself and the work it took to create it can be seen as akin to Antiquity's culture of self care.

Here I should clarify that neither the memoir nor this dissertation is an attempt to promote or glorify disordered eating habits. Instead the work of Hornbacher and my own is to write about how through the use of disordered eating habits, Hornbacher becomes involved in an enterprise to create an ethos for herself. Although disordered eating has detrimental risks to the body, it is the tool Hornbacher uses to craft a self.

\section{Care of the Self in Antiquity}

To better understand Foucault's writing on the ancient practice of care of the self and its relevance to the twentieth century, I first outline Foucault's writing on attending to one's self, how the culture of disordered eating is a way of life, and why Marya lacks self determination. By summarizing care of the self in ancient Greece 
and Rome and then discussing the relevance of care of the self to disordered eating, and then, finally explaining Foucault's comments and writing regarding how the practice has been adjusted and reaffirmed throughout history, I am not arguing that Marya or Hornbacher consciously practices the ancient style of care of the self or even knows about the concept. Instead I am arguing that Hornbacher's care of the self through the culture of eating disorders resonates with the ancient Greeks' concern with creating an ethos or way of life that is not founded in religion or the law. Because many people no longer believe that an ethical existence must be associated with religion, according to Foucault, there is a contemporary search for the creation of one's ethos, which recalls the Ancient Greeks' and Romans' search for ethos outside of religion or the law (Foucault, "On The Genealogy of Ethics: An Overview of Work in Progress", 255-256).

In the interview "The Ethic of Care for the Self as a Practice of Freedom", Foucault explains the Greco-Roman concept of care of the self and ethos. For the Greeks and Romans, ethos was "a way of being and of behavior. It was a mode of being for the subject, along with a certain way of acting, a way visible to others... extensive work is required for this practice of freedom to take shape in an ethos that is good, beautiful, honorable, estimable, memorable, and exemplary" (286). In order to create an honorable, estimable, and exemplary way of life, or ethos, the Ancient Greeks and Romans first must understand the self in order to live life according to one's ethics. In the quote, "extensive work" refers to the self-knowledge that is required to develop an ethos and live an ethical life. Developing knowledge of the self and living beautifully and honorably is the act of caring for the self. Earlier in the 
interview Foucault explains care of the self as "knowledge [connaissance] of the self - that is the Socratic-Platonic aspect - but also the knowledge of a number of rules of acceptable conduct or of principles that are both truths and prescriptions" (285). The extensive work in the earlier quote also refers to caring for the self to understand the self, but also the rules of conduct of the world one lives in. Ethos is the creation of self because it is a choice in creating a way of life instead of living one's life in obligation to the religion or law (Foucault, "On The Genealogy of Ethics: An Overview of Work in Progress", 271). Ethos is a choice of existence, a choice in creating a self (Gros 511).

In "The Ethic of Care for the Self as a Practice of Freedom", Foucault also explains that through care of the self a person also develops logos of the self where because one knows the self, one can thus use that knowledge to control fears and desires (286). By knowing one's self, one can "get rid of all the bad habits, all the false opinions that one can get from the crowd or from bad teachers, but also from parents and associates. To 'unlearn' (de-discere) is one of the important tasks of selfcultivation" (Foucault, "The Hermeneutic of the Subject" 97). In Ancient Greece and Rome, through care of the self one expels destructive and harmful influences of the self and transforms and self-cultivates. One can manage one's issues and problems through the act of care of the self. The relationship with the self is reciprocal and Foucault is not suggesting that caring for the self and self-cultivation is an instant process or progression. Instead caring for the self is a lifelong relationship where one is always working on the self and attempting to understand one's way of life and understand how one's self is influenced by others. One is not suddenly affected by 
false opinions, but must constantly work on the effects of those false opinions throughout life. Moreover, the idea of caring for the self is not about totally eliminating the false opinions that constantly effect one's self, but is about becoming aware of the bad habits and false opinions that influence one sense of self and attempting to resist them. This resistance is possible because as Foucault suggests with power there must be freedom, and with freedom there is always the possibility of resistance (Foucault, "The Subject and Power" 342).

Because ethos is "a certain way of acting, a way visible to others"(Foucault, "The Ethic of Care for the Self as a Practice of Freedom" 286), one learns about the act of caring for the self through a mentor or the work of a mentor. Part of caring for the self involves "a relationship with the other insofar as proper care of the self requires listening to the lessons of a master. One needs a guide, a counselor, a friend, someone who will be truthful with you" (287). Because care of the self is about knowing one's self, one can learn truths about the self and one's position in society through a mentor who is also caring for the self and invested in speaking the truth. One is guided or instructed in how to learn to gain self-knowledge and create an ethos. In Antiquity often people engaging in care of the self could learn about others' ethos through writing. In "Technologies of the Self” Foucault writes about texts by authors such as Socrates, Plato, Epicurus, and others and how the writing instructs the readers' how to study the self in order to gain self-knowledge to then use that knowledge to help others attend to the self (226-230).

In Wasted Marya's and Hornbacher's practice of disordered eating and memoir writing is an adaptation of care of the self within Antiquity because it is 
about the search for and the development of her own ethos after Marya is objectified and ignored by parents, and peers in her lack of an autonomous self. My use of the word after is not to suggest that Marya was suddenly subjected in school and previously lived free from subjection, but my use of the word is meant to reflect Hornbacher's representation of Marya's objectification. It is only after we as readers are given the story of Marya's objectification that she attempts to resist objectification.

The act of memoir writing involves reflection of the past, researching one's own life and the life of one's family, possibly finding records, photos, or interviewing people in order to verify one's memory of the past, and then the act of bringing all the work together and authoring a depiction of one's self in writing. The process of memoir writing is a means to care for the self, in that it "requires knowing [connaitre] oneself. Care of the self is, of course, knowledge [connaissance] of the self... but also knowledge of a number of rules of acceptable conduct or principles that are both truths and prescriptions (Foucault, "The Ethics of the Concern for Self as a Practice of Freedom", 285). By crafting the memoir, it is Hornbacher who gains knowledge of the self and knowledge of the truths and prescriptions that affect her. By examining the past of Marya, it is Hornbacher who then uses that knowledge to develop an ethos and create a self through the creation of the memoir. By creating the memoir Hornbacher is caring for the self. Hornbacher gains self-knowledge of Marya's past by locating her moments of subjection and how and why Marya lacked a sense of self. The memoir also informs the reader how Marya was affected by the culture of disordered eating and instructed how to transform herself through anorexia, bulimia, 
and dieting. As the memoir continues and Marya develops disordered eating, Hornbacher explains how the use of anorexia and bulimia becomes a way of life for her to finally control her body and thus control her existence.

\section{Marya as Subject}

In the 2016 article "“The sickness stands at your shoulder...'; Embodiment and cognitive metaphor in Hornbacher's Wasted: A Memoir of Anorexia and Bulimia” Karsten Senkbeil and Nicola Hoppe use Hornbacher's use of mirror imagery to claim that the narrator searches for a sense of self due to "her struggle to define a clear, congruent image of herself in relationship to the world" (13). Although the authors only write about Marya's search for a sense of self in just a few pages of the article, their argument about Marya's struggle to define or create a sense of self is important. The mirrors are not the only literary devices used in the memoir to comment on the desire for a self, but throughout the book Marya explains that while growing up she never felt as though she existed or had a sense of self. Instead she felt that she existed only as a subject of her parents' dysfunctional marriage, a gendered and sexualized subject, and later a medical and psychiatric subject.

The first relationship Hornbacher describes as problematic to her desire to have a sense of self is her relationship with her parents because for her parents, she believes she only exists as a tool to aid in their failing marriage and to cope with their own neuroses. In the beginning of the memoir, Hornbacher explains that her parents were always greatly unhappy, did not initially want a child, were neglectful yet overly clingy, and often fought in front of her (17-22). Her parents' inadequacies as a couple 
are highlighted when Hornbacher explains the story of her parents discovering her mother was pregnant. "I was accidental. My conception caused my mother to lock herself in her bedroom and cry for three weeks while my father chain-smoked in the backyard under the cherry tree. They seem to have gotten it together by the time I was born, because I was met with considerable more joy than one might have expected" (17). In the passage Marya's parents go from people incapable of being parents, to loving parents in a joyful state during the arrival of their daughter. Hornbacher's depiction of her parents is thus contradictory. The use of a contradictory description of her parents points out their erratic state, because they go from one extreme emotion to the other, the inability to communicate with one another and desire a child, to working well together and being joyful at the arrival of their child. Before and after she was born, her parents lacked communication skills and coping mechanisms, leading to Marya becoming the couples' coping mechanism. Her use as a coping mechanism is evident in the passage above, which suggest the parents' eventual love for their upcoming child was the only way the couple was able to get themselves together and prepare for her birth. Hornbacher does not reveal how the parents came together and stopped crying and chain smoking, but her vague writing suggests only that they did get it together for the arrival of baby Marya. The contradictory passage sets up the parents as emotionally inconsistent and immature, and also as people who use their daughter as a tool of communication.

Hornbacher further compares herself to a coping mechanism for her parents when she writes about the way her parents handled her picky eating as a toddler. Marya's refusal to eat as a young child (this is before she began to practice bulimia 
and anorexia) was often the only time the parents stopped arguing and came together to tell their daughter to eat. Hornbacher refers to her parents' management of her eating as the process where the child becomes a symptom bearer for an unstable marriage. The child reenacts the parents' problems, allowing the parents to momentarily unite to focus on the problem of the child (23). Marya exists only in relation to her parents.

Marya's role as a symptom bearer is also evident through her parents' manipulation of her affection in order to manage their failing marriage. Marya's parents often use food and other treats to win their daughter's favor and become the so-called better parent. While looking back on her relationship with her parents, Hornbacher attempts to understand the competition to be the better parent. She writes "Shrinks also note that, lacking a marital alliance, each parent will try to ally him/herself with the child. The child becomes a pawn, a bartering piece, as each parent competes to be the best, most nurturing parent, as determined by whom the child loves more. It was my job to act like I loved them both best - when the other one wasn't around" (26). By being a symptom bearer used by her parents to momentarily be unified, and as a pawn to manage the lack of a marital alliance, Marya's identity and reason for being was since birth, linked to others and never her own. Her existence for her parents since birth it not to suggest she was not also subjected by other powers since birth, but the power relation of her parents' is one of the systems of power Hornbacher chooses to detail. Marya existing to fix or deny a problematic marriage led to her being made a subject to power relations of her parents. 
Marya's subjectivity is also reflected through her parents' expectations. Early in the memoir Hornbacher reveals that her parents did not expect such a loud and illmannered child and therefore were always correcting Marya and trying to mold her into something else. Her parents' expectations and attempts to change Marya, along with her role as symptom bearer and marital pawn, lead to Marya experiencing anxiety over her lack of an autonomous self. This anxiety and lack of a self is reflected here.

I was not what my parents expected. My father expected, or at least hoped for, a child who would adore him and make him feel needed, one who also would remain a child, world without end, amen. My mother, by contrast, expected a miniature adult. Quit acting like a child she'd say... Sit up straight. Use the right fork, put your napkin on your lap, say excuse me, say please, smile for chrissakes, smile, stop crying, quit whining, quit asking why... By the time I was five or so, I began to believe in some inarticulate way that if I could only contain my body, if I could only keep it from spilling out so far into space, then I could by extension, contain myself. If I could be a slip of a thing, a dainty, tidy, bony little happy thing, then the crashing tide of self within the skin would subside, refrain from excess, be still (24-25).

The passage indicates the pressures Marya endured as a child and how she served to soothe her father's insecurities and fulfill her mother's issues of control. Through these expectations, Marya developed a "crashing tide of self" (25), meaning that she was constantly uncertain of who she was and her sense of self was always chaotic.

Her parents' expectations of their child also lead to Marya's fear of spilling out and no longer existing. Hornbacher's use of "spilling out" in the passage is rather complicated in that it can refer to both her desire to form a sense of self that will not be lost to her parents' expectations but also her desire to become skinny and not physically spill out through weight gain. The use of the phrase "spilling out" is 
clearly tied to Marya's eventual turn to bulimia and anorexia when she states that she yearns to be a "slip of a thing", dainty, and a "bony little happy thing" (25).

Hornbacher's use of these words and phrases importantly come after her discussion of her parents' expectations and how they effect her sense of self, indicating that spilling out is a metaphor for both her chaotic self and her belief that once she becomes slender, or really emaciated, she will become a person instead of a device that serves her parents' needs and whose existence is constantly in danger of crashing into itself. This disordered eating will also lead to her jubilation because she will be a "bony little happy thing" (25).

Notably in the passage Hornbacher still uses objectifying language that removes her from her personhood. The use of the word "thing" connects to how Marya's parents treat her as an object that needs to be well behaved and idolize her father. The objectification of Marya by her parents is highlighted by Hornbacher's use of parallel writing when she lists her mother's orders of decorum for several sentences. In each portion of the run on sentence Marya is lectured by her mother but the voice of Marya is never heard through a reply or protest. Her mother's endless orders, enhanced by the use of the run on sentences, crush out Marya completely. Marya's inability to feel like she exists as a person and not a symbol of others' needs or issues is also connected to her sexualization by her peers. Because Marya develops breasts so early she becomes a target of her male peers almost instantly. During lunch boys often snapped her bra strap and commented on her growing breasts (51). In the following pages, Hornbacher connects the boys' bullying concerning her changing body to the cultural concept of puberty. On the next page 
Hornbacher states that according to health classes, nurses, and the media once a girl reaches puberty she has become a woman, and according to the memoirist, being a women coincides with weight monitoring and society's assumption that women must be slender (52). By placing the scene of the boys' abuse of Marya's maturing body just two paragraphs before she writes on the idea of becoming a woman in American culture, the author is linking her objectification to the cultural ideal of womanhood. Not only does Marya's entrance into menstruation signify her growing obsession with weight loss, she became bulimic at age nine one year before her first period, but it signifies her sexual objectification and further denial of any type of self not associated with others' desires or issues.

Marya's feeling as though she does not have a sense of self due to the effects of regiments of power such as her family, school, peers, and society can be considered in the context of Foucault's writing on subjectivity and power relations but also psychologists' concept of objectification theory. Objectification theory emerged in psychology in the mid 1990s and is an attempt to understand cultural effects on women's bodies in patriarchal societies and how "the female body is socially constructed as an object to be looked at and evaluated, primarily on the basis of appearance" (Tiggemann 36). The objectification of female's bodies is seen in mediated images of women, sexual harassment, sexual discrimination, social institutions, and sexual violence. According to the theory, women may internalize the cultural and social objectification of their bodies and unconsciously or consciously view themselves as objects. This internalization contributes to eating disorders, obsessive thoughts on one's appearance, body shame, and depression if one cannot 
obtain an ideal standard of beauty (36-39). Objectification theory is noted for including works of feminist writers in their idea that the concept of gender is a social construction.

Despite psychologists' research that women view and turn themselves into objects, psychologists such as Barbara L. Fredrickson and Tomi-Ann Roberts, two of the early scholars in the movement, explain that women who objectify themselves can still have agency. Often women with eating disorders respond to the objectification of their bodies by using their eating habits for an unconscious or conscious protest. By controlling their bodies through starvation or binge eating the women have agency over their bodies in a world that constantly objectifies them (191-192).

Marya's existence and subjectivity is influenced by others and the culture around her. After puberty she is also labeled and objectified as a sexual being by her male peers and her health class. Once again Hornbacher shows how Marya is fit into a category whose sense of self is shaped by others. Through the effects of relations of power, Marya feels she has no individuality, leading to her inability to feel as though she exists. Hornbacher only forms existence for herself after practicing anorexia and bulimia. In the next section I first explain the difference between care of the self and renunciation in Christianity in order to contextualize Foucault's comments on the similarities in thoughts on ethics between Greco-Romans and contemporary people. Then I will outline how the culture of disordered eating recalls the search for an ethical way of life in Antiquity. 


\section{Care of the Self versus Christian Morality and the Reaffirmation of Care of the}

Self

Before explaining Foucault's points on the Ancient culture of the care for the self, as well the sporadic eruption of care of the self throughout time, it is first important to understand the Ancient Greeks' and Romans' lack of interest in creating an ethos associated with religion and the law. Because Foucault argues that contemporary people are also no longer concerned with forming an ethos based on the rules and morals of Christianity, Foucault's writing on the difference between care of the self and Christianity needs to be clarified.

In "On the Genealogy of Ethics: A Work in Progress" Foucault explains that in Antiquity citizens were not concerned with how their ethics related to religion or other social organizations.

What strikes me is that in Greek ethics people were concerned with their moral conduct, their ethics, their relations to themselves and to others much more than with religious problems. For instance, what happens to us after death? What are the gods? Do they intervene or not? - these are very, very unimportant problems for them, and they are not directly related to any social - or at least any legal- institutional system (255).

Morality for the Greeks was not associated with the concept of morality within Christianity or even the law. Instead, as explained earlier, ethics was the individual's personal choice in cultivating of a way of life.

Care of the self in Ancient Greece and Rome is about understanding the self and learning truths about the self to create a better way of life suited to one's ethics. By truths Foucault does not mean that in Ancient Greece and Rome the people believed there was an eternal truth about one's self because all humans are products 
of human nature and that the soul has been lost or needs to be bettered through self sacrifice to God. Foucault explains this point when he responds to a question about practices of self-freedom. "It is what one could call an ascetic practice, talking asceticism in a general sense- in other words, not in the sense of a morality of renunciation but as an exercise of the self on the self by which one attempts to develop and transform oneself, and to attain to a certain mode of being" (Foucault, “The Ethic of Care for the Self as a Practice of Freedom”, 282). In Christianity one must renounce part of one's self and self-sacrifice in order to become a better person that follows the rules of God. In Greco-Roman culture a person engages in care of the self to gain self-knowledge to develop and attain "a certain mode of being" (282). Although Foucault uses the word asceticism, a word typically associated with selfdiscipline under religion, in the quote he means, as he states, a sense of asceticism. In "An Aesthetics of Existence" Foucault again explains the difference between care of the self in Ancient Greece and Rome and morality within Christianity. "[I]n Christianity, with the religion of the text, the idea of the will of God, the principle of obedience, morality took on increasingly the form of a code of rules... from Antiquity to Christianity, we pass from a morality that was essentially the search for a personal ethics to a morality as obedience to a system of rules" (49). Care of the self is about gaining self-knowledge to create a way of life true to one's personal beliefs. Christianity in contrast is about obeying God and transforming the self according to another's, God's, codes of conduct.

Foucault explains the similarities between contemporary people's search for an ethical way of life when he proposes that codes of conduct associated with 
Christianity have disappeared and therefore people are searching for a new way of life. In "An Aesthetics of Existence" Foucault states that Christian morality is no longer the main method in which people define themselves.

From Antiquity to Christianity, we pass from a morality that was essentially the search for a personal ethics to a morality as obedience to a system of rules. And if I was interested in Antiquity it was because, for a whole series of reasons, the idea of a morality as obedience to a code of rules is now disappearing, has already disappeared. And to this absence of morality corresponds, must correspond, the search for an aesthetics of existence (49).

For Foucault it is not about copying the Greco-Roman style of care of the self today, but his interest, and my interest, in care of the self is that similar to Antiquity, people today, and when Foucault conducted the interview in the 1980s, are searching for an ethical way of life that is not associated with rules and obedience to God. Foucault makes similar remakes in other interviews. In "On the Genealogy of Ethics: A Work in Progress" after explaining the Greeks' and Romans' lack of interest in forming an ethics around God or the law, Foucault connects Antiquity to the contemporary world.

Well, I wonder if our problem nowadays is not, in a way, similar to this one, since most of us no longer believe that ethics is founded in religion, nor do we want a legal system to intervene in our moral, personal, private life... They need an ethics, but they cannot find any other ethics than an ethics founded on so-called scientific knowledge of what the self is, what desire is, what the unconscious is, and so on. I am struck by this similarity of problems (255-256).

Again, Foucault is not interested in returning to Antiquity and recreating their style of care of the self but finds similarities between Ancient Greeks' and Romans' search for an ethical way of life outside of religion and the law, and modern peoples' search for an ethical way of life outside of religion and the sciences. Later in "On the 
Genealogy of Ethics: A Work in Progress", as well as other works such as "The Return to Morality" (244), Foucault explicitly states that ethics of the Ancient Greeks and Romans were not admirable, and that nothing could be gained by returning to a historic period other than the period in which one was born into (Foucault, "On the Genealogy of Ethics: A Work in Progress" 256-257).

In "On the Genealogy of Ethics: A Work in Progress" Foucault also asserts how practices similar to the Greco-Roman style of care of the self never disappeared completely but have just been altered and can be seen during other moments in history.

What is interesting is that during the Renaissance you see a whole series of religious groups... that resist this pastoral power and claim the right to make their own statutes for themselves. According to these groups, the individual should take care of his own salvation independently of the ecclesiastical institution and of the ecclesiastical pastorate. We can see, therefore, a reappearance, up to a certain point, not of the culture of the self, which had never disappeared, but a reaffirmation of its autonomy (278).

Claiming the right to making statutes for themselves and creating a path to salvation outside of ecclesiastical institutions mirrors the Greco-Roman style of care of the self and the creation of an ethos. The religious groups in the Renaissance were likely unfamiliar with care of the self in Antiquity and were thus not actively trying to recreate the classic style of care of the self. As Foucault points out, the religious groups' practice of care of the self was instead like an analogy of Greco-Roman care of the self or as Foucault suggests, "a reaffirmation of its autonomy" (278).

Other writers have also argued that the Greco-Roman care of the self has never fully disappeared but revisions or variations of the style have appeared in post 
Antiquity times. In “An American Foucault” Dan C. Williamson's argues that Ben Franklin's life and his autobiographical writing was an attempt to invent and create a self and is aligned with the invention and creation of self Foucault writes about when studying the philosophy of Ancient Greek and Roman care of the self (192). Towards the end of his essay Williamson also compares the founding of America and the freedom of democracy to the practice of care of the self in Antiquity. "One cannot escape the idea that, in all this, there is the kernel of a highly prized American ideal of the first order: in any occupation and way of life, an American chooses his or her life freely and- just as important - he/she will do it in a way that is honorable and honest, with something like a care of the self that involved knowing the truth of oneself" (202). For the author the cultural concept of being American, the freedom to pursue happiness, is reminiscent to care of the self in Antiquity because it is about selftransformation and the development of ethos.

\section{Hornbacher's Development of an Ethos through the Culture of Disordered}

\section{Eating}

In the introduction to the dissertation, I explained the cultural consensus of anorexia and bulimia and how cultural figures and artifacts such as Karen Carpenter and the media's coverage of her death, made for television movies about disordered eating, and trends in fashion that celebrated emaciation, such as the heroin chic craze, all participate in creating the cultural meaning of disordered eating. These representations of disordered eating are what I mean by the culture of disordered eating. Although most of these texts are designed to discourage disordered eating and 
warn readers or viewers about anorexia and bulimia, they all feature female characters who start off with a problem such as low self esteem, abusive parents or boyfriends, undiagnosed depression, and other issues that lead to the girls' use of disordered eating and becoming a different person, anorexic or bulimic, who no longer suffers from her earlier issue. As an audience we are supposed to understand that the girls' eventually learn that disordered eating is not the answer to their problems so they stop relying on the practices but the narratives present a contradictory story. Because the eating disorders are the tools the girls use to become a different person, anorexia and disordered eating are the answers to their problems within the narratives.

The use of eating disorders to become a new and better person is also depicted indirectly through fashion trends such as the heroin chic craze and other advertisements. In Susan Bordo’s article “Not Just a White Girl Thing” she explains the dilemma between presenting an unrealistic standard of beauty while also presenting a path towards becoming a new happier person who is in control of her body and life.

On the one hand, the idealization of certain kinds of bodies foments and perpetuates our anxieties and insecurities - that's clear. But, on the other hand, such images carry fantasized solutions to our anxieties and insecurities, and that's part of the reason why they are powerful... [Fashion magazines] speak to young people not just about how to be beautiful but also about how to become what the dominant culture admires, values, rewards. They tell them how to be cool. 'get it together,' overcome their shame. To girls and young women who have been abused they may offer a fantasy of control and invulnerability, and immunity from pain (52).

The images in magazines and advertisements are problematic because they create and enforce an unrealistic standard of beauty, but they also create narratives that tell girls 
that through the possession of a slender body, one will be beautiful, and with beauty one can control her life and become immune from pain.

In her book Unbearable Weight Bordo makes other similar arguments when she explains the rhetoric of food advertisements and that in American culture being skinny is associated with being successful at life (10-11). She argues that in dieting advertisements slender, happy, and confident women are displayed alongside captions that chronicle their obsessive thoughts over desserts. The happy presence of the beautiful woman is in contrast to the obsessive thoughts about dieting, creating the narrative that through dieting one will be beautiful and therefore not mind being constantly hungry (61-64). Bordo argues that advertisements often teach women not to eat by featuring women only eating small bites of food or not eating at all. While not eating or only daintily eating the women smile and look beautiful and content $(85)$.

The messages narrated through advertisements and stories of anorexia and bulimia are part of a culture of disordered eating because they create an ethos where women become happy, beautiful, in control, and free of problems after they use anorexia and bulimia to create a new life. Even if dieting is what it depicted, because the women are featured not eating and possessing slender bodies the presence of eating disorders is implied even if unintentional. The advertisements and other texts are thus modern versions of the mentors and guides in Antiquity that helped their students or friends begin the journey of caring for the self. The intent of the advertisements and narratives of disordered eating does not matter. The advertisements are really designed to sell products and not encourage disordered 
eating, and as stated before, the narratives of anorexia and bulimia are usually created to repel girls away from following the eating habits. The narratives still present disordered eating as a way to understand the self and solve other problems and eventually become a better stronger person. Or the narratives indirectly support disordered eating by telling women through dieting or not eating beauty and happiness will occur. What is important is how people interpret the advertisements and stories of disordered eating. Girls like Marya in Wasted interpret the depictions of disordered eating and dieting as a way to a better life and follow the ethos of disordered eating dictated to them through the media or even by other individuals. Through Wasted Marya and Hornbacher use the ethos of the culture of disordered eating to finally feel like she exists and to eventually cultivate a self.

Wasted addresses the culture of disordered eating through descriptions of mothers' eating habits, advertisements, and references to The Best Little Girl in the World. It is through Marya's immersion in these cultural texts that she learns of a way of life to finally feel alive and realize that she matters. Hornbacher does not use the phrase culture of disordered eating or ethos. I am applying those theories and terms to her work. Her writing concerning dieting and narratives of disordered eating indicate that she is aware of the culture of disordered eating and is using the act of memoir writing to attempt to understand and tell her story of anorexia and bulimia.

In the first chapter Hornbacher directly comments on the culture of disordered eating.

I do believe that the cultural environment is an equal, if not greater, culprit in the sheer popularity of eating disorders. There were numerous methods of self-destruction available to me, countless outlets that could have channeled my drive, perfectionism, ambition, 
and an excess of general intensity, millions of ways in which I could have responded to a culture that I found highly problematic. I did not choose those ways. I chose an eating disorder. I cannot help but think that, had I lived in a culture where 'thinness' was not regarded as a strange state of grace, I might have sought out another means of attaining that grace (6-7).

Although Hornbacher's tone towards disordered eating is negative by referring to it as self-destructive and calling society's obsession with slender bodies highly problematic, for Marya it was the tool she used to channel her ambition and perfectionism. For Marya, because she lives in a culture that associates thinness with a means of attaining grace and views thinness as a saintly act, she was instructed by society to attain grace by being anorexic.

The culture of disordered eating and how it instructs girls to eat is evident in the second chapter and indicates how at five years old Marya already knew that fat is bad and one must eat health food in order to have an acceptable body. In the section five-year-old Marya and her friend Gina are searching for food in Marya's home, but only find weird healthy food. The food described as healthy is unsalted peanut butter, alfalfa sprouts, diet iced tea, and whole wheat bread. After Gina criticizes the food, Marya explains that her parents are weird about food and only eat healthy, which is food without sugar, added salt, and whole grains (10-11). Being weird about food is not eating sugary, salty, processed food, or in other words, not eating fatty foods. Marya internalizes her parents' weirdness with food when she studies the nutritional value of cereal. "I pull out a box, look at the nutritional information, run my finger down the side and authoritatively note, It only has five grams of sugar in it. I stick my chin up and brag, We don't eat sugar cereals. They make you fat" (11). Despite that Marya thinks the food is weird, she has internalized the idea that fat is bad and that 
not eating sugar is a source of pride, indicated by her raised chin. Through the use of "We", Marya indicates that she has learned this behavior from her parents. Gina is also aware of the importance of managing one's weight and responds to Marya by stating that she also does not eat sugar and professes that she is on a diet after Marya claims to be on one. Marya is not alone in relying on the culture of disordered eating to change herself because others do as well.

In the scene five-year-old Marya also imagines that if she diets she will be glamorous. After getting in a fight with Gina by calling her mother fat Marya puts on her sunglasses, drinks the diet tea, and imagines herself as the "sophisticated bathing suit lady in the Diet Lipton Iced Tea commercials, tan and long and thin. I lean back casually, lift the can to my mouth. I begin to take a bitter sip and spill it all over my shirt" (11). Although the image of the lady in the iced tea commercials is unattainable, indicated by Marya's failure to reenact her pose and elegance, her recreation of the ad suggests that it is through both her parents and the media that Marya has learned how to conduct herself as a girl. Although the young Marya is likely unaware of the meaning of recreating the pose, by recreating the woman's pose and diet she is attempting to create a better self, even if that self is associated with gender norms and unrealistic body standards.

Although the story of Gina and her encounter with Marya's parents' food is told through Marya's perspective, indicated by the use of first person, Hornbacher is the one who chose to include the story early in the memoir. Similar to her choice to explain the cultural influence in girls' development of disordered eating on the sixth and seventh page of the memoir, including the story so early in Wasted is a way for 
Hornbacher to highlight the importance of food and being thin in her early life. Her editing choices and decision to include these moments so early in the book is the act of Hornbacher studying and understanding herself and gaining knowledge of herself through the act of the memoir. Because Hornbacher is writing a memoir and actively choosing to include the scene where Marya reenacts the pose of the Lipton Iced Tea woman, she is using the memoir to reflect on a past memory to then develop a way of life. Marya's recreation of the pose is not about her subjection by gender norms and standards of beauty, but is about Hornbacher recreating moments of Marya's past to then develop an ethos represented through the body of Wasted.

Another place where Marya associates beauty and becoming a better person with managing one's weight is when she reads the novel The Best Little Girl in the World, a novel based on the real life story of a girl's struggle with anorexia. At this point Marya has already started using bulimia, to comfort herself during moments of unhappiness and stress, (she started at age nine), but The Best Little Girl in the World is where she learns about anorexia in detail.

Shortly after I became bulimic, I went to the library one day to check out a book on anorexia nervosa called The Best Little Girl in the World. I wanted to be her: withdrawn, reserved, cold, wholly absorbed in her own obsession, perfectly pure. Shutting everything out. It is in face a rather romanticized account, written by a doctor intent upon demonstrating not the experience of having an eating disorder but rather his own genius in curing them... I decided that if I did nothing else with my life, I would be an anoretic [Hornbacher's spelling of anorexic] when I grew up (43).

Bulimia may have been her tool in feeling better, but anorexia is the tool needed to transform herself. By relying on anorexia she will become pure and live a romantic life, because that is how she interprets the narrative of The Best Little Girl in the 
World. Despite that the book is a warning of the dangers of anorexia and only accidently romanticizes the eating habit, to Marya, disordered eating is a way of life and a way of life where she will become something better than what she is.

In the quote the present day voice of Hornbacher reflects back on her encounter with The Best Little Girl in the World. This moment resembles the scene between Gina and Marya in that again Hornbacher is looking back on the past by using the medium of the memoir to better understand herself and what about The Best Little Girl in the World inspired her disordered eating. The quote is not from the point of view of Marya but is from the point of view of Hornbacher. By looking back on the past it is Hornbacher who is developing an ethos of disordered eating. Although Hornbacher may no longer practice anorexia, the "real" Hornbacher is irrelevant. Hornbacher is conveying a life of truth associated with disordered eating instead of Marya, because it is Hornbacher who decides what aspects of her life lead to her life of truth.

Eventually Marya stops studying the culture of disordered eating and actually practices anorexia in order to become the graceful, sophisticated, and pure person she learned about from the culture of disordered eating. Quickly after becoming bulimic and then anorexic, Hornbacher summarizes the effects of disordered eating. "When I returned, everything was different. Everything was calm, and I felt very clean. Everything was in order. Everything was as it should be. I had a secret. It was a guilty secret, certainly. But it was my secret. I had something to hold on to" (41-42). Her association of disordered eating is also present when she writes, "My eating disorder was for me, as it is for many of us, one of the only things that I could call my 
own" (67), and later when discussing her time in an asylum, she remarks, "I still had my laxatives, therefore I still had my eating disorder, and therefore I still had myself" (192). The use of "my" is possessive and conveys Marya's growing connection to her anorexia. Anorexia is hers and something to hold on to. Anorexia is herself and something of her own that cannot be taken away from her.

The use of past tense and "us" in the quotes signals the reader to Hornbacher's presence. Because Hornbacher is present here instead of the voice of Marya it is Hornbacher who is creating a sense of self through disordered eating and her repeated use of "my". In her choice to use possessive words and soothing diction such as “calm", "clean", and "in order", Hornbacher, not Marya, is the one developing a desirable ethos and sense of self through anorexia and bulimia. There are other moments in the memoir where Hornbacher uses Marya's voice to depict a glamorous relationship with anorexia, but then undermines that depiction by speaking as Hornbacher and using quotation marks, diction, or other literary devices to point out the lack of glamour actually involved in purging and starving her body. Here, although the quotes are in the voice of Hornbacher, she is not questioning her past relationship with anorexia but is instead embracing anorexia and owning the relationship through the use of "my". It is Hornbacher again who is using literary tools and a literary genre about recalling one's past to create an ethos. The use of "us" in the middle quote suggests that Hornbacher's creation of an ethos through disordered eating is also part of something larger. The "us" refers to all women and girls who developed disordered eating to create an ethos and learned about the disordered eating from the culture of disordered eating. 
As I explain in the analysis of the quotes above, Hornbacher's formation of an ethos through anorexia and bulimia is supported by the genre of the memoir and how Hornbacher composes Wasted. This is indicated through the circumstances of Marya's birth. Hornbacher does not provide the reader with details of her birth until page seventeen (17). The previous seventeen pages chronicle an anorexic friend's near death experience after the disordered eating habits weaken her heart, Marya's lowest weight, her current [when the memoir was written] eating habits, her issues with other writings on disordered eating, her early issues with food before she became bulimic, and her desire to feel like she exists (1-16). On page two of the memoir Marya describes her disordered eating from age nine to eighteen in a lengthy introduction to biographic details of life.

I became bulimic at the age of nine, anorexic at the age of fifteen. I couldn't decide between the two and veered back and forth from one to the other until I was twenty, and now, at twenty-three, I am an interesting creature, an Eating Disorder Not Otherwise Specified [the DSM's name for someone who practices both anorexia and bulimia]. My weight has ranged over the past thirteen years from 135 pounds to 52 , inching up and then plummeting back down. I have gotten 'well,' then 'sick,' then 'well,' then 'sicker,' and so on up to now; I am considered 'moderately improved,' 'psychologically stabilized, behaviorally disordered,' 'prone to habitual relapse.' I have been hospitalized six times, institutionalized once, had endless hours of therapy, been tested and observed and diagnosed and pigeonholed and poked and prodded and fed and weighed for so long that I have begun to feel like a laboratory rat (2-3).

The passage above is full of declarations of existence such as "I became bulimic at age nine", "I am an interesting creature", and "I am considered 'moderately improved,'" (2-3). Although some of the declarations are connected to psychiatric institutions' attempted control of her body, as well as the language of sickness and the 
phrases “"moderately improved,” "“psychologically stabilized, behaviorally disordered," "“prone to habitual relapse"” (3). Hornbacher's use of parentheses suggests that those labels of identity inflicted by the medical community were only temporary. The parentheses make "'sick", "“well”", and “"psychologically stabilized, behaviorally disordered," "transitory states instead of the lasting state of anorexia and its connection to her declaration of self that is shown through her creation of the memoir. The memoir and its ethos of disordered eating will always exist so it is then not just a transitory state of identity. Importantly Hornbacher also includes specific details of her weight and diagnosis, not just to possibly shock and draw in the reader, but also because weight and the ability to fit into diagnostic criteria of disordered eating are common traits anorexic and bulimic women use to identify themselves. Like the use of "us" in an earlier quote, the mention of her various weights connects the writing to a larger practice of care of the self, where in the culture of disordered eating, the controlling of one's weight is connected to the creation of an ethos and self. The declaration and creation of self through disordered eating is akin to the cultivation of self that occurs through the Ancient Greeks' and Romans' practice of care of the self because creation of self occurs through self knowledge and guidance from a mentor. Hornbacher gains self-knowledge through the act of memoir writing and the culture of disordered eating is her guide.

The declarations of existence through first person also mirror her declaration of birth several pages later when she writes, "I was born in Walnut Creek, California, to a pair of exceptionally intelligent, funny, wonderful people who were perhaps less than ideal candidates for parenthood" (17). Similar to her remarks regarding the 
history of her disordered eating, Hornbacher uses first person to establish her state of existence and entrance to the world. But because she marks her entrance into the world first through her writing on her bulimia and anorexia the eating disorders become the signifiers of herself and ethos. Her eating disorders' connection to her ethos is further indicated by Hornbacher's comments about her birth in a sentence directly after the passage cited above. The author writes, "It must also be noted that I was not very well suited to childhood and should have been born fully formed, like Mork and Mindy's kid, who hatched from an egg an old man and grew progressively younger" (17). Here Hornbacher is removing her parents and date of birth, concepts typically associated with the beginning of a person's entrance into personhood, of any rights to her identity. Through memoir writing, Hornbacher is born.

It is important to note that Hornbacher affirms early in the memoir that disordered eating "is an attempt to find an identity, but ultimately it strips you of any sense of yourself, save the sorry identity of 'sick"' (6). This comment occurs after her long introduction of herself through her description of her early years of bulimia and anorexia, her various weights, and hospitalizations. Through the placement of these details of disordered eating before the disclosure of other biographic details and factors of her identity, the structure of the memoir is attributing Hornbacher's ethos to anorexia and bulimia, even if that is not the intention of the memoirist. Anorexia and bulimia may not be the tools the non-literary Hornbacher used to form or claim an identity, but they are the tools she uses to create the ethos of the literary version of Hornbacher in Wasted. 
The genre of the memoir is also connected to Hornbacher's use of anorexia and bulimia to cultivate an ethos. The genre of memoir is about crafting an identity and depiction of self through literature, even if the crafted identity is not related to the reality of the memoirist's sense of self (Gornick 17-25). Because memoirs are often alternations of reality and performances of self, the genre of memoir is also about crafting and performing a self (Buss xiv). Memoirs are also not a complete history of a person's life, but are focused on a specific time or event in the memoirist's life (2). For Hornbacher the specific time and event of her life is her use of bulimia and anorexia. Because she structures the declaration of self to coincide with a history of her disordered eating and because the genre of memoir is always about a specific time in one's life, Wasted itself is also a declaration of the memoirist's disordered eating self.

\section{Conclusion}

In the interview "The Ethics of the Concern for Self as a Practice of Freedom" Foucault is asked if the concept of care of the self in Antiquity can be applied to modern thought (295). Foucault responds with yes but explains that it is not about rediscovering a philosophy from the past and directly applying it to contemporary times. He concludes this thought by commenting, "Which does not mean that contact with such and such a philosopher may not produce something, but it must be emphasized that it would be something new" (295). The something new that has been produced in the twentieth century is the culture of disordered eating that guides girls in how to create an ethical way of life through anorexia and bulimia. As explained in 
the introduction, disordered eating always existed throughout time but the language to discuss anorexia and bulimia did not emerge until the twentieth century, and the culture associated with disordered eating did not emerge until the 1980s with the death of Karen Carpenter.

It is through cultural artifacts of disordered eating such as images of women in magazines, her parents' eating habits, and The Best Little Girl in the World that Marya learns about how to craft a better self and find happiness and acknowledgement of her existence. It is Hornbacher though who uses the genre of memoir writing to return to her past to gain self-knowledge and understand how disordered eating made her feel like a person. Hornbacher is the one who uses the genre of memoir writing to create an ethos associated with anorexia and bulimia and it is Hornbacher who declares existence by creating a self through the structure, tense, and language of Wasted. 
Works Cited:

American Psychiatric Association: DSM III-R: Diagnostic and Statistical Manuel of Mental Disorders. Brunner, 1987.

Bordo, Susan. "Not Just a White Girl Thing." Critical Feminist Approaches to Eating Dis/orders, edited by Helen Malson, Routledge, 2009, pp. 46-59.

Bordo, Susan: Unbearable Weight: Feminism, Western Culture, and the Body. University of California Press, 1993.

Buss, Helen. Repossessing the World: Reading Memoirs by Contemporary Women. Wilfrid Laurier University Press, 2002.

Foucault, Michel. "An Aesthetics of Existence.” Foucault: Politics, Philosophy, Culture: Interviews and Other Writings 1977-1984. Translated by Alan Sheridan and Others, Routledge, 1988, pp. 47-53.

---. Discipline and Punish: The Birth of the Prison. Translated by Alan Sheridan, Vintage Books, 1975.

---. "The Ethics of the Concern For Self as a Practice of Freedom." Ethics Subjectivity and Truth. Translated by Robert Hurley and Others, The New Press, 1994, pp. 281-302.

---. "Hermeneutics of the Subject." Ethics Subjectivity and Truth. Translated by Robert Hurley and Others, The New Press, 1994, pp. 93-106.

---. "On The Genealogy of Ethics: An Overview of Work in Progress." Ethics Subjectivity and Truth. Translated by Robert Hurley and Others, The New Press, 1994, pp. 253-280.

---. "The Return to Morality." Foucault: Politics, Philosophy, Culture: Interviews and Other Writings 1977-1984. Translated by Alan Sheridan and Others, Routledge, 1988, pp. 242-254.

---. "The Subject and Power." Power. Translated by Robert Hurley and Others, The New Press, 1994, pp. 326-348.

---. "Subjectivity and Truth." Ethics Subjectivity and Truth. Translated by Robert Hurley and Others, The New Press, 1994, pp. 87-92.

---. "Technologies of the Self." Ethics Subjectivity and Truth. Translated by Robert Hurley and Others, The New Press, 1994, pp. 223-251.

Fredrickson, Barara L., Roberts, Tomi-Ann. “OBJECTIFCATION THEORY: 
Towards Understanding Women's Lived Experiences and Mental Health Risks." Psychology of Women Quarterly vol. 21, 1997, pp. 173-206.

Gornick, Vivian. The Situation and the Story: The Art of Personal Narrative. Farrar, Strauss, Giroux, 2001.

Gros, Frederic. "Course Context." Michel Foucault The Hermeneutics of the Subject: Lectures at the College de France 1981-1982. Translated by Graham Burchell, Picador, 2001, pp. 507-550.

Hornbacher, Marya. Wasted: A Memoir of Anorexia and Bulimia. Harper Perennial, 1998.

Senkbeil, Karsten, and Hoppe, Nicola. “"The sickness stands at your shoulder...'; Embodiment and cognitive metaphor in Hornbacher's Wasted: A Memoir of Anorexia and Bulimia." Language and Literature, vol. 25, no. 1, 2016, pp. 317, DOI: 10.1177/0963947015608084. Accessed 16 Oct. 2017.

Tiggemann, Marika. "Objectification Theory: Of relevance for eating disorder researches and clinicians?" Clinical Psychologist, vol. 17, 2013, pp. 35-35.

Williamson, Dan C. “An American Foucault." History of Philosophy Quarterly vol. 26, no. 2, Apr. 2009, pp. 189-207, JSTOR, jstor.org/stable/27745156. Accessed 3 Mar. 2017 


\section{Chapter 3: \\ Disordered Eating and Blogging as Hupomnemata, Control, and Means of Care of the Self}

In "Self Writing" Foucault explains the importance of writing in Antiquity in

order to meditate on the self to gain self-knowledge and to then use that knowledge to

master the self and transform one's existence into an ethical way of life. "It seems

that, among all the forms taken by this training (which included abstinences,

memorizations, self-examinations, meditations, silence, and listening to others),

writing - the act of writing for oneself and for others - came rather late, to play a

considerable role" (208). Self-examinations, meditating, and listening to others is part

of the practice of caring for the self. As explained in the previous chapter caring for

the self entails gaining knowledge of the self to reach self-betterment. One needs a

guide or to listen to a mentor to facilitate caring for the self. In the article Foucault

goes on to directly equate the meditative use of writing to the act of attending to the

self. According to Foucault self-writing in Antiquity, and specifically the writing of

Epictetus and Seneca, was exercised in two different ways.

One takes the form of a linear 'series': it goes from meditation to the activity of writing and from there to gumnazein, that is, to training and trial in a real situation - a labor of thought, a labor through writing, a labor in reality. The other is circular: the meditation precedes the notes which enable the rereading which in turn reinitiates the meditation. In any case, whatever the cycle of exercise in which it takes place, writing constitutes an essential stage in the process to which the whole askesis leads: namely, the fashioning of accepted discourses, recognized as true, into rational principles of action. As an element of self-training, writing has, to use an expression that one finds in Plutarch, an ethopoietic function: it is an agent of the transformation of truth into ethos (209).

In writing about the self one first must meditate on the self in order to engage in the activity of writing about the self. Writing becomes a process of self-training because 
with the training of self meditation through writing one reflects, assimilates "and in this manner prepares itself to face reality" (209). Through writing one is trained to work through problems and to learn to face those problems in reality. Self-writing in Antiquity also allowed for further meditation by allowing one to reread one's writing to then further self-meditate, grow, and face one's problems.

The self reflective use of self-writing is seen through Pro Ana and Mia blogs. The medium of blogging has often been associated with self-reflection and selftransformation. Mia Loveheim (338) and Brandi Bell (96) have written about the selfreflective practice of blog writing, and Deborah Silverman Bowen argues that the journal-like practice of blogging provides a source of truth telling for writers and an avenue to encourage self-transformation (311-325). Furthermore, the collective space of blogging allows one to not only write about the self but to include random images, poems, songs, and links to others blogs that further stimulate self-meditating. The blogs are contemporary styles of the Ancient Greek practice of self-writing called the hupomnemata which is similar to a notebook and served as

guides for one's ethical behavior. The notebooks consisted of significant quotes, records of events, and self-reflections. The hupomnemata served as an aid for memory, as an aid to selfexamination, self-reflection, and self-regulation... The notebooks were meant to be reread and consulted; they provided a framework for meditation, reflection, and conversation (McLaren 149).

The medium of the blog is an unconscious modernization of this style of writing because as noted by Loveheim, Bell, and Silverman Bowen, it is self reflective. It also resembles the hupomnemata because it provides an online space where one can record "significant quotes, records of events" and have "conversation[s]" (McLaren 149) with other bloggers. 
Self-reflection through blog writing is repeatedly witnessed in the Pro Ana and Mia blogs. In SkinnyLove the author Kat not Jas uses the blog to understand herself, and through the self-understanding achieved through blogging, attempts to better herself by controlling her emotions. This is conveyed in the most recent post on the blog from August $29^{\text {th }}, 2013$. In the post titled "(btw I think I probably was just being paranoid)" she reflects on her non-existent relationship with A, a boy she has been trying to date while in college.

I noticed that there's a HUGE difference in my mood when things are going well vs. iffily (I just made that word up, I think)... ie. I get super depressed during those moments when I feel certain that it isn't going to work out [with A]. Which I know is bad... my mood should be more stable and not depend so much on the actions of someone else, but that's how it's been (Kat not Jas).

Through blogging Kat not Jas has a self-reflective space to understand her changing mood and attempt to better control her emotions by writing about them in order to grasp the origins of her depression. In other posts on the blog she questions her previous encounters with A and meditates on what to do in order to express her feelings towards him (Kat not Jas, "Are any of you good (or even just adequate will do) with guys?"). Although the self meditating is about a potentially trivial matter such as how to tell a boy you like him, the writing conveys the self-reflective aspect of blogging and its aid in having the writer face reality.

Other blogs such as Ana, Mia, \& Moi are much more serious and uses the act of blogging to understand and develop coping skills to overcome depression, suicide, and a general sense of feeling lost. Throughout the blog the author PoisonedShadow writes about her depressive state. In a March $4^{\text {th }} 2011$ post titled “Adulthood." she 
writes about turning 18, her bipolar thoughts, being forced to change her psychiatrist, and her fears in facing this change.

I know that I am entering adulthood with so much rubbish and such a messed up mind. How is that a good way to start? Will it all get worse?

My psychiatrist is setting up a meeting with the adult psychiatric services so as to transfer me over to them. I will, again, have to go through my life history with someone I don't know. My current psychiatrist, my friend. I trust him so much and I don't know how I'll manage without him to be quite honest... he picks me up when I collapse and we try again (PoisonedShadow).

In the post PoisonedShadow is reflecting about how she will continue to navigate through her depression without the coping mechanism of her psychiatrist. It is an act of self-reflecting to train herself to face the reality of her situation. Through writing and disordered eating she is able to face the reality of her problems and overcome them, or at least begin to overcome them. PoisonedShadow expresses the importance of writing in engaging in self-reflecting when she comments "I really need to start writing regularly again. I miss it. This is my one outlet, and it works well" ("It's Been a While $<3$ "). Self-writing is her outlet to reflect, and as indicated in a later post, disordered eating is the action to use to cope with her depression and other problems. "My relationship has fallen through the floor, my thoughts have started to speed up again and my life feels like it's literally falling apart. And guess what? I know exactly what to do when that starts to happen! Control my food. I have to start restricting again. It makes everything better" (“Here we go again.”). Regardless if disordered eating or restricting her food actually helps PoisonedShadow overcome and control her emotions in the "real" world, it is the coping mechanism she is prioritizing on her blog to feel better about herself and overcome her problems. 
Disordered eating and blogging about herself is the way for PoisonedShadow's online self to face the reality of her situation.

In the previous chapter I argued that through the mentor of the culture of disordered eating and act of memoir writing, Marya constructed a self after being subjugated by others. This chapter will continue my argument regarding the mentor relationship of disordered eating but rather than arguing how disordered eating and the online space of blogging creates a self for the bloggers, this chapter will explore how the blogs are recreations of the Ancient Greek practice of self-writing through the hupomnemata and self writing that facilitates self reflection to encourage self transformation for the blogger. The blog provides an outlet and is a space where the blogger can try to overcome difficult situations and face reality by writing and controlling one's body through disordered eating.

Before moving on I need to clarify my use of the term control, the use of female pronouns when writing about the blogs, and the clarification that the blogs are unconscious modern styles of care of the self instead of a purposeful direct recreation of care of the self from Antiquity. Although the bloggers are consciously using the blogs as sites to gain self-knowledge, write openly and honestly, better the self, and relate disordered eating to a way of life, like in the previous chapter on Wasted I am not arguing that the bloggers are consciously practicing care of the self or recreating the exact conditions and styles of care of the self in Antiquity. Instead I am arguing that the bloggers' use of the medium of blogs and disordered eating are modern alternations of the practice of care of the self and the hupomnemata. 
Because this chapter explores the role of controlling one's body and emotions through disordered eating and blogging, I will define control and my use of the term. For this chapter control means the bloggers' attempt to physically control her body when circumstances beyond her control such as traumatic events, parental power, and romantic relationships claim ownership or affect the blogger's body. Control of the body is a type of power the bloggers use to alter the power relation between herself and her abuser, herself and her parent, or herself and her romantic partner. By controlling her body and documenting the use of disordered eating to manage one's body, the bloggers hope to gain control over their bodies when previously they did not feel like they were in control. As explained by Foucault power relations are always changing ("The Ethics of the Concern for Self as a Practice of Freedom” 283), so the control of one's body through disordered eating and blogging documents that shifting relations of power between the bloggers and others, organizations, and social norms who earlier subjugated the bloggers.

The bloggers' gender also need to be addressed. Although I have been using female pronouns to address the bloggers, the pronouns do not suggest that only people who identify as female create and visit the blogs. This is incorrect and through my research I have found male commenters and blog creators, but those commenters and creators are rare. I will use female pronouns because the majority of the blogs are presented as being created by women, the bloggers refer to themselves as girls, have feminine gendered names, and when posting pictures the poster appears to identify with the female subjects of the photographs. Because there is always a certain level of anonymity online the use of female pronouns, names, and pictures do not mean that 
the bloggers and commenters are female or identify as female, but they are presenting themselves as female online and therefore I will use female pronouns unless the blogs and commenters indicate otherwise.

In what follows I outline the history and structure of the Pro Ana and Mia blogs, the plethora of scholarly writing that exists regarding the blogs, and how the bloggers use disordered eating and blogging to meditate on the self and better the self. For the scope of this paper and the similar research conducted in the previous chapter I do not go into detail regarding how Ana and Mia, the names coined by the bloggers to refer to the two types of disordered eating, are mentors that help the bloggers through the process of caring for the self. Their role as mentor is similar to how the culture of disordered eating guides Marya to use anorexia to craft a self.

Although I will write about other Pro Ana and Mia blogs as well, I will most closely explore care of the self in Ana, Mia, \& Moi, Thin Intentions, and SkinnyLove.

\section{The History of Pro Ana and Mia and its Scholarship:}

Because Pro Ana and Mia blogs are so abundant, and because the websites are often shut down by online providers such as Yahoo, it is impossible to know when the sites first started. Blogging became popular in the mid 1990s (Bell 97) so it can be assumed that Pro Ana and Mia blogs began then. Elisa Burke traces the blogs' beginnings to 1998 (70). Bell defines the general medium of blog writing in her article "Girls' Blogs and Shifting Boundaries". She separates discourse on blogs into two categories, listed here: “one view focuses on blogs mainly as personal writing in the style of a journal or diary, while the other approach defines blogs more in terms of 
gathering internet links and information. For those who define blogs as an online journal or diary, importance is placed on the personal nature of the blog entries and the use of blogs to write about opinions and daily experiences" (96). In the second approach to blogs, the blogs are composed of links and commentary on the gathered information. For this style of blogging, the author's commentary is what is valued by the blog's visitors. The "personal writing is conceptualized as a critique of information as opposed to personal opinions and descriptions of one's everyday life" (96). Pro Ana and Mia blogs are the approaches to blogging that are about the everyday experience of the blogger and serve as an interactive online journal.

The journal like style of the blog is notable through the structure of the eating disorder sites. Almost all the blogs are identical. The blogs sometimes have a main page that acts as a trigger warning, informing the viewer that the blog is a Pro Ana and Mia blog and that if the viewer disagrees with the Pro Ana and Mia lifestyle, or is worried about being triggered by the site, the viewer should stay away. This is seen in the homepage of Pro Ana Goddess where the blog creator writes "HI THIS IS A BLOG ABOUT THE PRO ANA LIFESTYLE IF YOU ARE AGAINST THAT, PLEASE LEAVE" (ProAnaGoddess). On the homepage of Beauty From Pain the blogger beauty makes similar comments but also warns the viewer that the site may trigger disordered eating thoughts. "Some images, links text and thinspiration may be considered triggering in nature... If you do not accept the condition of anorexia/bulimia/other eating disorders then you must also leave this website immediately" (beauty, "Welcome To The World Of Beauty From Pain."). After clicking the enter button the visitor is linked to the latest blog entries of the site. The 
main section of the blogs consists of the blog entries that are usually in reverse chronological order, meaning that the viewer has to search through the most recent posts to get to the first blog entry although sometimes the viewer can search the blog entries by month or year. Most of the blogs are made from free design systems such as WordPress, Blogger, and Weebly. They are free of publisher, editor, and monetary influence and do not have to meet advertiser demands or have large audiences.

The sites also contain sections that outline the religion or lifestyle traits of Ana and Mia, letters to Ana and Mia (when bloggers write to Ana or Mia for advice), types of diets and tips, guides for keeping disordered eating secret from others, a forum section, the ability to comment on posts, links to inspiring poetry and music, help on how to deal with cravings, links to other Pro Ana and Mia sites, the blog creator's weight goals, general tips on practicing disordered eating, and a thinspiration section. The thinspiration pages or images can be separate pages on the websites or can be images inserted into the blogger's posts. The thinspiration images can contain images of the blog creator, although most of the time the pictures are of celebrities or are anonymous pictures of slender girls that can be found on the Internet. Often the same pictures of celebrities or unknown girls are found on several sites. Visually the photographs resemble the aesthetics of the photographs in the "My Eating Disorder Story" videos on YouTube. The lighting is dark to exaggerate the subject of the photograph's bones and angles hide the subjects' face and again enhance the emaciated body being shown.

As blogging continued throughout the late 1990s the blogs became more popular. "It is estimated that websites that cater to discussions about eating disorders 
number anywhere from 200 to $400 \ldots$ to over 500 (Schott and Lagan 1159). Due to the huge numbers of blogs, in the early 2000s the general public became aware of Pro Ana and Mia websites. The blogs received the most critical attention after a 2001 episode of The Oprah Winfrey Show where the talk show host discussed Pro Ana and Mia blogs and showed the audience thinspiration pages (Polak 89-90). After the episode aired the media began to feature articles on the websites declaring them a menace to society. In the early to mid 2000 s media outlets such as $A B C N E W S$ (Depowski and Hart), NBC News (The Associated Press), and NewsWeek (Springen) claimed the sites glamorized disordered eating and helped young girls to kill themselves. As media coverage of the websites increased so did demands to censor the blogs.

The earliest mass censorship of the blogs occurred in 2001 when Yahoo started to delete any eating disordered focused blogs after a series of complaints. As social media grew blog like platforms such as tumblr banned Pro Ana and Mia posts. When tumblr users searched the terms "Pro Ana" or "Pro Mia" the users were directed to PSA announcements about the dangers of disordered eating. Other social media platforms such as Pinterest and FaceBook also banned and censored Pro Ana and Mia content. In response to the anxiety over Pro Ana and Mia materials, France began eliminating advertisements and fashion spreads with overly thin models (Schott and Lagan 1160). In 2014 the websites were again brought to attention when Dr. Oz had a television episode about the Pro Ana and Mia site PrettyThin. In the episode he claimed that the site taught young girls how to be anorexic, a claim in opposition to the goals of the online community which states the site is about creating a virtual 
community where people with disordered eating habits can message each other about anorexia and bulimia (“About PrettyThin”).

Much of the scholarly writing on Pro Ana and Mia websites focuses on either the harm in censoring the websites or the need to censor the websites. Unlike the majority of news sites and the general media that argue that the blogs are alluringly deadly communities, the majority of gender studies in contrast argues that the panic over the blogs are another way to silence young girls, objectify them into victims, and subject them to medical discourses in a patriarchal world. Psychological and sociological writing on the blogs are more mixed and are often fusions of the two understandings on Pro Ana and Mia. In this section I briefly outline the academic writing concerning the blogs to give an overview of the theoretical work that already exists on the blogs. I also overview the writing to emphasize how the writing on the world of Pro Ana and Mia needs to become more comprehensive and explore the specific narratives constructed on individual blogs instead of writing about the blogs in mass. This exploration of the personal narratives of the blogs, rather than the general ideology of the blogs, differentiates this chapter from earlier work on the Pro Ana and Mia community. This differentiation is not to suggest the work on Pro Ana and Mia blogs is not useful, innovative, or compelling, the writing on the blogs is crucial to my work and the authors' respective field, but to suggest that the Pro Ana and Mia blogs must be further explored in academic writing. Due to the vast array of writing on the blogs, I have strived to include writings from when the blogs first received national attention in the early 2000 s, to writings on the blogs from as recent as 2015 . 
Pro Ana and Mia blogs grew to attention in the media after Internet servers actively shut the blogs down once they were deemed too dangerous to exist and Oprah featured the websites on her show during a 2001 episode (Polak 89-90). Since then a significant amount of gender theory has been produced surrounding the blogs. Much of the authors' arguments are similar and they write that the blogs are the attempts of young girls to gain control over their body in a world that is constantly trying to dictate how their body should look or behave. Through the community of the websites the girls create a community of resistance that challenges the medical community. According to the authors the media's and others' attempt to censor the blogs correlates to the patriarchy's systematic control of women's bodies. This is directly stated in the 2015 gender theory and sociological article "Proanorexia/bulimia censorship and public service announcements: the price of controlling women" by Nicole Danielle Schott and Debra Langan. In the article Schott and Langan claim "critiques of censorship are in keeping with feminist analyses that alert us to the many ways in which women's bodies and voices are controlled in patriarchal society" (1170) and that organizations such as the National Eating Disorder Association is a discursive power that routinely produces so called truths about the body, truths which devalue women's personal experiences with their own bodies (1165). Moreover, the authors explain that censoring the websites is “about silencing women" (1170) and stop the blogs' critical analyses of discursive powers and their control of women's bodies (1170). 
In Karen Dias’ 2003 article 'The Ana Sanctuary: Women’s Pro-Anorexia Narratives in Cyberspace", like Schott and Langan, she also proposes that the sites are acts of resistance. In the beginning of the article she lays out her theoretical goal.

In this paper I explore cyberspace as a space in which women who are struggling with anorexia can potentially find sanctuary from the surveillance and regulatory mechanisms of control of the public sphere... Taking seriously the voices of these women can be viewed as a transgressive act, in contrast to hegemonic biomedical and psychiatric discourses of anorexia that portray women with eating disorders as 'irrational' and 'in denial' of their behavior, and pathologize and medicalize their experiences (31).

The websites give voice to women with disordered eating rather than giving voice to the medical communities that pathologize the women and labels them as victims.

In the 2009 article "Pro-anorexia and the Internet: A Tangled Web of Representation and (Dis)Embodiment" Elisa Burke makes similar arguments and professes that "the movement began to represent an 'active' negotiation of discourses and meanings not just about femininity but also about anorexia itself” (71). Burke however questions the empowering aspects of the websites and explains that although the Pro Ana and Mia community challenges medical discursive powers, through the thinspiration portion of the sites Pro Ana and Mia still promote thin ideals and the objectification of the female body (75). For Burke the sites are acts of resistance that challenge systems of power and their treatment of the female body but are also sites that objectify the female body and promote standards of beauty. Despite the problematic use of thinspiration images, Burke argues that the sites should still not be censored because they open up discussion regarding how the female body is regulated by systems of power (78). Other authors such as Paula Saukko (Saukko 60-61) and Katy Day and Tammy Keys (Day and Keys 94) have made similar theories about the 
websites' function as both resistant texts that also promote patriarchal standards of beauty.

Other gender theory writers have focused on the role of identity creation and community through the blogs. In her chapter of the book Growing Up Online: Young People and Digital Technologies Polak notes that the "construction of personal websites allows for a merging of private and public space and site creators are not only aware of this fact but use it to define their sites' purpose... Girls claim ownership of their sites and profess their identities through site design and inclusion/exclusion of content" (84). Identity is created through the content and design of the websites, which is then used to attract community members who also have similar disordered eating identities and lifestyles (84). Through the community of the blogs, the visitors can get both help in practicing disordered eating and moving on from disordered eating. The sites are a communal space (91-92).

Sociological and psychological writing on disordered eating is more divided and some writers create similar arguments as in the field of gender studies, while others equate the blogs to murderous acts and sites that need to be immediately shut down. In the paper "Constructing identities in cyberspace: The Case of eating disorders" David Giles argues that the websites are used by the bloggers to construct identities. The author relies on membership categorization analysis to study 20 websites and the categories of identities the members of the blogs use to construct an online identity and social group. Through the analysis of the categories of identity and interaction in the community, Giles' concludes that investigation of the websites can be beneficial to psychologists and other clinicians who treat disordered eating. The 
websites are important because they provide a venue for understanding disordered eating where psychologists can study disordered eating and interact with the community members in a way that is not available outside of the Internet (466-475).

Teresa Sofia Castro and Antonio Osorio argue in "Online violence: Not beautiful enough... not thin enough. Anorectic testimonials in the web" that the websites may provide a supportive community for people with disordered eating, but are harmful and contribute to the maintenance of an eating disorder and can trigger the development of disordered eating in young children (169-171). In "Effects of Viewing a Pro-Ana Website: An Experimental Study on Body Satisfaction, Affect, and Appearance Self-Efficacy" psychologists and behavioral scientists Monique J. Delforterie, Junilla K. Larsen, Anna M. Bardone-Cone, and Ron H. J. Scholte found through a series of questionnaires concerning body satisfaction, restrictive eating habits, and appearance self-efficacy that women exposed to Pro Ana and Mia websites were not more dissatisfied than participants exposed to only websites that promoted body positivity, fashion magazine websites, or non disordered eating websites (323-331).

Kathleen Custers' paper "The urgent matter of online pro-eating disorder content and children: clinical practice" offers a bridge between the contradictory findings of the two articles summarized above. According to Custers' research in certain cases the supportive community of Pro Ana and Mia has been beneficial to people with eating disorders, but at the same time numerous studies have shown that people exposed to the websites are more likely to copy the disordered eating tips and to feel dissatisfied with their bodies than those who did not visit the sites (430-431). 
Custers' assertion that despite the effect on viewers' eating habits and body satisfaction, the websites are an important source of clinical study that need to be discussed in recovery programs due to the high use of the websites for people with eating disorders. Doctors should also not discourage the use of the websites due to the emotional support provided by the Pro Ana and Mia community (431).

Through a review of gender theory and sociological and psychological research on Pro Ana and Mia websites it is apparent that thoughts on the sites are divided where gender theorists in general find the sites to be sources of community and resistance against systems of power, and sociologists and psychologists have found the websites to provide emotional support for people with disordered eating, but are sites that may or may not be harmful for recovery and may or may not promote disordered eating habits in viewers. Regardless of the contradictory findings by the scholars, the researchers are focused on the websites' ideologies and effect on the public rather than the creation of individual narratives through the websites by the creators of the blogs. In the next sections I will explore the journal- qualities of the blogs, how they are related to the ancient Greek use of hupomnematas, and the narrative of care of the self constructed through Pro Ana and Mia websites. The discursive qualities of blogging as a vehicle for the eating-disordered subject needs to be addressed.

\section{Hupomnemata, Blogging, and Self Reflection through Pro Ana and Mia:}

The goals of the bloggers and the self-reflexive design of blogs can be classed among what Foucault calls acts of care of the self, and the medium of blogging can be 
seen as a form of hupomnematas and self meditating to begin to care for the self. Foucault writes about the Ancient Greeks' use of hupomnematas in various works such as The Hermeneutics of the Subject and "Self Writing" and explains how the notebooks were used in Antiquity not as diary like acts of confession, but as creating a conversation with one's self to recount the day's activities, summarize various literature one was reading, record random thoughts of the day, and as a way to self reflect, meditate, and better the self by overcoming weakness and problems (McLaren 149). The notebooks are about gaining self-understanding and are used to transform the self. They are part of the process in caring for the self. Many of the problems that the bloggers are struggling with are serious issues such as the effects of depression, rape, and molestation and the authors use the hupomnemata writing style of the blogs to understand the self and their trauma. Other bloggers have less serious problems but are still searching for self-understanding and a way of life through the use of disordered eating and blogging. Pro Ana and Mia blogs such as Ana, Mia, \& Moi and ThinIntentions use the blogs to write through emotions, meditate on the self to gain self understanding, and transform the self. The self reflective nature of blog writing helps the Pro Ana and Mia community by granting them a medium to meditate, examine themselves, and use writing to work through one's problems. Thus, the Pro Ana and Mia blogs are modifications of hupomnematas and their use in caring for the self.

Foucault explicates the use of the hupomnemata in "Self Writing:"

Hupomnemata, in the technical sense, could be account books, public registers, or individual notebooks serving as memory aids. Their use as books of life, as guides for conduct, seems to have become a common thing for a whole cultivated public. One wrote down quotes in them, 
extracts from books, examples, and actions that one had witnessed or read about, reflections of reasonings that one had heard or that had come to mind. They constituted a material record of things read, heard, or thought, thus offering them up as a kind of accumulated treasure for subsequent reading and meditation. They also formed a raw material for the drafting of more systematic treatises, in which one presented arguments and means for struggling against some weakness (such as anger, envy, gossip, flattery) or for overcoming some difficult circumstance (a grief, an exile, ruin, disgrace) (209-210).

Through the notebooks one could work through various problems such as grief, anger, gossip, and other issues. The notebooks reflected the daily experience and readings of the writer. Through these notes the writer could understand their daily experience and begin to care for the self. Although one can also self reflect by talking to others or reflecting on the self without writing, the hupomnematas differ because they provide a place for one to reread one's daily activities and have a permanent recollection of one's thoughts. Even if one forgets one's feelings regarding a difficult moment or an inspirational poem, these memoires can be revisited through the record of the journal.

Despite the meditative use of the hupomnematas the notebook should not be confused with a diary and the act of confession. In "Self Writing" Foucault addresses the difference between hupomnemata and the later Christian diaries of confession.

However personal they may be, these hupomnemata ought not to be understood as intimate journals or as those accounts of spiritual experience (temptations, struggles, downfalls, and victories) that will be found in later Christian literature... They do not have the aim of bringing to the light of day the acrana conscientiae, the oral or written confession of which has a purificatory value. The movement they seek to bring about is the reverse of that: the intent is not to pursue the unspeakable, nor to reveal the hidden, nor to say the unsaid, but on the contrary to capture the already said, to collect what one has managed to hear or read, and for a purpose that is nothing less than shaping of the self" (210-211). 
Instead of recording an internal truth, the notebooks were used to record one's daily experience and readings to then meditate on the day's activities to shape a self and to better the self.

The medium of blogs and their use in the Pro Ana and Mia community resembles the use of the hupomnematas in Ancient Greece and blogs have often been compared to journal like writing. According to Bell one of the most common types of blogs is the journal style of blogging that narrativizes one's daily experience (96). Deborah Silverman Bowen relates blogging to truth telling in her article "e-Criture Feminine" and asserts that the Internet provides a unique space where one can tell a narrative free from patriarchal discourse. According to Silverman Bowen the blogs are free of patriarchal discourse because the bloggers are able to create new language, modes of expressions, and communities outside of patriarchal influence (311-313). Loveheim also praises blogs for their self-reflective qualities and the medium's ability to create an ethical space to evaluate social norms and discourse. Through the immediacy of the blogs, the sites can be both self reflective for the writer as well as the reader who can be enticed to also self reflect and negotiate cultural meanings and norms by reading and responding to the blogs (338-350).

In Pro Ana and Mia blogs the authors use the blogs to reflect on the events of the day, list the inspirational art the blogger recently encountered, and as a means to help one struggle against a weakness of difficult circumstance. I'llgettheresomeday's ThinIntentions and PoisonedShadow's Ana, Mia, \& Moi are examples of the hupomnemata style of the blogs. I'llgettheresomeday's blog chronicles her weight management during and after her pregnancy and is an outlet for her to overcome the 
trauma of being raped, becoming pregnant after the rape, and giving up the baby for adoption. PoisonedShadow's blog is also dark and through the journal medium of the blog she uses disordered eating to understand her depression. Both blogs are concerned with creating "raw material for the drafting of more systematic treatises, in which [the bloggers] present arguments and means for struggling against some weakness" and for "overcoming some difficult circumstance (a grief, an exile, ruin, disgrace)" (Foucault, "Self Writing” 210).

Because the hupomnematas are about recording one's daily activities and what one witnesses much of the content of the blogs is not a lengthy autobiography but recounts what the blogger ate during the day, how the blogger kept purging or anorexic eating habits secret from a parent, friend, or boyfriend, the blogger's daily exercises and weight, and how the blogger currently feels about her body. For example in one of the first blog posts by PoisonedShadow the author explains her day. "Down to $1271 \mathrm{bs}$ and I am already finding it hard. The fact that I cannot purge when I eat something is hell for me, it's like breathing. Extra exercise is really helping me shed the pounds though as I have started kickboxing/karate and it is fantastic.... I'm doing quite well in sticking to the 300cal limit. I had a plain salad with a little bit of salad cream today, about 150cals" ("Almost In Sight Of my 1st goal..”). I'llgettheresomeday makes other similar posts in her blog where she summarizes her mundane day. On an April 11 ${ }^{\text {th }}, 2013$ post, like PoisonedShadow, I'llgettheresomeday writes about dieting. "My grandmother and I have been talking about dieting after I give birth. We're going to do a fast together for 3 days to cleanse our bodies. Then I'm going to be on a whole foods diet. I'm not going to eat any 
processed foods, except for diet soda. I'm probably going to do the 'Rainbow Diet' after Noah is born as my first diet" (I'llgettheresomeday, "Dieting.”). Like PoisonedShaodw's post I'llgettheresomeday is using the posting section of the blog to explain her daily actions and thoughts and to plan for future activities. This recalls Foucault's explanation of the hupomnematas and how the notebooks were used to constitute "a material record of things read, heard, or thought, thus offering them up as a kind of accumulated treasure for subsequent reading and meditation" ("Self Writing” 209). The blogs serve as recordings of the blogger's daily experience with disordered eating.

Through the blogs' records of the day's activities and random thoughts, the blogs resemble the hupomnemata in Ancient Greece and its use as a medium of note taking to meditate on the self and develop codes of conduct to guide one in self governance, to then manage one's weakness and get through difficult circumstances. As stated before the posts on the Pro Ana and Mia blogs are seemingly just about the author's dieting habits, but issues of weight are just the surface content of the blog, and in actuality, whether conscious or not, the bloggers use the site to self examine and handle their problems. This is seen when reading PoisonedShadow's full post on June $10^{\text {th }} 2010$. After commenting on her weight, her exercise regime, and the salad she ate, she writes about her current emotional state.

Feeling a bit low at the moment and I can sense a relapse working it's way back. I do feel rather lost and feel like I'm losing touch on reality - madness sneaking its way back in - and it really frightens me. I was going through an atlas and looked at a picture of the universe and our planet and I realised just how insignificant we all are. If I died, disappeared or lost my sanity entirely it would make no dent whatsoever to life as a whole. Nothing would change ("Almost In Sight Of My $1^{\text {st }}$ Goal..”). 
Through the self-reflective details of the post PoisonedShadow indicates her emotional instability and her sense of being lost. This lack of control is in contrast to the control of the previous paragraph in the post that summarizes her meticulous control of her body through exercise and dieting. Other posts from the blog also depict the contradiction between PoisonedShadow's constant control of her body and her inability to control her emotions due to her depressive thoughts. On a July $4^{\text {th }}$, 2010 post PoisonedShadow again comments on her place in the overall universe and how her death would seem insignificant in the grand scheme of existence (PoisonedShadow,“This is the Way..”). Her comparison of herself to the overall universe and her minuscule status compared to the universe indicates not only her existential depression, but her lack of control. Through the imagery PoisonedShadow also writes herself as a small and minuscule entity that is on the verge of disappearing, thus using diction and imagery to visualize her desire to physically erase herself. The next post uploaded the next day again comments on PoisonedShadow's lack of power but in this post her lack of control is connected to her binging. "Got to work, ate a twix and a galaxy bar, then a hot chocolate with whipped cream. So what did I do?? Purge.. at work. If I had just managed some margin of self control then this would never have happened. I hate myself. Stupid, greedy, fat bitch. Urghh. Water only tomorrow. Absolutely NO exceptions" (PoisonedShadow, “Shit"). In the next post on July $9^{\text {th }}$, she again writes about food but in this post she has regained control and is purging, rather than binging, and writes that she has "recovered from self-loathing slightly" (PosionedShadow,"Calm After Storm"). Her control and its soothing effect is reflected in the title of the post 
"Calm After Storm". For PoisonedShadow food is the only condition that she can control and therefore disordered eating is the only habit that makes her feel in control and capable of stabilizing her emotions and helping her overcome her self hatred. Through disordered eating and writing about disordered eating she is developing the codes of conduct to get over her problems by writing about her emotional state, and as I will explore later, reflect on her writing about her emotional state.

I'llgettheresomeday's ThinIntentions also functions to help her overcome difficult situations and self reflect. Like PoisonedShadow she uses disordered eating to gain control over her body and blogging as a self reflective and soothing space. Instead of working through her depression I'llgettheresomeday is working through the trauma of being raped, becoming impregnated by her rapist, and giving up her child for adoption. Her desire to gain control of her body through disordered eating after her traumatic experience is indicated in her first post. "This blog is going to be used for me to escape my life and talk about it. It will also be my food log and diary. Last May, I was seeing a therapist for anxiety and EDNOS. However, we couldn't afford the sessions anymore and I wasn't ready to recover from EDNOS" (I'llgettheresomeday, “First Post!”). Because I'llgettheresomeday lacks control of her life, disordered eating is her way to regain control of her body after being raped and becoming pregnant. The earlier post about dieting with her Grandma was not just about finding a way to gain a slender body, but it was about finding a way to gain control of her body and thereby, hopefully gain control of her emotional response to her trauma. The first post also conveys I'llgettheresomeday's need for an outlet to express her feelings and to have a place to write about her disordered eating after no 
longer being able to afford a therapist. Her writing is not just a means of escape but it is also a means to self reflect and understand her emotions, similar to how she previously used a therapist to work through the emotions behind her disordered eating.

Although disordered eating is what helps PoisonedShadow feel in control and capable of managing her feelings, like I'llgettheresomeday, blogging is the outlet to reflect on disordered eating and her need for control. The self-reflective power of blogging and its ability to record her thoughts and daily activities to then use for selfexamination is conveyed through various posts. In the post that occurs the next day after her "Calm after the Storm" post PoisonedShadow rereads her previous writing and comments on her mental state. "Sorry about the random post last night, I re-read it this morning and realized that it didn't really make a lot of sense. I'm going to try to make my next post(s) more consistent and.. well.. sane. They tend to be pretty detached at the moment as that is the way my brain seems to process my thoughts and feelings; like an abstract painting" (PosionedShadow "Maybe Not."). Through the hupomnemata like medium of the blog, PoisonedShadow is able to not only record her thoughts but to reread her posts and better understand her mental state. Her claim that she desires her writing to be more consistent and sane suggests that her use of the word abstract means disorder, confusion, without logic, and difficult to understand. By rereading the post she theorizes that the erratic writing matches her erratic, or insane as she writes, mental state. Through reflecting on her past posts PoisonedShadow also explains how she will attempt to better grasp her emotional state by creating more consistent posts. By changing and controlling her writing, she 
hopes she can change and control her real life chaotic thoughts and feelings that cause her distress and hopefully find peace or calm after the storm. Because the blogs are reflective of her thoughts and feelings, sane and clear writing will come when she no longer is having troubled thoughts. Once she understands why she is thinking and writing so erratically, she can attempt to address the cause of that thinking in real life. The self writing and hupomnemata like style of the blog then is helping her not only in reflecting on her need to have control over her body but also to help her understand her mental states during the time of her blogging and to manage her self stated madness in real life.

Writing's ability to help PoisonedShadow is apparent in other posts as well, and does not just serve as a medium to express one's emotions but as a means of selfreflecting. In the next post from July $12^{\text {th }}$ the author blogs

I know that I said my next posts would be more coherent etc however, I don't think this one will be. I've had a really bad night tonight and writing appears to be my only outlet right now. I self harmed approximately one hour ago and it's the first time that I have done this in a long time... The thing is, watching the blood trickle down my arms gives me the most warped sense of satisfaction that nothing else does. Cutting and weighing a little less are my only vices ("I Know What I Said.”).

The grim and haunting post represents PoisonedShadow's need for control, as indicated through her practice of cutting which functions similarly to her use of disordered eating as a means to control her body when she is feeling depressed or empty. By writing about her painful experience she is also taking control of that experience by writing and recording it. She is controlling the narrative of her life like she is controlling her physical pain. The connection between disordered eating and cutting is apparent when she writes that weighing less and cutting are her only vices. 
Her use of the word vice is noteworthy because the meaning of vice implies immoral and wicked behavior, but according to the post, although cutting and disordered eating are physically harmful they are the only actions that allow PoisonedShadow to feel in control. The blog post is self reflective because it shows that PoisonedShadow informs the audience, and herself, that she is aware of the self destructive aspects of cutting and disordered eating and that they are the only tools she feels she has to feel better about herself or assert control. It is writing on the blog and not just the act of cutting or disordered eating that helps PoisonedShadow to express her emotions. Through blogging and disordered eating, and here cutting, PoisonedShadow is able to self reflect by examining her actions through writing to understand her emotions while cutting and to have an outlet that helps her manage her emotional issues. Disordered eating and writing about that disordered eating helps PoisonedShadow feel in control of her body, and writing and rereading the blog helps her understand why she feels the need to control her body and emotions. Like the hupomnemata the blog helps her to grapple with difficult situations. She is learning to self govern and care for the self through disordered eating and blogging. Regardless if PoisonedShadow follows her own advice and does attempt to better her life in real life, the blog is a space of control that creates a representation of caring for the self. Besides PoisonedShadow other bloggers have also written that disordered eating helps them attend to the self by controlling their food intake, which then helps the blogger feel better or overcome other issues. This is stated on beauty's Beauty From Pain's "My Story" page. On the page she explains that she developed disordered eating at age 12 in response to her parents breaking up and despite 
disordered eating's negative effect on her school work, it made her happy and feel better about her life. Disordered eating also made her feel alive (beauty). Anaisbeauty from the blog with the same name also self reflects through her blog and traces her disordered eating to being bullied as a child (Anaisbeauty, "Ana Is a Beauty"). Kat not Jas from SkinnyLove also relates controlling her weight to feeling in control of her life and her post on August $29^{\text {th }}, 2013$ implies that blogging provides her a self reflective space that helps her understand her emotional state and how her depressive moods emerge when she does not feel in control of her weight (Kat not Jas, "(btw I think I probably was just being paranoid)"). Like PoisonedShadow, beauty, Anaisbeauty, and Kat not Jas use disordered eating to feel in control of their bodies and emotions and use blogging to understand and narrate that need for control.

The Pro Ana and Mia blogs also include quotes and other recordings besides the reflective writing of the posts, another aspect that makes the blogs function as recreations of the hupomnemata. Here I briefly outline the self reflective and controlling aspects of the other record like sections of the blog. These recordings are used similarly to the self-writing in the post section of the blog and help the authors self govern and reflect. As explained by Foucault and McLaren the quotes, references to literature, and other records in hupomnematas were used as guides of conduct to self govern and to meditate on the self (Foucault, "Self Writing" 209-210). The quotes and images are used to self-reflective and self-govern. For example ThinIntentions' author I'llgettheresomeday has various pages that outline helpful diets to rapidly lose weight. On the "Different Diets" page she records diets such as The Vegan Model Diet, The Super Reduction Oatmeal Diet, The Russian Gymnast 
Diet, and The Rainbow Diet (I'llgettheresomeday, "Different Diets"). These posts are not about I'llgettheresomeday herself but are simple lists of diets and how the diets work. Because control of eating is what helps I'llgettheresomeday in how she cares for herself, they are part of her caring for the self-process and she thus needs a space to record these diets. Other sections such as "Happy Foods," a section that details the calorie content of food, "Restaurant Rules' which are tips about how to avoid eating a lot of food while dining out, and "Ana's Medicine Cabinet", a page that details weight loss supplements, serve as records that I'llgettheresomeday posts to the blog so she and others can return to the site in order to get help with the practice of disordered eating and continue to control the body and emotions to care for the self.

The thinspiration images are also about recording and control. Polak defines thinspiration pages as visual text that is

represented through posted pictures of models and other celebrity icons walking down the runway or posing on the red carpet. There is a canon of respected women among pro-ana followers; model Kate Moss is popular, with the recent eating disorder admission [recent at the time of this article] by Mary-Kate Olsen moving her to the top of the list, as the body that represents a personal goal for many that identify within the pro-ana movement. There are two divisions of thinspiration photos: those that display posed photos of well known celebrity icons, and 'bone pictures,' photos that depict female bodies in various forms of emaciation (86-87).

As Polak explains, the photographs serve to inspire the blogger and the blogs' visitors to attempt to use disordered eating to recreate the subject of the photograph's body. The images inspire control and inform the reader how the blogger wants her body to look. This is expressed on SkinnyLove. Kat not Jas often posts images of thinspiration in blog entries where she is writing about when she overeats and worries that she has lost control. This is expressed in the posts (“7/2/13") and ("bleh") and the inclusion of 
thinspiration images suggests that she want to look like the fictional anorexic character of Cassie from Skins and model Gemma Ward. Through the inspiration of the images she will reinvigorate her self-control and therefore better the self because she feels better and happier if she is skinny and in control of her appetite. In one post she includes thinspiration images and comments "WE CAN DO THIS!" ("105.2") indicating that she relates to and is inspired by the photographs to control her own body. In an earlier post Kat not Jas connection to the bodies depicted in the thinspiration images is directly expressed. After including a picture of Mary-Kate Olsen she comments "I love MK. She's small like me, so her look may be actually attainable..." (“105”).

Kat not Jas and the other bloggers mostly construct their sense of self and how to better the self through their physical bodies. This sense of self is why many feminist and sociologists writers argue that the blogs are not progressive and are examples of how society instructs women to place their value on their appearances. Their sense of selves are also conveyed through their representation of other life experiences and interests, but these other experiences and interests are represented on the blog which is about the use of disordered eating so disordered eating frames all the other experiences and interests the blogger chronicles. The bloggers show little concern in how they look to others and instead the visual appeal of their bodies is for their own pleasure. Because the control of their bodies and emotions through anorexia is often an attempt to gain control over their bodies after being raped or otherwise violated, the desires to control their bodies through starvation are also acts of resistance against the patriarchy. By controlling their bodies physically not only can 
the bloggers strive to manage their traumatic feelings over being violated, but they regain control of their bodies and the narratives of their bodies. Although the blogs can be invaded by intrusive forces that can sexualize and objectify the female bloggers this rarely happens and the only aggressors I have found are readers who either state the bloggers are not truly anorexic or comment that the blogs are dangerous. Besides these criticisms the blogs are safe spaces. Despite that the bloggers are striving to recreate traditional standards of beauty, it appears that for the bloggers obtaining a slender body is not about being desirable to others but is about controlling one's narrative and body in a world where others constantly attempt to and succeed in controlling or violating their body. The bloggers also live in a world where others tell the bloggers they do not possess the correct type of body and narrative of that body.

In blogging they can defy the assumption that there is a correct body or way to be anorexic and thus a way to be a person. The blogs also defy the assumption that there is a correct way to take care of the body. The bloggers may take care of their bodies in ways that are physically harmful but it is the bloggers' choice to take care of their bodies through "unhealthy" practices. Ballerinas, athletes, and other individuals also heavily monitor their bodies, but their actions are usually not considered taboo or pathologized. How are art and sport practitioners justified in encouraging emaciation and obsessive focuses on the body where the bloggers are not? The blogger's bodies may not be associated with art but are associated with narrative creation complicating the idea that the bloggers are wrong for using disordered eating. In the creation of the blogs and presentation that they use disordered eating in real life, the bloggers assert 
their agency and rebel against the idea that parents, medical professionals, search engines, and blogging platforms are who and what decide how they should treat their bodies. The bloggers are who and what decides how they should treat their bodies. The act of blogging is not just a mechanism to self reflect and record one's attempts to control the body through not eating, but blogging is also an act of control. Silverman Bowen argues about the realm of control created through blogging and explains that blogging allows an endless opportunity for a person to carve out an existence.

She can sprawl herself over and around, an amorphous, fluidity, sectioning off space with words and images, linking pages together as she deems appropriate. The entire enterprise is subject to her whim; she can choose to add or remove content at will, she can choose to rearrange documents, she can choose to pull the whole thing down and start afresh. Most importantly, she dictates all of the content the site contains (314).

Although Silverman Bowen is writing about the creation of an ethos through blogging she is also arguing about the allure of control through blogging. The bloggers dictate the aesthetics of the blogs, the posts on the blogs, the images, and whether or not to delete the blogs or posts. The post and other sections of the blog are not just about self reflecting and documenting how one controls her disordered eating but is about practicing the ability to control by controlling the blog and the blog becomes an analog for the body and self. The practice of control of one's body is not only a part of the narrative of disordered eating constructed online, but has been studied in various disciplines that explore the mechanics and origins of disordered eating. The next section will outline writing on control that already exists on disordered eating in psychology, sociology, and gender studies and explains how the control of one's body 
was a common practice in Antiquity to care for the self. The final section also examines the idea of who is allowed to control one's body and the complications that arise when one tries to control one's body through anorexia and bulimia.

\section{Writings on Control and Disordered Eating and Control of the Body in}

\section{Antiquity:}

The desire to feel control is a common narrative on the Pro Ana and Mia blogs and much psychological and sociological literature has been written about control and disordered eating. Psychologists Franzisca V. Froreich, Lenny R. Vartanian, Jessica R. Grisham, and Stephen W. Touyz conducted a 2016 study to examine what role control plays in disordered eating. In their paper "Dimensions of control and their relation to disordered eating behaviours and obsessive-compulsive symptoms" the authors come to the conclusion that their "findings suggest that there may be similar underlying fear of losing self-control among individuals who engage in disordered eating" (Froreich, Vartanian, Grisham, Touyz 1). Other authors in psychology and sociology have found similar findings. Castro and Osorio explain that bulimia is a way for people to take control of their life (181) and Catrina Brown argues that “controlling the body has become a precarious substitute for real control in women's lives” (1). Hilde Bruch, psychologist and author of Eating Disorders: Obesity, Anorexia Nervosa, and the Person Within one of the first books on disordered eating written in the $20^{\text {th }}$ century, relates disordered eating to people's desire to claim ownership over their bodies in a world where they did not feel in control (102).

In A Hunger So Wide and So Deep by Becky W. Thompson the author claims that disordered eating is common in people who were sexually abused, and that 
dieting is a means to regain control that was lost during abuse (46-48). In the beginning of the book she asserts how disordered eating can emerge "as survival strategies- as sensible acts of self-preservation- in response to myriad injustices including racism, sexism, homophobia, classism, the stress of acculturation, and emotional, physical, and sexual abuse" (1-2). Due to elements beyond someone's control such as abuse, stress, racism, or intense emotions, disordered eating often develops because food intake is something the person can control. Gender studies authors such as Susan Bordo and Maree Burns also write about disordered eating and control. Bordo suggests that bodily control through dieting is intoxicating (134) and in Burns' article "Bodies as (im)material? Bulimia and Body Image Discourse" the she comments that bulimia is often associated with the desire for control (128-129).

In the last post on the blog called "Weight," PoisonedShadow addresses psychological literature and other scholars who write about the role of control in disordered eating.

A lot of people say that we control our eating because we have lost control over some other aspect of our lives. However, why food and weight? Why would we not choose to control our academic career or simply creating a precise wake up routine for the morning?... Yes we may be slightly more perfectionist than most but at the end of the day it is a lifestyle choice. Because it is how we want to live our lives as we are not happy with how we are at this moment. So why the hell shouldn't we be able to change ourselves in any way we please? If we should have any right, it should be the right to our own bodies. There is not a lot left in life that is truly ours, apart from our own mind, our body and our choices (PoisonedShadow).

For PoisonedShadow control of her body is one of the only ways she can feel in control, and as she explains, this desire for control and ownership of her body and choices is a common experience of disordered eating. This commonality is stressed 
through her use of the word "our". The post is also self reflective in that PoisonedShadow attempts to understand and justify why she and others turn to food as something to control rather than school or some other aspect of her life. Again, the blogs are an online location of self-reflection and as explained earlier, the ability to control the space of the blog contributes to the self-betterment of the blogger by creating another more helpful outlet of control.

Control of one's body to care for the self was present in Ancient Greece. In her book McLaren summarizes Foucault's writing on care of the self and explains how care of the self was not only linked to writing but also management of one's body.

Care of the self included self-knowledge, but was also concerned with bodily practices. In his studies of Antiquity, Foucault points out that the practices of the self concern the body. Dietetics involves close attention to what one eats, when one eats, and how it affects one's body... Almost all of these regiments concerning diet, health, sexual activity, and household management required a careful record of activity. In order for these practices of the self concerning the body to become an art of existence, they should include some reflection on oneself set down in writing (148).

Blogging on Pro Ana and Mia websites are a form of this process of gaining selfknowledge through bodily management and writing about that bodily management. Through control of her eating habits and writing about those eating habits PoisonedShadow reflects on her emotional state and comes to understandings regarding her bipolar behavior. Through records of her weight in various posts, as well as the section called "The Goals" that tracks her various weights and posts that recount what she eats that day, she is using the record of the blog to write about her 
need to control her body, and therefore self reflects and gains self knowledge to care for the self. She knows her body to know her self, to then care for the self.

In "The Ethics of a Concern for Self and as a Practice of Freedom" Foucault expresses how caring for the self is not only about self knowledge but it is also about controlling one's self and body to gain self mastery. He explains that to know one's self is to "surpass oneself, to master the appetites that threaten to overwhelm one" (285). For the bloggers they master their appetites literally in order to care for the self. PoisonedShadow masters her appetites and writes about mastering her appetites in order gain control to feel better about herself and to gain an understanding of her bipolar emotions. Through disordered eating she is able to help prevent her depression from overwhelming her. This is seen in two recent posts on her blog. In a post from June $21^{\text {st }}, 2012$ titled "Realisation" she summarizes her depressed state and writes that she fears she will never find happiness, love, or be able to accept herself. In the next post from August $27^{\text {th }}, 2012$ called "Better.." she explains that she now feels better, has a happy love life, is doing well in school, and that "eating one small meal a day and exercising every other day seems to be doing the trick... I did four hours of tennis yesterday and feel great today" (PoisonedShadow). Through disordered eating she is able to master her physical appetite to master the other appetites that threaten to overwhelm her, her self-hatred and depression. Throughout her blog PoisonedShadow repeatedly goes back and forth between her self hatred and feeling like she has no control due to her bipolar thoughts, and to controlling her weight and therefore feeling better about herself and writing that her emotions have stabilized. This back and forth between feeling in control and capable of bettering her 
self and feeling like she is overwhelmed by her emotions is part of the care of the self process. Foucault explains that care of the self is a lifelong practice ("Hermeneutic of the Subject" 94), so even though PoisonedShadow goes back and forth between feeling like she is bettering the self and mastering her appetites and feeling out of control, it is part of the process because one must constantly master the self in the lifelong practice of caring for the self.

Other writers have also argued that disordered eating and its power of control are related to care of the self. The role of disordered eating to aid one in management of their problems is the basis of the Thompson's book A Hunger so Wide and So Deep although she is not connecting her findings to the works of Foucault or the blogs. In the opening of the book she writes, "eating problems begin as survival strategies- as sensible acts of self-preservation- in response to myriad injustices including racism, sexism, homophobia, classism, the stress of acculturation, and emotional, physical, and sexual abuse" (1-2). The use of disordered eating for selfpreservation resembles the process of caring for the self and how PoisonedShadow uses blogging and disordered eating to control her appetites, self reflect, and better the self.

In Abigail Bray's “The anorexic body: Reading Disorders" she relates disordered eating to the practice of caring for the self. "Without denying the historical differences between ancient 'pagan' practice and our own time, one might also recognize that contemporary weight-loss regimes deploy related techniques in the name of an ethics of self-care, involving a similar transformation of the self through process of measurement" (425). Although Bray only connects Foucault's 
examination of care of the self to disordered eating on this one page of her article, the quote indicates that disordered eating can be related to care of the self. Control of the body is part of the care of the self process for anorexic and bulimic people, and is a process that is facilitated by the hupomnemata medium of blogging.

It is important to note that authors such as Megan Warin (1-3) and Saukko (18) have argued that women with disordered eating habits are often labeled as victims because the disordered eating practices emerge when the women lack control in their everyday lives. As victims women are thought to be more susceptible to bodily pressures of being skinny and therefore being a victim is a so-called natural state of being a woman (Saukko 4-8). By writing about the bloggers' need for control and their emotional traumas, I am not placing the women into the position of victims or attempting to define their online identities by the various traumas they have endured. I am also not arguing that tales of disordered eating must always be associated with tragedy. For example, the bloggers also write about other mundane events such as dating, college life, doctor appointments, watching films, and growing up. These narratives are still structured around disordered eating and the need to control what one eats, but they are not all narratives of tragedy and sadness. On SkinnyLove, Kat not Jas focuses on losing weight and her need to control her emotions, but she also writes about her romantic life ("Too much"), drinking alcohol on her roof ("Too much"), college life (“106.2”), and interacting with her friends (“happy”). Ell’s blog A Journey to Bones is similar in that it is also about her first years of college and dating experiences while chronicling her use of disordered eating ("Saturday, 20 June 2015”). Despite the many haunting posts of PoisonedShadow's blog she also writes 
about movies that have inspired her ("A Little Late I Know") and cites literary quotes that speak to her ("So Beautifully True.").

Instead I am arguing that the bloggers value control, and that their use of control over their bodies and emotions is part of the process of care of the self, a process that is guided by the hupomnemata style of the blog. Control is just part of the narrative of disordered eating and how one cares for the self through blogging and management of one's body, and how the bloggers have chosen to tell their journeys of attending to the self. Furthermore, by writing about the bloggers narratives of disordered eating, as well as narratives of sadness and the mundane, I am attempt to let the bloggers tell their own narratives by examining and directly citing their individual writings to lend their voices to scholarly writing on Pro Ana and Mia theory that has often overlooked the individual voices and narratives of the bloggers. As PoisonedShadow writes, "There is not a lot left in life that is truly ours, apart from our own mind, our body and our choices ("Weight.") therefore the bloggers' choices, even if they tell stereotypical stories of disordered eating as a response to tragedy and abuse, must be explored.

\section{Conclusion:}

This chapter has attempted to explain how through the Pro Ana and Mia websites the bloggers record their day-to-day activities and their random thoughts in order to reflect in a hupomnemata-like medium to gain self-knowledge. That self knowledge is used to better understand the self and one's emotions and through that self understanding the bloggers can attempt to overcome, or momentarily overcome, difficult weakness and circumstances by caring for the self. As seen by the blog posts 
and various psychological, sociological, and gender studies authors, disordered eating and the control over one's body is an act of care of the self because it helps the bloggers to feel in control of their bodies and emotions after traumatic experiences and depression, or just after failing to make friends in college.

This chapter also attempts to explain that the narratives of disordered eating told through blogging are more than just a creation of an impersonal ideology of self creation, resistance, and community, as suggested by the majority of academic writing on Pro Ana and Mia blogs. Instead the blogs tell individual narratives that explain how one uses disordered eating and blogging to cope with a trauma, to understand one's chaotic emotions, to no longer feel lost, to understand one's relationships with others, and to better the self through the self training like practice of disordered eating. The individual narratives of the blogs must be explored in order to understand the blogger's personal journeys in caring for the self and the blogger's individual needs for control. Without examining the individual narratives and only studying the blogs as mass narratives rather than personal and individual narratives, as this chapter has hopefully done, writing on Pro Ana and Mia blogs further silence the bloggers, even when the scholarly writers' aim is to point out how censorship of the websites is part of a patriarchal tradition of censoring women's voices. 


\section{Works Cited}

Anaisbeauty. "Ana is Beauty." Anaisbeauty, Weebly,

http://anaisabeauty.weebly.com/. Accessed 18 Jun. 2017.

AssociatedPress, "Pro-anorexia movement has cult-like appeal." NBCNEWS.com, 31 May 2005, NBCNEWS.COM, http://www.nbcnews.com/id/8045047/ns/health-mental health/t/proanorexia-movement-has-cult-like-appeal/\#.WUcsXRMrL8N. Accessed 9 Jun 2017.

Beauty. "My Story." Beauty From Pain, Weebly, http://beautyfrompain.weebly.com/story-of-beauty.html. Accessed 18 Jun. 2017.

---. "Welcome To The World Of Beauty From Pain." Beauty From Pain, Weebly, http://beautyfrompain.weebly.com/. Accessed 18 Jun. 2017.

Bell, Brandi. "Private Writing in Public Spaces: Girls' Blogs and Shifting Boundaries." Growing Up Online: Young People and Digital Technologies, edited by Sandra Weber and Shanly Dixon, palgrave macmillan, 2007, pp. 95112.

Bordo, Susan: Unbearable Weight: Feminism, Western Culture, and the Body. University of California Press, 1993.

Bray, Abigail. "The anorexic body: Reading disorders.” Cultural Studies, 2006, vol 10, no. 3, pp. 413-429. Academic Search Complete. 10.1080/09502389600490251. Accessed 10 Jun. 2017.

Brown, Catrina. "The Control Paradox: Understanding and Working with Anorexia and Bulimia." National Eating Disorder Information Centre, 1990, NEDIC, http://nedic.ca/sites/default/files/control-paradox-understanding-andworking-anorexia-and-bulimia.pdf. Accessed 18 Jun. 2017.

Bruch, Hilde. Eating Disorders: Obesity, Anorexia Nervosa, and the Person Within. Basic Books, 1973.

Burke, Elisa. "Pro-anorexia and the Internet: A Tangled Web of Representation and (Dis)Embodiment." Counseling, Psychotherapy, and Health, vol. 5, no. 1, 2009, pp. 60-81.

Burns, Maree. "Bodies as (im)material? Bulimia and Body Image Discourse." Critical Feminist Approaches to Eating Dis/orders, edited by Helen Malson. Routledge, 2009, pp. 124-134. 
Castro, Teresa Sofia and Osorio, Antonio. "Online violence: Not beautiful enough... not thin enough. Anorectic testimonials in the web." PsychNology Journal, 2012, vol. 10, no. 3, pp. 169-186. Academic Search Complete, http://www.psychnology.org/. Accessed 10 Jun. 2017.

Custers, Kathleen. "The urgent matter of online pro-eating disorder content and children: clinical practice.” Eur J Pediatr, vol. 174, 2015, pp. 429-433. Academic Search Complete. D01 10.1007?s00431_015_2487-7.

Day, Katy and Keys, Tammy. "Anorexia/bulimia as resistance and conformity in pro-Ana and pro-Mia virtual conversations." Critical Feminist Approaches to Eating Dis/orders, edited by Helen Malson. Routledge, 2009, pp. 87-96.

Delforterie, Monique J., Larsen, Junilla K., Bardone-Cone, Anna M., and Scholte, Ron H. J. "Effects of Viewing a Pro-Ana Website: An Experimental Study on Body Satisfaction, Affect, and Appearance Self-Efficacy." Eating Disorders, vol. 22, 2014, pp. 321-336. Academic Search Complete, 10.1080?10640266.2014.898982.

Depowski, Kristen and Hart, Kelly. “'Pro-Ana' Web Sites Glorify Eating Disorders.” abcNEWS, 13 Jun. 2006, abcNEWS, http://abcnews.go.com/Health/story?id=2068728. Accessed 9 Jun 2017.

Dias, Karen. “The Ana Sanctuary: Women's Pro-Anorexia Narratives in Cyberspace." International Women's Studies, vol. 4, no. 2, Apr. 2003, pp. 3145. Academic Search Complete, http://vc.bridgew.edu/jiws/vol4/iss2/4.

Ell. "Saturday, 20 June 2015." A Journey to Bones, 20 Jun. 2015, blogspot, http://ajourneytobones.blogspot.com/. Accessed 18 Jun. 2017.

Foucault, Michel. "The Ethics of the Concern For Self as a Practice of Freedom." Ethics Subjectivity and Truth. Translated by Robert Hurley and Others, The New Press, 1994, pp. 281-302.

---. "Hermeneutics of the Subject." Ethics Subjectivity and Truth. Translated by Robert Hurley and Others, The New Press, 1994, pp. 93-106.

---. "Self Writing." Ethics Subjectivity and Truth. Translated by Robert Hurley and Others, The New Press, 1994, pp. 207-222.

Froriech, Franzisca V, Vartanian, Lenny R., Grisham, Jessica R, and Touyz, Stephen W. "Dimensions of control and their relation to disordered eating behaviours and obsessive-compulsive symptoms." Journal of Eating Disorders, 2016, pp. 1-9. Academic Search Complete, http://crossmark.crossref.org/dialog/?doi=10.1186/s40337-016-0104$4 \&$ domain $=$ pdf. 
Giles, David. "Constructing identities in cyberspace: The Case of eating disorders." British Journal of Social Psychology, vol. 45, 2006, pp. 463-477. Academic Search Complete, DO1:10.1348?014466605X53596. Accessed 10 Jun. 2017.

i'llgettheresomeday. “Ana's Medicine Cabinet.” ThinIntentions, blogspot, http://thinintentionsforever.blogspot.com/p/anas-medicine-cabinet.html. Accessed 18 Jun. 2017.

---. "Dieting." ThinIntentions, 11 Apr. 2011, blogspot, http://thinintentionsforever.blogspot.com/2013/04/dieting.html. Accessed 18 Jun. 2017.

---. "Different Diets.” ThinIntentions, blogspot, http://thinintentionsforever.blogspot.com/p/different-diets.html. Accessed 18 Jun. 2017.

---. "First Post." ThinIntentions, 9 Apr. 2013, blogspot, http://hinintentionsforever.blogspot.com/2013/04/first-post.html. Accessed 18 Jun. 2017.

---. "Happy Foods." ThinIntentions, blogspot, http://thinintentionsforever.blogspot.com/p/happy-foods.html. Accessed 18 Jun. 2017.

---. "Restaurant Rules." ThinIntentions, blogspot, http://thinintentionsforever.blogspot.com/p/restaurant-rules.html. Accessed 18 Jun. 2017.

James. "About PrettyThin.” PrettyThin, WordPress, http://www.prettythin.com/. Accessed 18 Jun. 2017.

Kat not Jas. "105.” SkinnyLove, Jan. 18, 2011, Blogger, http://sk1nnylove.blogspot.com/2011/01/105.html. Accessed 17 Jun. 2017.

---. “105.2” SkinnyLove, 3 Jun, 2011, Blogger, http://sk1nnylove.blogspot.com/2011/06/1052.html. Accessed 17 Jun. 2017.

---. “7/2/13.” SkinnyLove, 2 Jul, 2011, Blogger, http://sk1nnylove.blogspot.com/2013/07/7213.html. Accessed 17 Jun. 2017.

---. “Are any of you guys good (or even just adequate will do) with guys?"SkinnyLove, 15 Aug, 2013, Blogger, http://sk1 nnylove.blogspot.com/2013/08/are-any-of-you-good-or-evenjust.html. Accessed Jun. 182017. 
---. "bleh.” SkinnyLove, 18 Nov., 2013, Blogger, http://sk1nnylove.blogspot.com/2011/11/bleh.html. Accessed 18 Jun. 2017.

---. “(btw I think I probably was just being paranoid)." SkinnyLove, 29 Aug, 2013, Blogger, http://sk1 nnylove.blogspot.com/2013/08/btw-i-think-i-probably-wasjust-being.html. Accessed 18 Jun. 2017.

---. “Too much.” SkinnyLove, 16 July, 2011, Blogger, http://sk1nnylove.blogspot.com/2011/07/too-much.html. Accessed 12 Jun, 2016.

Loveheim, Mia. "YOUNG WOMEN'S BLOGS AS ETHICAL SPACES." Information, Communication, \& Society, 2011, vol 14, no. 3, pp. 338-354. Academic Search Complete, D01: 10. 1080/1369118X.2010.542822. Accessed 10 Jun. 2017.

McLaren, Maraget A. Feminism, Foucault, and Embodied Subjectivity, State University of New York Press, 2002.

PoisonedShadow. "A Little Late I Know." Ana, Mia, \& Moi: My life, body and self control, 27 Jun. 2010, WordPress, https://poisonedshadow.wordpress.com/2010/06/27/a-bit-late-i-know/. Accessed Jun 182017.

---. "Adulthood." Ana, Mia, \& Moi: My life, body and self control, 27 Aug. 2012, WordPress, https://poisonedshadow.wordpress.com/2011/03/04/adulthood/. Accessed Jun 182017.

---. "Almost in Sight of $1^{\text {st }}$ Goal." Ana, Mia, \& Moi: My life, body and self control, 10 Jun. 2010, WordPress, https://poisonedshadow.wordpress.com/2010/06/10/almost-in-sight-of-1stgoal/. Accessed Jun 182017.

---. "Better.." Ana, Mia, \& Moi: My life, body and self control, 27 Aug. 2012, WordPress, https://poisonedshadow.wordpress.com/2012/08/27/better/. Accessed Jun 18. 2017.

---. "Calm After Storm." Ana, Mia, \& Moi: My life, body and self control, 9 Jul. 2010, WordPress, https://poisonedshadow.wordpress.com/2010/07/09/calmafter-storm/. Accessed Jun 18. 2017.

---. "Here we go again." Ana, Mia, \& Moi: My life, body and self control, 13 Jul. 2011, WordPress, https://poisonedshadow.wordpress.com/2011/07/13/herewe-go-again/. Accessed Jun 18. 2017. 
---. "I Know What I Said." Ana, Mia, \& Moi: My life, body and self control, 12 Jul. 2010, WordPress, https://poisonedshadow.wordpress.com/2010/07/12/i-knowwhat-i-said/. Accessed Jun. 182017.

---. It's Been a While <3." Ana, Mia, \& Moi: My life, body and self control, 5 Jun. 2011, WordPress, https://poisonedshadow.wordpress.com/2011/06/05/itsbeen-a-while-3/. Accessed Jun 17. 2017.

---. "Maybe Not." Ana, Mia, \& Moi: My life, body and self control, 10 Jun. 2010, WordPress, https://poisonedshadow.wordpress.com/2010/07/10/maybe-not/. Accessed Jun 17. 2017.

---. "Realisation." Ana, Mia, \& Moi: My life, body and self control, 21 Jun. 2012, WordPress, https://poisonedshadow.wordpress.com/2012/06/21/realisation/. Accessed 18 Jun. 2017.

---. "The Goals." Ana, Mia, \& Moi: My life, body and self control, WordPress, https://poisonedshadow.wordpress.com/the-goals/. Accessed 18 Jun. 2017.

---. "Shit." Ana, Mia, \& Moi: My life, body and self control, 5 Jul. 2010, WordPress, https://poisonedshadow.wordpress.com/2010/07/05/shit/. Accessed Jun 17. 2017.

---. "So Beautifully True." Ana, Mia, \& Moi: My life, body and self control, 27 Jun. 2010, WordPress https://poisonedshadow.wordpress.com/2010/06/27/sobeautifully-true/. Accessed 18 Jun. 2018.

---. "Weight." Ana, Mia, \& Moi: My life, body and self control, 18 Oct. 2012, WordPress, https://poisonedshadow.wordpress.com/2012/10/18/weight/. Accessed Jun 18. 2017.

Polak, Michele. "'I think We Must be Normal ... There are Too Many of Us for This to be Abnormal!!!': Girls Creating Identity and Forming Community in ProAna/Mia Websites." Growing Up Online: Young People and Digital Technologies, edited by Sandra Weber and Shanly Dixon, palgrave macmillan, 2007, pp. 81-94.

ProAnaGoddess. "HELLO BEAUTIFUL." PRO ANA GODDESS, WordPress, https://proanagoddess.wordpress.com/hello-beautiful\%E2\%9D\%A4\%EF\%B8\%8F/. Accessed Jun. 182017.

Saukko, Paula. The Anorexic Self: A Personal Political Analysis of a Diagnostic Discourse. State University of New York Press, 2008.

Schott, Danielle and Langan, Deborah. "Pro-anorexia/bulimia censorship and public service announcements: the price of controlling women." Media, Culture \& 
Society, 2015, vol. 37, no. 8, pp. 1158-1175. Academic Search Complete, D01: $10.1177 ? 0163443715591672$.

Silverman Bowen, Deborah. "e-Criture Feminine: Women's Online Diaries and the New Female Discourse." Webbing Cyberfeminist Practice: Communities, Pedagogies and Social Action, edited by Kristine Blair, Radhika Gajjala, and Christine Tulley, Hampton Press, Inc, 2009, pp. 309-326.

Springen, Karen, "THE DANGERS OF PRO-ANOREXIA WEB SITES." NewsWeek, 6 Dec. 2006, NEWWEEKLLC, http://www.newsweek.com/dangers-pro- anorexia-web-sites-105601. Accessed Jun 92017. 


\section{Chapter 4:}

\section{Narrative of Truth and Ethos Through the Representation of Disordered Eating and Recovery in The Body Tourist}

On Dana Shavin's website she overviews the goal of her 2014 memoir The Body Tourist. On her "my book page" she writes

While many writers have written candidly and eloquently about their struggles with depression, addictions, and eating disorders, those stories usually conclude once there is progress toward recovery. Beyond recovery — whether from addictions, illness, or even the death of a loved one or divorce - there is another story, one that is about how we re-join the world, and, in the living years that follow the darkness, pursue a life that is creative, engaged, and deeply felt in our bones. This is the territory of The Body Tourist (Shavin).

As Shavin points out, the territory of her memoir is atypical in the genre of eating disorder narratives, both in memoirs as well as other representations of anorexia and bulimia such as the YouTube videos. In memoirs such as Wasted, Not All Black Girls Know How to Eat, and Purge: Rehab Diaries the writers chronicle their experiences with disordered eating and document their struggles with anorexia and bulimia. All the books include epilogues or other jumps into the future where the writers no longer practice disordered eating and now consider themselves wiser, in control of their emotions, and creators of ways of life that no longer require the use of disordered eating. In the YouTube videos the move away from disordered eating is usually not part of the uploader's confession. Instead the focus of the videos is the reveal of a disordered eating past through photographs and the YouTuber's orations. The videos end with the uploaders' declaration of pride in being able to move beyond from what they suggest is a shameful past of anorexia and bulimia. 
Usually the blogs have no jumps into the future where the bloggers have moved on from disordered eating and instead there is a sudden end to the narrative of caring for the self through disordered eating and "recovery" takes place off screen. The absence of "recovery" in the narratives of disordered eating does not problematize the texts because the story of "recovery" is not part of the authors" stories of anorexia and bulimia. Wasted is not focused on Marya's "recovery" but is focused on the origins of her disordered eating and her creation of a self, while the blogs actively resist the idea of "recovery" and archive the everyday use of disordered eating as a therapeutic tool. But as Shavin proposes, there are other stories to tell of former practitioners' use of disordered eating and their abilities to "re-join the world, and, in the living years that follow the darkness, pursue a life that is creative, engaged, and deeply felt in our bones" (Shavin). By not including representations of "recovery" the practice of disordered eating becomes elusive in that a person's movement away from anorexia and bulimia is concealed, silencing the continuation of the person's story and suggesting that "recovery" is a sudden and permanent state of being. "Recovery" becomes a permanent state of being, as opposed to a lifelong process as depicted in The Body Tourist, implying that being cured is a spontaneous moment where a person is returned to their genuine and authentic pre anorexia and bulimic state. Because the narrative of a post anorexic and bulimic life is the narrative mostly conveyed through the identical My Eating Disorder Story genre on YouTube, the prominent story of life after an eating disorder is also linked to a hermeneutic style of story telling and an essentialist state of being. This chapter addresses the void of "recovery" in the texts by examining how in The Body Tourist Shavin uses the 
representation of disordered eating as a parrhēsiastic tool that bares all and candidly proclaims how disordered eating lead to her creation of an ethos. The memoir does not depict "recovery" as an instant and non-representable event that brings her salvation and a return to her natural pre disordered eating self. Alternatively Shavin's prose questions the idea that someone can be swiftly cured through diagnosis and rehabilitation and it is instead herself who determines what it means to be "recovered". "Recovery" does not lead to a preordained existence but is part of her process of caring for the self and creating an ethos.

The Body Tourist differs from the narratives explored in the previous chapters by including a narrative of "recovery" but also bridges the gap between the other chapters and continues the narrative of caring for the self where Marya and the bloggers leave off. In my second chapter, I describe how Marya uses the culture of disordered eating and the act of memoir writing to create a personhood. The bloggers self starve off screen in order to gain control and understand the effects of their depression and various traumas. The act of blogging mirrors the use of the hupomnematas in Ancient Greece where writing was used as a tool of meditation and to overcome false habits and influences. This final chapter of the dissertation argues that Shavin's work actualizes the act of attending to the self evident in both Wasted and the blogs but also conveys how the usage of anorexia, one's starved body, and the act and style of her writing, is an epitome of truth telling. Furthermore, the concluding chapter in this dissertation asserts that through writing and the representation of disordered eating The Body Tourist functions as a literary 
embodiment of Shavin's art of life and her journey from having an inhabitable body to her use of her body as a tool of truth telling, fulfillment, and ethos creation.

"Recovery" is a tricky term and I use quotations to make the problematics of the term evident. Being "recovered" suggests that there is a natural state to return to, a state of existence that one must restore and redeem. Above I place the term in quotations to point out the predicament in using the word due to the ideology it originates from. Henceforth I will remove the quotations to avoid them becoming a hindrance to the reader but I still question the connotations of the word. The term implies the act of salvation. One's "true" self is returned after one lost one's way due to drugs, disordered eating, depression, or some other curable state that altered one's core of existence. The assumption that people have a natural and preordained self is in opposition to the findings of Foucault and his analysis of subjection and power relations. For Foucault there is no natural state of being and the idea of an essentialist selfhood has been implanted in our culture by various systems of power that make one subject. The idea of an essentialist self is evident in the identical YouTube videos that present disordered eating as uniform experiences and make the uploaders subjects of the social media platform and branding.

My concern with the essentialist concept of recovery is not to suggest that movement away from addiction is impossible or to undermine all the work of therapists and the medical community. There are many forms of treatment for people who wish to end their relationship with anorexia and bulimia that do not subject them to a diagnosis or equate recovery with hermeneutic concepts of what it means to be healthy. Recovery also has positive connotations that do not link the term to 
essentialist ideology. In a 2012 article from the American Psychological Association Dr. Gwendolyn Puryear Keita defines recovery as a "“process of change through which individuals improve their health and wellness, live a self-directed life, and strive to reach their full potential'" (43). Although the term health can have essentialist connotations the rest of Keita's definition of recovery resembles the process of caring for the self. Like her concept of recovery caring for the self is about understanding the self to create a new self-directed way of life and self-improvement. Recovery is not a return to a state of normalcy and the genuine self, or, as other writers in the field of psychology have written the "reclaiming of one's humanity and reconnecting with one's true self' (Mager).

For Shavin recovery means her ability to no longer practice disordered eating habits, stop living a life of restraint, conclude her relationships with emotionally abusive men, the rejection of a career as a therapist, and finding happiness through horse caretaking. Shavin's movements towards this lifestyle, or recovery, is represented through the narrative of truth conveyed in The Body Tourist.

The first section of the chapter overviews Foucault's writing on parrhēsia and examines literary scholars' ideas on the role of truth telling in the genre of the memoir. As the chapter continues I claim that The Body Tourist is a narrative of truth telling through Shavin's representation of Dana's disordered eating habits, living conditions, and expression of truths concerning recovery and the field of psychology. The reader functions as Shavin's interlocutor. In the chapter on Wasted I already wrote at length about the genre of the memoir as a tool of self-examination and persona creation. This also occurs in The Body Tourist but in this chapter I instead 
focus on the act of memoir writing as a form of parrhēsia. The chapter will conclude with the exploration of The Body Tourist as a narrative of Dana's journey to recovery and happiness. Through the memoir not only does Shavin chronicle her creation of an ethos but also chronicles how Dana achieves recovery.

As in Wasted there is a distinction between the subject of the memoir, Dana, and the authorial voice of the memoir, Shavin. Therefore I will use Dana to refer to the past representation of Shavin who actively conceals or confesses her anorexia and use Shavin to refer to the parrhēsiastic author who avoids essentialist language of pastoral powers and continuously expresses the truth. It is also important to clarify that unlike in the other chapters where I argue that the act of disordered eating is a means to care for the self, here the act or writing and representing disordered eating is a means for truth telling. Without her disordered eating past Shavin would not have this memoir to write, and as I argue in the last section of the chapter, her past disordered eating leads to her move away from a life of restraint and unhappiness and to a life of truth and fulfillment.

\section{Parrhēsia and Feminists' Use of the Late Works of Foucault:}

In The Body Tourist Shavin uses the act of writing as a vehicle for truth telling about her past use of anorexia, her self inflicted life of poverty, her relationship with her mother, and the concept of recovery. In the book it is the author Shavin and not Dana who practices parrhēsia. Dana in contrast often lies to others and attempts to hide her use of anorexia. When Dana does not lie about her anorexia she instead confesses her use of disordered eating. Unlike the other writers explored in this 
dissertation through the disconnect between the truthful Shavin and the untruthful Dana the writing of The Body Tourist informs the reader that Shavin did not suddenly become a truth speaker. Alternatively we witness, or read, her journey to parrhēsia. In Wasted, like the act recovery, the journey to becoming a truth teller is not portrayed to the reader. In the blogs we do witness the writers' engagement with truths of the self and the world around them, but their truth telling is not risky, a condition of parrhēsia, because their identities are often veiled through the anonymity granted through the Internet. Shavin's truth telling in contrast is risky because she has no alter ego to hide behind and tells truth about her family, boyfriends, and psychology that could hurt her loved ones and damage her reputation as a former therapist. Like recovery, the narrative of how one becomes a parrhēsiast is often not depicted and is left off the pages or computer screens. In the following sections I will refresh the reader on the meaning of parrhēsia and then overview critical theory on the memoir genre's connection to the concept of truth telling.

As explained in the introduction of the dissertation, parrhēsia is the act of truth telling. In Fearless Speech Foucault historicizes that the word parrhēsia first appeared around 484-407 B.C.E in the Greek literary text Euripides and continued in ancient Greek writing into the Fifth Century (11). The epistemology of the world means to speak everything. A parrhēsiast is "someone who says everything he has in mind: he does not hide anything, but opens his heart and mind completely to other people through his discourse" (12).

The practice is not just about speaking truths but further involves speaking to others and the continuous act of truth telling. To practice parrhēsia one must have an 
interlocutor to speak truths to. Truth speaking is also a risk because the spoken truth may cause bodily or emotional harm to the parrhēsiast. Parrhēsia is a lifelong practice and if one is a parrhēsiast they will always speak the truth. Foucault's use of truth in his explanation of parrhēsia is not to be confused with the ideas of universal truths that are produced through religion and other systems of power. Truth for parrhēsiasts is not manipulation or rhetoric (Foucault, The Courage of Truth 1-13). Truth, or alèthēs, refers to "that which exists and remains beyond any change, which remains in its identity, immutability, and incorruptibility" (219). Truth in parrhēsia is different than truths produced by systems of power, because as Foucault often explains, power and subjectivity is always shifting so there can never be a truth produced by religion or another regime of power that is beyond change, even if those relations of power insist that the truth produced is eternal.

It is important to address the issue of gender and truth telling in Antiquity. Historically women were denied the role of parrhēsiast because in Ancient Greek society women, along with slaves, children, and immigrants, were oppressed and deprived many rights, including parrhēsia (12). In his writings Foucault makes sure to explain that his interest in caring of the self in Ancient Greece is not to suggest a return or exact recreation of ethics in Antiquity. When asked in an interview if he finds the style of existence in Antiquity to be admirable he responds with a simple "No" ("The Return to Morality" 244). Foucault's interest in care of the self in Ancient Greece is that it was a Pre Christian society without "the problematization of the constitution of the self as subject" (253), and therefore individuals were able to construct an ethics of self outside of subjection (253). Recreating elements of the 
Ancient Greek practice of care of the self is not about recreating specific values and hierarchies of Ancient Greece, such as the exclusion of women, but is about the modernization of the philosophy that one may attempt to create one's own self and way of life outside of subjection. Because it is an adaptation or contemporary style of the creation of self, in modern times women do not have to be excluded from caring for the self and truth telling.

In Michel Foucault and the Games of Truth Herman Nilson reaffirms Foucault's interest with care of the self in Antiquity was "not a question of nostalgic 'return to the Greeks' as the effort to overcome the ever-present Christian Weltanschauung and order of values; it is rather concerned with a reproblematization of ancient self-technologies as an opportunity to give one's individual life a form which, because it is reflexive, necessarily includes one's own transformation" (xiv$\mathrm{xv}$ ). Earlier in the introduction Nilson contends that the "culture of the self is not reserved for those athletes of the intellect, the philosophers, but is open to all those individuals who are willing to care for themselves as possibly the most important item" (xiii). For Nilson, Foucault's theorization on the use of caring for the self in contemporary times is open to all and not reserved for those who fit the requirements of the original practitioners of caring for the self in Antiquity.

Despite the historic exclusion of women, feminist authors have found Foucault and the concept of parrhēsia useful in their work. Authors such as Mariana Valverde and Margaret McLaren have argued that the recreation of parrhēsia in contemporary times is active in Alcoholics Anonymous, coming out and trauma narratives (Valverde 69-72), the National Organization for Women, narrative therapy, 
and other conscious raising groups (McLaren 155-167). Both Valverde and McLaren address the absence of gender in Foucault's work but still claim his writing is useful for feminists. In "Experience and Truth Telling in a Post-Humanist World" Valverde theorizes that many styles of feminism worry about the use of philosophy, language, and other tools of patriarchal discourse. She agrees that this is a valid concern and we should look to Foucault's use of "tools from a number of otherwise incompatible sources and traditions" (77) in his composition of analyses and arguments. As she suggests "everything is corrupt, but by the same token, everything is available and usable and transformable" (77). At the end of her article she proposes that Foucault's writing on truth speaking, regardless if his sources are on ancient practices that excluded women, is useful because truth telling rather than confessing "remains an integral part of ethical reflection, among ordinary people who read The Prophet as well as among feminist philosophers" (88). Foucault's writing on parrhēsia is useful to feminists, as well as all other writers, interested in studying narratives of truth telling instead of narratives of confession.

Tim R. Johnston's article “Transgressive Translations: Parrhesia and the Politics of Being Understood" exhibits Valverde's advice of using Foucault's work on parrhēsia as a tool, regardless of the historic gendered practice of truth telling. In the article Johnston attests that transgender coming out narratives are parrhēsiastic styles of truth telling where one tells a narrative of one's trans self that is in opposition to the medical narrative of trans identity. Johnston claims that a selfcomposed narrative of coming out is different than the medical world's narrative of coming out as trans. To be approved to receive hormone therapy and gender 
reassignment surgery, a person must first provide documents from psychologists, therapists, or other medical professionals that declare the person has Gender Identity Disorder. One is forced to conform to the language and subjection of biopowers. In contrast when a person constructs their own narrative of coming out, the person does not have to create their sense of self through language of medical institutions (85-88). Johnston does not address the historic practice of parrhēsia or Foucault's lack of focus on trans identity. Instead Johnston uses Foucault's writing as a useful tool in understanding coming out narratives in the $21^{\text {st }}$ century.

Margaret McLaren's book Feminism, Foucault, and Embodied Subjectivity is centered on the use of the late work of Foucault in feminism and directly addresses the application of Foucault's work to feminist issues. For McLaren despite the absence of the female body and gender differences in his work, Foucault's writing on the self and body has been beneficial to feminist writers. McLaren theorizes that even though Foucault does not write about gender difference one should not assume that he views the body as gender neutral. His concept of the subjection of the body is effective in analyzing gender difference and how women are subjugated by rape culture, standards of beauty, rigid reproductive laws, and sexuality (82-92). In the sixth chapter of the book she proposes how his work on truth telling is useful for feminists. "Foucault's notion of practices of the self can be fruitfully applied to some contemporary feminist practices. I explore consciousness-raising as the practice of truth telling or parrhesia" (144-145). Focused mostly on consciousness-raising organizations in the 1970s McLaren asserts "consciousness-raising provided a forum for women to discuss their experience and articulate the ways that sexism affected 
their daily lives" (156). The forum of truth telling provided by the consciousnessraising groups can lead to self and society transformation (156). Foucault's writing and the concept of parrhēsia in contemporary times are useful tools in examining people's construction of truthful narratives.

Because knowledge of the self is an important component of caring for the self, speaking truths, and living a life of truth, it is important to note how the process of gaining self-knowledge functions differently in The Body Tourist than it does in Wasted and the blogs. In Wasted the act of writing on the self provides Hornbacher with a tool of self-examination. Through the act of memoir writing she has a means of tracing the beginnings of her anorexic behavior, her eating habits' relation to her subjection, and how the culture of disordered eating lead to her construction of a way of life. In the memoir Hornbacher often writes in the present tense to understand her current state of life. In a section towards the end of the book titled "Present Day" Hornbacher speaks in the present tense and uses writing to reflect on her current activities such as obsessively working out at the gym and feeling a sense of pride then immediate guilt when she learns she lost weight, and her panic attacks (288-289). In earlier moments she questions if she will ever be able to stop having anorexic thoughts and will relapse (143-144), narrating and reflecting on her feelings. Hornbacher also includes footnotes that comment on her representation of Marya and directly writes in her present voice through the use of parentheses (22). These devices call attention to the act of memoir writing by bringing attention to the authorial voice of the memoir and suggest that the act of writing provides Hornbacher with a tool of self-understanding. 
In the blogs writing to understand the self is more evident because the writers can easily return to their writing to understand their feelings when they wrote and uploaded the post. As read in the previous chapter, PoisonedShadow repeatedly rereads her posts and explains how the act of writing and rereading grants her new knowledge of the self ("Maybe Not").

Because caring for the self is a lifelong process it would be contradictory to suggest that Shavin, or the authorial version of Shavin, stopped the act of understanding the self when she finished writing her memoir. Instead I am arguing that Shavin uses the experience of writing to understand the self, but that experience of understanding the self through writing does not become a narrative of the book the way understanding the self through writing is a narrative of Wasted and the blogs. In The Body Tourist as readers we cannot witness her research methods, her gathering of facts of her past, and her writing process of collecting and creating her narrative of her self. In the blogs we can witness more closely the day-to-day of the bloggers' understanding of their selves and disordered eating habits, and in Wasted Hornbacher often comments on the process of gathering the medical records she includes in the book (3). The narratives of Wasted and the blogs are about understanding the self and creating a personhood for self-betterment rather than being narratives of truth telling. What is notable about The Body Tourist is that we may not witness Shavin's act of writing truthfully we do bear witness to her authorial truth telling and Dana's concealment and confessing of the truth. The memoir is a narrative of truth telling and Dana's eventual transformation into the truth speaker Shavin. 


\section{Truth Telling Through Memoirs:}

Memoir writing and other styles of self-writing have often been equated with truth telling. Because the genre of memoir writing is considered to be non-fiction and an account of one's life it is often assumed that memoir is truthful writing. Michael Steinberg addresses the assumption that memoir writing is always truthful writing in his article "Writing Literary Memoir: Are We Obliged to Tell The Real Truth?" Steinberg explains that it is often difficult or impossible to tell the literal truth of a certain time in one's life because one often cannot remember exact details or those exact details are boring and do not create a unified and thematically clear narrative. Steinberg explains that there are also different categories of memoirs that relate to their representation of the truth. One style of memoirs is the journalistic style that aims to faithfully present the facts of an event to the reader. Other types of memoirs called self-exploration memoirs are not focused on writing a journalistic account and investigation of an event because the subject of the memoir is on the self and the construction of a story through memory rather than investigative journalism. Because memory is not always accurate and the link of life events to personal development is not always clear, Steinberg suggests that a certain reshaping, rearranging, and alteration of events is required in order to compose one's memoires into a comprehensible story. The memoirs of self-exploration may not represent the exact truth but the memoirs represent the truths of one's often chaotic, non-chronological, and fragmented memoires (142-144).

Vivian Gornick, a memoirist and prominent scholar in the genre of memoir writing defines the genre in her article "Why memoir now?" 
Memoir writing shares with fiction writing the obligation to lift from the raw material of life a tale that will shape experience, transform event, deliver wisdom. It differs from fiction writing in the way it approaches the task, the chief difference being that a fictional 'I' can be, and often is, an unreliable narrator, the nonfictional ' $I$ ' can never be. In memoir, the reader must be persuaded that the narrator is speaking truth (5).

Gornick's use of the phrase nonfictional ' $\mathrm{I}$ ' is important because it clarifies that she is referring to the representation of the 'I' in the memoir or the 'I' of the author created through the art of memoir writing. The author's "real" non-literary self is not necessarily the same as the 'I' represented in the memoir or the authorial presence in the memoir. Both the 'I' represented and the voice of the author are nonfictional 'I's. Therefore the nonfictional ' $I$ ' must be reliable and speaking the truth. This does not mean that the author is recreating the exact reality of what happened but is creating a truth consistent with the 'I' represented in the memoir.

The meaning of truth through the reliability of the nonfictional ' $I$ ' becomes clearer when Gornick defines her meaning of truth.

Truth in a memoir is achieved not through a recital of actual events; it is achieved when the reader comes to believe that the writer is working hard to engage with the experience at hand. What happened to the writer is not what matters; what matters is the large sense that the writer is able to make of what happened. For that, the power of a writing imagination is required... The narrator in a memoir is an instrument of illumination, but it's the writing its self that provides revelation (5).

Truth in memoir is not to be confused with truth under the law or journalism where an exact and precise narrative of the truth is expected and required. In memoir writing, as Steinberg argues, truth telling is achieved in the art of memoir writing and creating a truthful account of the experience and the author's emotional understanding of that 
experience. Truths in memoirs are based in a truthful representation of an event or time in one's life rather than an exact retelling of the event.

In The Body Tourist I am not arguing that Dana or even the "real" life Shavin is the parrhēsiast. Instead I am arguing that through the narrative of the memoir and the act of representing her past the author version or nonfictional I of Shavin is engaging in truth telling to her interlocutor reader.

\section{The Body Tourist and the Narrative of Truth Telling:}

Early in The Body Tourist after Dana has been released from an eating disorder clinic and declared cured she is interviewed for a job as a therapist at a halfway house. In the interview she is asked to explain what relapse means to her. For Dana relapse occurs when people lose touch with their feelings and needs and get too overwhelmed to continue with their therapeutic program (21). The interviewer and her future boss Mr. Jenkins then asks "Spoken from experience?" before Dana quickly responds "I-myself-have-never-had-an-alcohol-or-drug-related problem" (21). After her response the author immediately includes a description of her emaciated body and the pain she feels as she sits on a hard chair without any extra padding on her body to protect her from the hard surface. In other moments Dana is directly asked if she practices bulimia or "aacking" as her co-worker Linda calls it, and timidly states "no" (43-44). This question, then, is framed by Shavin's explanation that anorexic people are often proud of their abilities to self starve rather than binge and purge, and that Dana has always chosen anorexia over bulimia (44). In these passages Dana is not lying. She has never had a drug or alcohol addiction and 
has never been bulimic. By pairing these moments with descriptions of her emaciated body and favoritism of anorexia over bulimia she is equating her use of anorexia with a still ongoing problem like addiction and therefore implying that Dana is concealing the truth. Through the writing of the memoir the truth of her past way of life is told to the reader despite that Dana hides the truth from Mr. Jenkins and her co-worker.

Shavin's comparison of disordered eating to an addiction could be problematic for its appearance in a memoir that otherwise questions discursive labels of psychology. But for Shavin, as I argue later, her issues are with the concept of binding labels of diagnoses that ignore one's personal story and the idea that with the proper diagnosis and treatment one cab be cured and restored to one's former self. The idea of restoration and the perfect life through recovery is prevented in these moments because despite the eating disorder clinic declaring her to be cured, through her description of her overly slender body, it is apparent that she still practices disordered eating even if she no longer views herself as anorexic. The author compares her use of disorder eating to an addiction suggesting that her disordered eating can be resolved the way an alcohol addiction can be resolved, it is just not resolved through a sudden or almost magic act or singular cure.

Other times Dana is candid about her disordered eating even if her moment of truth speaking is inappropriate. Dana's improper truth telling occurs during one of her sessions with her clients at the halfway house. During the session she asks her clients to practice what she calls "write your orbit", an exercise designed to help people understand what they want out of therapy and recovery. After others share their orbits, Dana shares her own, breaking the boundaries she is supposed to set up as her 
clients' therapist. “'Dana overcame a lifelong weight problem, became a well-known psychotherapist, and ran a sanctuary for homeless animals" (61). As she comments on her self her clients question her eating habits, appearance, and the exact type of weight problem she is suffering from. These questions lead to Dana's recanting of her apparent spoken truth and her protestation that she did and does not have an eating problem and instead has a medical condition that prevents her from gaining weight. Like her reasoning that she never had a drug or alcohol problem, her explanation of having a medical condition that prevents her from gaining weight is not untrue and yet it conceals the truth simultaneously. For insurance, anorexia is considered a preexisting medical condition and it does prevent a person from gaining weight. She is also not lying when she tells her clients that she overcame her weight problem. To Dana she has overcome her problem even if Shavin makes sure to discredit this idea by continuously describing her anorexic eating habits and obsession over her weight. There is again a disconnect between the always truthful Shavin and Dana, who does not lie but twists and alters the truth.

The disconnect between Shavin the truth teller and Dana the truth concealer is evident through the overly descriptive and repetitive scenes of her anorexic eating habits. After explaining her sudden beginning with anorexia, or as she puts it salvo, one of the first descriptions of Dana's eating habits are reported. On her first day at the halfway house her co-workers inform her that lunch is provided for the clients during regular work hours so all therapists eat for free with the clients at lunch. Dana immediately panics about the act of eating in front of people and the possible outcome of having to eat more than she wants. In panic she creates a lie to get out of 
attending lunch everyday. She informs her co-workers that she has an appointment to buy a cat that afternoon and thus needs to miss lunch. Dana cleverly theorizes that her need to feed her cat at lunch will keep her from having to eat with her clients and coworkers. As the memoir continues the reader repeatedly witnesses Dana's acts of secret and private anorexic eating habits. In the first scene Dana eats boiled green beans, four saltine crackers, and two pieces of gum (54). The next descriptions of her solitary lunches are also sparse and consist of meals of air popped popcorn (55) and green beans and crusts from toast (155). In writing Shavin is telling the truth to her readers. Dana conceals her intimate moments of private, secret, and scant eating and Shavin candidly details those moments to the interlocutor reader. Shavin is truthfully telling the reader about her disordered eating past.

Intermixed in Shavin's repetitive description of her green bean lunch is Mr. Jenkins advice to her in how to get clients to speak during group therapy sessions. “"Pick around it,' he says. 'Let the pressure build. Make 'em think you already know, but get them to spill the beans"" (81). The use of the phrase "spill the beans" has multiple meanings here. Dana is repeatedly eating green beans and hiding her anorexic behavior from her co-workers by going home each day to eat lunch in secret. Like Dana, who is not "spilling the beans" about her anorexic habits to the people in her life, her clients are not talking during their weekly sessions. The phrase "spill the beans" also implies that one has a secret to keep or conceal, like Dana's anorexia, and possibly her clients do not feel comfortable revealing secret information. Dana's eating habits may be associated with secrecy and the need for confession, but Shavin's representation of those eating habits are openly expressed to the reader so 
much that the reader witnesses multiple scenes of Dana's sparse eating habits. It is again Shavin that is practicing parrhēsia in narrating her past private use of anorexia and not Dana. Shavin is telling the truth through the representation of disordered eating rather than telling the truth through the practice of disordered eating. And Shavin is telling the truth rather than confessing the truth or "spilling the beans" as Dana will do later.

Dana's confession of her anorexic lifestyle occurs after being confronted by her new friend Moira. After a series of other failures and questionable practices as a therapist at the halfway house, Dana moves back home and goes to graduate school to further her education in psychology. Shortly after meeting Moira in a graduate school class Dana and her classmate go out drinking. While at the bar Moira directly asks her “"How long have you been anorexic?"” (167). Dana replies "“I'm not -"” but then pauses before explaining “"Three years ago, I went from a hundred and thirty pounds to about eighty in eight months. But I'm not anorexic anymore, I'm okay now"” (167). Moira asks her to write her weight down on a piece of paper and says she will do the same. Dana and Moira at first lie and write 115 and 225 but quickly change the numbers to their actual weights and list 103 and 250 (168). Shavin frames this scene as a confession. In the scene Shavin refers to the document of written weights as “confessional paper" (172) and when she recounts her anorexic past to Moira, Shavin refers to this act as secret telling (167). Her use of the word secret implies a confessional act. Dana may be confessing but through her memoir Shavin is not confessing. Unlike Dana there is no alteration or reveal of the truth, Dana says she is no longer practicing anorexia and at first attempts to lie. Shavin in contrast is openly 
conveying this moment to the reader like she openly writes about Dana's past anorexic eating habits while Dana claims to have moved beyond disordered eating. Although Shavin is likely not consciously thinking about the act of confession versus the act of parrhēsia her composition of her narrative creates a progression from Dana's confessing and twisting of the truth to her current role as an author and truth teller.

Dana's concealment of her anorexic eating is also in contrast to Shavin's descriptions of the dilapidated and dangerous homes Dana lives in while she continues to practice disordered eating. The empty yet barely inhabitable homes embody Dana's empty and barely inhabitable body and life as an anorexic person. Unlike Dana the homes and her emaciated body bare the truth of her anorexia and also tell the truth of her destructive relationships with men and her tendencies to deny herself many of her needs.

The first bare home deprived of basic essentials of living is Dana's apartment during the time she works at the halfway house. Shavin describes the apartment as being poorly constructed and at the end of a "useless rural road leading to nowhereland" (63). Despite living in the apartment for a year Dana never buys furniture, except for one green chair, and lives out of boxes and sleeps on the floor. She also describes the apartment as appearing unoccupied (128-131). The empty apartment is a metaphor for the empty Dana. Not only is she physically empty by depriving herself of food and essential needs like furniture, but she is emotionally empty because she is hiding the reality of her anorexia from herself. During her time as a therapist at the halfway house, she has no relationships with others. Dana considers having an affair 
with her client Joe but it stops at one kiss, and besides a periodical friend in one of her co-workers, she deprives herself of any type of friendship or partnership with another person. Dana may attempt to hide her tendencies to strip herself of basic needs, but her apartment bares the truth of her barren lifestyle.

The next three homes Dana lives in are also symbolic of her self-starvation and hollow relationships with others. In graduate school Dana first moves into a quadruplex in an extremely poor neighborhood. "The property is a dump. The driveway is rutted with standing water and the front yard is weedy and mushylooking. Someone has kicked a green plastic flowerpot with a dead plant into the middle of it and, next to that, a muddy pink tricycle lies on its side" (148). Her first apartment is associated with death through Shavin's explanation that the apartment is located on a dead end street. Dana is at a dead end in her recovery process so the apartment is symbolic of her stinted life. The new house in also surrounded by death. Shavin uses phrases of death and stagnation to describe the house's exterior. The house is surrounded by "standing water", a dead plant, and a muddy tricycle on its side (148), all symbols of the house's lack of life, movement, and joy. The house is also associated with garbage by being called a dump and is unkempt due to its weedy landscape (148).

Dana lives in the house until the ceiling caves in making it inhabitable. She then moves to another home that is stuck and in disarray, just like her. Her next apartment is situated on top of precarious stilts over a garage with broken stairs that lead to the interior of the apartment. Inside are the remnants of Dana's attempt to pull up the carpet and the glue and carpet pieces she has not yet removed (184-187). The 
next house Dana moves to after she graduates from school is infested with mice and their droppings, has a punched in wall and exposed wires, and initially lacks heat, a stove, and a refrigerator (233-237). Shavin refers to the house as having good bones (251). Her emaciated body openly displays the bones of her body just like the house that displays its bones through the dilapidated structure and empty holes where the stove and refrigerator should be.

During her time in the apartment and mice ridden house Dana is also engaging in what Shavin calls her material anorexia (258). By material anorexia Shavin means that Dana lives a life of constant denial of her needs such as food, satisfying relationships, and basic comforts of home. In both locations she is in mentally abusive relationships. In the second apartment she dates a man who is engaged, a fact he hides from her for several months, and in the house she dates a man name Fisher whose religious upbringing prevents Dana from having a sexually satisfying relationship. While living in the house Dana also lives a life of poverty despite making a good living and deprives herself of essentials like a stove, refrigerator, heat, new clothes, and a clean and comfortable living space. When asked why she lives the way she does despite having money, she repeatedly states that she does not need to have a more comfortable and materialistic life (258). Dana's empty and deprived life is shown to the reader through Shavin's metaphorical use of the empty and barren houses, Dana's life of self inflicted poverty, and her relationships with men who cannot satisfy her emotional and sexual needs.

Although Dana is unaware of the reasoning behind her life of denial, Shavin uses metaphors of her anorexia to explain her past life of denial. Several times 
throughout the memoir Shavin repeats a saying of her mother that professes "A halfsandwich is the hallmark of a whole woman" (10). Shavin first includes this saying while she describes how she was fired from her pizza job for not weighing enough (10) and later when she proudly tells her father that she is saving all her money and does not need to splurge on any fun purchases (242). Shavin refers to this lifestyle as a mantra of desire without gratification, a mantra that she learned from her mother who also regularly monitored her food (243). In earlier moments from the memoir Shavin explains how she learned to diet through her mother, obsess over calories, and refuse to eat anything considered fatting (10-15). Through her description of her material anorexia and series of barren houses and relationships Shavin bares all to the reader and tells the truth regarding the reasons she lives a life of deprivation. She engages in relationships with unavailable men and practices anorexia and a life of poverty because she has been trained by her mother to deprive herself of all her desires. Like her emaciated body which is bare and to the bone, the houses and her life of poverty are bare and to the bone and openly declare Dana's choice of existence and issues in gratifying her needs, even when she attempts to conceal this behavior. Dana may not be a truth teller, but her body, houses, lifestyle, and relationships do tell the truth to the reader and those in Dana's life.

\section{Baring Truths of Recovery and Psychology:}

Besides her use of the memoir to profess truths of the reality of her past anorexic eating habits, Shavin uses writing as a means of truth telling regarding therapy, psychology, and recovery. It is important to not assume that Shavin is against 
therapy or psychology. She is critical of the idea that through therapy and psychology one can be easily saved or cured and that recovery is a uniform, fast, or sudden event. Shavin uses references to superhero narratives to express these truths concerning the field of psychology.

Her allusions to superhero stories begin on the first page of the memoir. After the copyright information and her dedication Shavin includes quotes from Comics: Anatomy of a Mass Medium by Reinhold Reitberger and Wolfgang Fuchs. "Each super-hero chooses in the beginning of his career a disguise and a battle name...He dons a mask and in doing so reaches back to the age-old custom of exercising demons and evil spirits by frightening them with a terrifying disguise" (qtd. in Shavin i). Shavin continues her metaphor of the superhero in an early chapter of her memoir, conveniently titled "Superhero", and by calling herself a superhero. In describing the town she will live in when she works at the halfway house she writes "It is here, in a town rich with folly and illness, that my superhero dreams spring to life" (4). Shavin's allusions to the mythical figure of the superhero connects the superhero to her actions as a therapist. As a therapist, like a superhero, she will help those who are ill and will function as a savior. Her description of a superhero is rooted in pastoral language of salvation. Through therapy people can be saved and restored, the way one's soul is restored or absolved in Christianity. The idea of the therapist as superhero and savior is also evident through her quote. "He dons a mask and in doing so reaches back to the age-old custom of exercising demons and evil spirits" (qtd. in Shavin i). The phrase "exorcising demons and evil spirits" has often been used to describe the act of psychoanalysis. In psychoanalysis one confesses one's past and 
emotional problems in hopes that these issues will be exorcised so one can then be cured or move on. The idea that one can trace the origin of one's illness to a specific moment is furthered by Shavin's incorporation of the quote in the beginning of the memoir. This chapter presents Dana's narrative as an origin story for a superhero. It is at the halfway house where she gets her start as a superhero and begins her life as a masked saver. Through the use of the quote, as well as the title of the chapter and her declaration of herself as a superhero, both Shavin and Dana are pairing the superhero with a therapist.

At the same time her description of the superhero is a description of secrecy and masking. In superheroes narratives the heroes almost always wear masks to hide their identities, a trait that Shavin describes through her quote of Reitberger and Fuchs. The theme of the secrecy of a superhero is continued in Dana's secrecy of her anorexic and masking of her eating habits. Dana is a superhero because she thinks that she can save people through therapy by exorcising their demons but also because she conceals aspects of herself like a superhero.

Although Dana is written as someone who believes in the myth of the superhero Shavin is quick to dismiss the fantasy of the superhero as well as the fantasy that therapists and psychologists can magically cure individuals. She dissolves the myth of the superhero in the first chapter.

Whichever superhero form I will ultimately take, Sherpa or guru, that I have this higher calling is clear. Never mind the black moods, the inability to weigh more than an eight-year-old, or the fact that I don't have a clue how to take care of my own health or happiness - these inconsequential, these failings and flailings I sweep under the cape of denial (6). 
Despite that Dana thinks she has been cured, Shavin points out the reality of Dana's current state and her inability to live a happy life that is not plagued by anorexic thoughts. Dana denies and conceals this reality from herself and others under the cape of the superhero. Because she cannot help herself, she cannot help others. Her inability to help her clients is supported later in the memoir when Dana proves to be ineffective as a therapist by ignoring negative behaviors when she likes clients (5759), encouraging and participating in a flirtatious relationship with a client (142), accidently allowing clients to take control of the group therapy sessions (61-62), and failing to see problematic relationships between clients (81-83). By undermining the reality and effectiveness of her role as a superhero therapist and writing truthfully Shavin suggests that unlike superheroes, psychologists and therapists cannot magically save or cure people and it takes hard work and time to recover. It is also not about saving anyone or being saved because recovery is about understanding the self in order to better the self. Shavin is not necessarily criticizing therapy and psychology but is criticizing the culturally propelled myth that recovery equals salvation.

Shavin also dismantles the myth of the superhero therapist by writing about her continuous practice of disordered eating despite professing that she is recovered. Shavin often questions the legitimacy of the concept of curing people. As stated before, Shavin uses descriptive scenes of her eating habits to inform the reader of the truth of Dana's anorexia despite that Dana repeatedly states that she is recovered. These are truths told by Shavin to address the ongoing use of anorexia in Dana's life and the idea that recovery is a sudden and permanent state of being. Early in the memoir Dana describes being released from an eating disorder rehabilitation center. 
"I was admitted to the hospital at eight a.m. Four months later, owing to a carefully scripted routine of cottage cheese, corn bread caps, and Raisin Bran, I was released at ninety-five pounds. The addictive cycle, I told friends and family, had been broken" (17). Shavin immediately discredits Dana's understanding of her recovery by telling the reader that recovery, which to Shavin means being capable of engaging in the world and being happy, was still many years away (17). She also provides no explanation of what led to her recovery other than describing her routine eating habits. Because the process of recovery at the rehab center is not provided to the reader and because she writes about her recovery at the center in just two sentences, Shavin composes this idea of Dana's alleged recovery as a sudden and quick, almost magical process. The word routine is often used to describe addiction so by using that word to describe the practices that lead to her release, Dana is equating recovery with addiction, which is a contradiction if Dana believes herself to be cured.

The idea that Dana's addictive cycle has been broken is framed between scenes of disordered eating and a description of her emaciated body. Later in the chapter Dana theorizes that her "release from the hospital was proof that I was as good as cured" (370). This scene is introduced by a depiction of her skeleton like frame and then followed by Mr. Jenkins' and her clients' response to seeing her overly slender body. Although Dana believes she is cured, through Shavin's arrangement of the chapter it is clear to the reader that Shavin does not consider Dana to be recovered. Furthermore, Dana may be concealing the truth of her anorexia from herself and the people around her, but her body and its emaciation does display the truth. 
Shavin counters the idea of a permanent notion of recovery through her author interjections but also through the character of Mr. Jenkins. When writing about what recovery means to her, her being Shavin and not Dana, she explains that Dana did not understand that "therapy is bigger than techniques and progress notes, and that people are not predictable or all the same" (40). Shavin's explanation of recovery implies that one does not have an essentialist self that can be unearthed and cured through psychological labels. Instead people are different and have multiple selves and do not find salvation through diagnosis. Therapy and psychology can and are helpful tools, but unlike Dana's early understanding of therapy and psychology, they are tools that do not function as a superhero that saves individuals by fitting them into neat and predictable labels.

Shavin uses the character of Mr. Jenkins and her second job as a therapist to truthfully inform the reader that one cannot be suddenly cured. Throughout the memoir Mr. Jenkins regularly asks "cure everyone already" (95) or makes statements such as "You did good. I'm sure Joe is cured now" (122). Mr. Jenkins' comments are weaved between problematic therapy sessions or interactions with her clients.

Directly before Mr. Jenkins' question about curing everyone Shavin includes a group therapy session where she loses control and does not shut down her client Joe's sexual innuendos towards her (61-62). His question is uncannily timed because Dana has done nothing to help or cure her clients. When Mr. Jenkins sarcastically professes Joe to now be cured he quickly refers to Joe as Dana's sweetheart, making it known that he is aware of the two's flirtatious relationship (122). The comment not only asserts Mr. Jenkins power over Dana as her boss and therapist with years more of 
experience than her but further exaggerates his sarcastic remark about Joe being cured. How can a cure be possible if his therapist is busy forming a romantic relationship with her client rather than helping him understand the reasons behind his addictions? Mr. Jenkins' use of the word cure does not just function to discredit Dana's work as a therapist but to discredit the idea that someone can be cured so suddenly and permanently. Mr. Jenkins is joking when he asks and states that the clients are cured because how can he know if the clients are cured if he was not part of the therapy sessions? His comment undercuts the idea that therapy and psychoanalysis lead to an instant cure.

In a later chapter the impossibility of a sudden cure is again addressed through Dana's criticism of the use of M\&Ms to treat behavioral problems of patients at Sheltered Workshop, a job site where people with cognitive development problems can work under the supervision of teachers and therapists. Shavin explains that the current employees use the M\&Ms as a reward system to prevent the clients from exhibiting annoying or inappropriate behavior. For example one client receives an M\&Ms whenever he stops repeatedly clapping. The M\&Ms only works for a half hour before the client again starts clapping until he earns another M\&Ms to keep quiet. Dana expresses the problems of the use of M\&Ms and how the candy system does not stop the unwanted behavior and instead encourages and rewards that unwanted behavior. Regardless of their known ineffectiveness Dana and the other workers refer to the use of the M\&MS system as a cure. Dana does attempt to discontinue the use of the M\&Ms but after failing to find alternatives gives up (255272). The inclusion of the section on the M\&Ms as a cure connects back to Mr. 
Jenkins' comments but also is in contrast to Dana's earlier comments on her own recovery and being suddenly released from the rehab clinic. Recovery is a long process and one cannot simply be cured, especially when the system used to cure does not even work and is for convenience.

Shavin's parrhēsiastic writing concerning therapy, psychoanalytic labels and diagnoses, and recovery are acts of courage. By telling the truths to the interlocutor of the reader Shavin is risking exposing her previous unethical behavior as a therapist but also risks being shunned from communities who disagree with her ideas regarding therapy, psychoanalysis, and recovery. She is not risking her life like other parrhēsiasts may do when they use the truth to challenge the government or dangerous individuals but she is risking her past reputation as a therapist as well as her relationships with her friends, ex boyfriends, family, and former clients.

In her metaphor of the therapist as a superhero her inclusion of Dana's thoughts and actions are in opposition to the idea of recovery and her use of the word cure undermines the concept that one can easily be saved/cured of addiction, depression, and other emotional problems through the salvation/cure of the superhero's/therapist's diagnosis and plan of treatment. The idea that one is saved or cured through diagnosis is a common medical narrative in western culture where once diagnosed and treated for a disorder one will have the perfect life and become the old self that was lost through the disorder. This is seen in commercials for pharmaceutical drugs where the person suffering from some aliment achieves salvation and a return to normalcy once the person starts taking the advertised drug. The story of salvation is also supported by and evident in YouTube videos where once diagnosed as 
anorexic, by a doctor or by themselves, and once the YouTuber declares they have been self cured or healed, they express that they now have a happy life and have regained their lost self.

Shavin's inclusion of Mr. Jenkins' comments and the use of M\&Ms as a cure is not to discredit the entire field of therapy and psychology or to suggest that people can never move away from addictions or eating disorders and improve themselves. In actuality many doctors, therapists, and psychologists agree with her criticisms and their findings corroborate Shavin's representation of a very long recovery process. In a 2015 study overviewed in the article "Inpatient treatment has no impact on the core thoughts and perceptions in adolescents with anorexia nervosa” psychologists Silvana Fennig, Anat Brunstein Klomek, Ben Shahar, Zohar Sarel-Michnik, and Arie Hadas conclude that people released from eating disorder clinics often still suffer from body dissatisfaction and the drive to be thin. The authors argue that change to treatment methods need to occur in order to provide more effective treatment plans during and after release to better help people who have eating disorders. The current treatment and weight restoration plans used in hospitals and clinics are effective in short term by helping the clients to gain weight but are not effective in promoting lifelong recovery which leads to high relapse rates (200-201). This assertion aligns with Shavin's representation of the period of her life after she was quickly released from an eating disorder clinic after gaining weight but on release she was still plagued by anorexic thoughts.

In another paper from 2017 called "The patient experience of illness, treatment, and change, during intense community treatment for severe anorexia 
nervosa" the writers argue for "an alternative to traditional treatment pathways for people with severe AN [anorexia]" and that their study "seeks to address some of the difficulties patients with AN have described in traditional models of care" (Hannon, Eunson, and Munro 281). The writers describe traditional treatment as treatment plans focused on weight gain and treatment that ends when the client is released from rehabilitation. The alternative treatment paths the writers describe consist of ongoing therapy after release, community interaction for support, personalized treatment plans, and a focus not solely on weight, but wellbeing. In the study the authors also found that clients who acquired self-understanding through the alternative style of therapy had higher success rates in recovering (280-291).

Lisa Dawson, Paul Rhodes, and Stephen Touyz explain that despite the idea of recovery having different meanings depending on the institutions, researchers, and doctors who define what it means to be recovered, the definitions and standards of recovery are often too narrow and need to be expanded to better represent the range of individuals in the population. For the writers the concept of recovery needs to be broadened to include clients' perspectives in what in means to be recovered. Recovery also needs to be thought of as something that is non linear and does not have a specific time frame of completion (166-173). Shavin's criticism of psychology and certain styles of therapy match the criticism of these psychologists' findings. Recovery should not be thought of as sudden event but is ongoing even after release. New alternative methods and meanings of recovery need to be determined.

Through her story of recovery as well as her inclusion of her role as a therapist who failed to help others recover from addiction, the text of The Body 
Tourist can be understood as criticism of certain methods used in treating addiction rather than a criticism of all aspects of psychology. The Body Tourist ends in Dana's recovery indicating that the idea of recovery is possible. Dana's recovery however is not linked to psychology but occurs through her embrace of a life outside of her career as a therapist and her pursuit of a life where she satisfies her needs. The memoir is a narrative of Dana's transformation into the parrhēsiastic authorial version of Shavin.

\section{The Body Tourist and Ethos Through Recovery:}

At the end of the book Shavin rejects a career in psychology, becomes an artist, moves to a farm with horses, and finally recovers from her anorexia. Shavin's recovery and switch to a life of artistry over a life in psychology and her discontinuation of self starvation do not occur abruptly but are alluded to and foreshadowed throughout the memoir. The practice of disordered eating may no longer be part of Shavin's life of truth but through the representation of her former use of disordered eating Shavin creates a literary embodiment of her life of truth. The representation of disordered eating is not just used as a parrhēsiastic tool to display what Dana actively conceals and is used to foreshadow Shavin's ethos or life of recovery.

Throughout the memoir Shavin chronicles Dana's eating habits. In all the descriptions of her eating Dana eats very little. As the memoir continues though Dana begins to eat more and more as she slowly, albeit unconsciously, moves away from her disordered eating lifestyle. In Dana's first apartment she routinely eats a meal of 
boiled beans, crackers, cheese, and gum. After leaving her first job Dana begins to incorporate hardier food into her diet such as chicken and sandwiches (190). The last meal Shavin recounts is not as filling as carb-loaded sandwiches, but in this last meal she uses language of satisfaction and pleasure to describe the meal. "I fold the mixture into a flaccid iceberg lettuce leaf and eat the whole thing standing over my stove, savoring every dry, fishy bite. Afterwards my stomach feels watery and full, like I used to feel when I ate only bullion and green beans, and then, like a thought that exists apart from my thinking it, I wish I had eaten only half of the tuna" (165). When Dana eats the tuna the scene is not a moment of sudden recovery and her anorexic thoughts are still present. Shavin's use of the word "flaccid" immediately resonates Dana's disgust in eating so much and Dana directly expresses that she wished she had only eaten half of the tuna. At the same time Dana also eats the meal with pleasure and savors every bite. The meal makes her full just like her past more sparse meals of only green beans. Dana's moment of pleasure through eating is important because throughout the memoir Shavin explains that she always deprives herself of any pleasure. Dana may not have moved away from disordered eating thoughts but this moment indicates that she is beginning to slowly satisfy her appetite, even if she later regrets it.

The idea that eating more and therefore weighing more means one is no longer anorexic is controversial. Many psychologists and anorexic people believe doctors and psychologists place too much importance on gaining weight and not enough on the emotional problems that lead to the disordered eating. In "“Eating disorders are not about food, they're about lives': Client perspectives on anorexia 
nervosa treatment" Nicola Rance, Naomi P. Moller, and Victoria Clarke interviewed numerous former anorexic people who explain that they often feel that they were released from a rehabilitation clinic too early and still had anorexic thoughts and depression after being declared recovered. The people interviewed further declare their desire to have more therapy focused on aspects of their life other than anorexia and bulimia (582-590). By equating aspects of Dana's recovery with her gaining weight I am not suggesting that her eating habits were the only issue in her disordered eating but am including these description because Shavin includes them for a purpose. As she slowly moves away from the practice of therapy and stops forming relationships with problematic men, Shavin purposely includes descriptions of her eating more and more during each meal. Through the narrative of The Body Tourist Shavin addresses the concerns of the people interviewed by Rance, Moller, and Clarke. Her memoir addresses Dana's issues with her food while also treating and representing her as a whole person by divulging how her relationship with her mother lead to her life of denial. Gaining weight is part of Dana's recovery, evident through Shavin's inclusion of these scenes, but is not the basis or only condition of her recovery.

As Dana begins to stop practicing disordered eating she also begins to no longer engage in relationships with unavailable and unsatisfying men and finally moves into a comfortable and safe home. The last relationship that occurs in the memoir is Dana's relationship with David, a nice man who is always available to Dana, is comfortable with sex, and does not cause Dana to deny any of her desires. Shavin describes him here. "In short, it is all the ways that David's manner and style 
do not resonate with the chronic self-denial and anorexic emptying-out that has for so long defined me, that attracts me" (319). David unlike Joe, Fisher, and the other men Dana dated is not another example of how she routinely denies herself of her desires. David is there for her, respects her, and is good to her. Although she breaks up with David at the end of the memoir his inclusion in the book symbolizes Dana's growth towards nourishing her desires.

The last home Dana lives in is also in contrast to the broken and infested homes she lived in throughout the memoir. After learning that a trailer on a horse farm is available for rent Dana quickly visits the property and moves into the trailer. The trailer is much smaller than the house she was previously living in but is much more comfortable and comes with heat. What really draws Dana to the trailer is not the trailer itself but is the farm it is located on. The farm is important because eventually Dana leaves her job as a therapist to take care of the horses full time. Dana's love for horses and the joy she receives from them is a prominent theme throughout the memoir but often her thoughts about horses are representative of the desires she constantly denies or does not have access to. Often Dana fantasizes about moving to a farm and taking care of horses (7), describes Joe's interest in her horse jewelry (94), and happily recalls riding horses as a child and being close friends with her riding partner Bobbi (117-118). In all of these examples the horses represent Dana's unfulfilled desires. She will never be a superhero therapist, her relationship with Joe is nothing but unsatisfied sexual desire, and while explaining the memory of Bobbi, Shavin also explains that after the two enjoyed a day of riding and eating oranges, Bobbi's father had a stroke and she never rode with Dana again (117-118). 
In all the examples the horses are symbolic of Dana's needs and in all the examples her needs are unfulfilled or taken away.

In another scene Dana tells Moira that she initially was able to convince her boyfriend to not move in with her, a desire she has been repressing, but in guilt changed her mind and overlooked her own desires to satisfy her boyfriend's desires. She says to her friend that changing her mind about the move because of guilt "was like leading a horse to water and watching it drink and prying its mouth open and shaking the water back out" (208). The metaphor links horses to the desires and needs Dana's is constantly forsaking. The metaphor also informs the reader that Dana's actions are what are preventing her from having a satisfying life because she controls the reins of herself and the metaphorical horse too tightly.

Another scene from the memoir functions similarly but the symbol of the horse is connected to her mother's needs. Throughout the memoir Shavin explains the unhappy marriage of her mother and father, mostly from her mother's viewpoints. She describes her mother as being unsatisfied by the marriage because her husband does not listen to or fulfill her needs. Like Dana in most of the memoir her mother is resigned to her life without gratification and tells her daughter that leaving her father would be too difficult and Dana would have to give up her horse because she could not afford the horse as a single parent. The childhood Dana immediately panics at the thought of losing the horse but decides to accept that loss in favor of the happiness of her mother. Her mother will not allow this loss and does not do something about her unhappy life. Instead her mother "pushed the desire to leave underground, where it lay fallow or festering, reappearing every year thereafter like a trusty perennial" 
(221). The horse represents her mother's inability to satisfy her desires and recalls her idea that a "half-sandwich is the hallmark of a whole woman" (7). Through the horse and food her mother teaches Dana how to deprive herself.

However, the horses grow to represent Dana's fulfillment of her needs. As explained before, at the end of the memoir Dana leaves her job and becomes an artist and takes care of the horses full time on the trailer farm. Towards the end of the memoir a wave of illness comes over the horses causing many to die. In her explanation of the dying horses Shavin includes a memory of a dream she had as a child where she joyfully finds a horse in her backyard. In the dream she can smell the horse but as she reaches out to pet her, Dana wakes up (329). Shavin ends the description of the dream and explains that at the time the dream lead to her ten year old self's resolution to eventually own a horse. Years later when Dana remembers the dream after the death of several horses on the farm, Dana finally begins to follow her heart (329).

Shortly after this scene Dana follows her heart and quits psychology in favor of a fulfilling career. Throughout the memoir Shavin conveys the unhappiness the career as a therapist causes Dana. Work at the halfway house not only stresses out Dana due to the threat of eating in public, but Dana constantly expresses that she feels inadequate as a therapist, is figuratively threatened by her clients, and desires to quit right away (49). Working at her second job Dana complains about the use of the M\&Ms as a form of treatment and unhappily is unable to do anything about the ineffective treatment (316), and when describing the thought of getting her $\mathrm{PhD}$ she 
comments about feeling burned out (236). The life as a therapist is not fulfilling for Dana but a life attending to horses is.

The trailer is symbolic of Dana's rejection of a career as a therapist and the embrace of a career with animals. The farm with the trailer is where she first becomes reconnected to her love of horses and is where she recalls her childhood dream. The trailer is also a symbol of Dana's growth in caring for herself by living in a habitable dwelling, and is where Dana finally feels like she has recovered and moved beyond anorexia and material anorexia. While thinking about the trailer Shavin informs the reader that Dana quit her job as a therapist and now will be an artist and care for the horses.

When I recall the moment I quit my job, and in turn my entire mental health career, I always see myself standing at the kitchen window of my trailer talking to Moira on the phone. It is dusk; the sky is gold and red, and the mares, with foals at their sides are glowing, Behind me, Jesse, Keithan, and Boomer [her dogs] are asleep in front of the sofa, and my desk is stacked with brightly painted pots, ready to go to my first real art show. A new road is taking shape, and a completely unfamiliar one (335).

Although there are no horses in Shavin's scene of Dana's moment of self understanding, recovery, and the path to a truthful life, because the trailer is on the horse farm the trailer is symbolic of Dana's pursuit of a gratifying life of being an artist while also taking care of horses, a goal she has had throughout the memoir but a goal that was always out of reach. The scene is also directly followed by the epilogue where Shavin explains that shortly after she quit her job she used her savings to buy a small farm with room for horses. By buying the farm she is ending her life of self inflicted poverty and also taking her desires by the rein and finally fulfilling them. She is choosing the new and unfamiliar road in which she shaped herself by quitting 
her job and pursuing her wants. She is recovered and has shaped an ethical way of life. At this point Dana knows herself and that she is not being fulfilled as a therapist, understands her needs for adequate shelter, supportive relationships, and filling food, and is living a life that satisfies those needs. Dana has created an ethos and has become the parrhēsiastic Shavin that truthfully narrates the story.

\section{Conclusion:}

In The Courage of Truth Foucault states that the artist's life is equated with a life of truth. He proposes that in the beginning of the $19^{\text {th }}$ century

something new appears which is different from what might be found in the Renaissance... This is the, I think, modern idea that the artist's life, in the very form it takes, should constitute some kind of testimony of what art is in its truth. The artist's life must not only be sufficiently singular for him to be able to create his work, but it must in some way be a manifestation of art itself in its truth (187).

One manifests one's life of truth through their actions but also through one's art.

One's life is a "work of art itself" (188). Art bares all by truthfully commenting on "culture, social norms, values, and aesthetic canons" (188). The artist and the artist's work is courageous in its commentary on culture and can also be rebellious through its rejection of established traditions, rules, and conventions of art (188-189).

The Body Tourist is a narrative of Dana's recovery and creation of an ethos, a creation of ethos that emerges from her life of disordered eating. But the memoir is also a piece of art. It is a composed written text that Shavin created, perfected, and released to the world. As a piece of art the memoir expresses truth about herself but also truths about her mother, therapy, psychology, and the concept of recovery. Her truth telling is courageous because she provides the interlocutor reader with truths 
that could hurt her family and prevent her from returning to a career as a therapist. The Body Tourist is also a piece of art that narrates how Dana learned to inhabit her body and pursue a life of satisfaction rather than a life where she repeatedly deprives herself of desire and basic needs like food, shelter, and love. As an artistic narrative of her life The Body Tourist is a manifestation of Shavin's and eventually Dana's creation of an ethos. Through Shavin's use of the memoir as the embodiment of her art of life, the narrative of recovery is prevented from being silenced or concealed as it is in other narratives of disordered eating. The memoir is also a narrative of continuous recovery. In writing the narrative Shavin in some ways finalized her recovery by putting it into a permanent physical state, but through her interlocutor readers Dana's recovery is a forever ongoing and continuous practice for whoever reads the book. In her manifestation of the art of life through the memoir the narrative of caring for the self is a story that is told to others for life, the life of the book, and told through the lives of those who learn and are inspired by her ethos. Her book is part of the culture of disordered eating described by Marya and Hornbacher, is part of the culture of disordered eating that influences the bloggers, and is even part of the problematic narrative of disordered eating told through YouTube. But unlike those other narratives, even the narratives of Hornbacher and the blogs that use disordered eating as a helpful tool of self-understanding and transformation, The Body Tourist, as the title suggests, is about constant movement or recovering from disordered eating and a constant movement of bettering the self and possibly bettering the reader. 


\section{Works Cited}

Dawson, Lisa, Rhodes, Paul, and Touyz, Stephen. "Defining recovery from anorexia nervosa: a Delphi study to determine expert practitioners' views." Advances in Eating Disorders, vol. 3, no. 2, pp, 2015, 165-176, DOI: 10.1080/21662630.2015.1009145. Accessed 2 Oct. 2017.

Fennig, Silvana, Brunstein Klomek, Anat, Shahar, Ben, Sarel-Michnik, Zohar, and Hadas, Arie. "Inpatient treatment has no impact on the core thoughts and perceptions in adolescents with anorexia nervosa." Early Intervention in Psychiatry, vol. 11, 2017, pp. 200-207, doi: 10.1111/eip.12234. Accessed 20 Sept. 2017.

Foucault, Michel. The Courage of Truth: The Government of Self and Others II Lectures at the College De France 1983-1984. Translated by Graham Burchell, Palgrave Macmillan, 2008.

---. "The Ethics of the Concern For Self as a Practice of Freedom." Ethics Subjectivity and Truth. Translated by Robert Hurley and Others, The New Press, 1994. 281-302.

---. Fearless Speech, edited by Joseph Pearson, SEMIOTEXT(E), 2001.

---. "The Return to Morality." Foucault: Politics, Philosophy, Culture: Interviews and Other Writings 1977-1984. Translated by Alan Sheridan and Others, Routledge, 1988, pp. 242-254.

Gornick, Vivian. "Why memoir now?" The Women's Review of Books, vol. 13, no. 10/11, Jul. 1996, p. 5. JSTOR, http://www.jstor.org.stable/4022461. Accessed 30 Sept. 2017.

Hannon, Julia, Eunson, Lindsey, and Munro, Calum. "The patient experience of illness, treatment, and change, during intensive community treatment for severe anorexia nervosa." Eating Disorders, vol. 25, no. 4, 2017, pp. 279-296, DOI: 10.1080/10640266.2017.1318626. Accessed 2 Oct. 2017.

Hornbacher, Marya. Wasted: A Memoir of Anorexia and Bulimia. Harper Perennial, 1998.

Johnston, Tim. R. "Transgressive Translations: Parrhesia and the Politics of Being Understood." philoSOPHIA, vol. 3, no. 1, 2013, pp. 84-97. Project Muse, http://muse.jhu.edu/article/516152. Accessed 29 Sept. 2017.

Mager, Dan. "Defining Recovery." Psychology Today, Psychology Today, 23 Jun. 2014, https://www.psychologytoday.com/blog/some-assemblyrequired/201406/defining-recovery. Accessed 26 Sept. 2017. 
McLaren, Margaret A. Feminism, Foucault, and Embodied Subjectivity, State University of New York Press, 2002.

Nilson, Herman. Michel Foucault and the Games of Truth. Translated by Rachel Clark, MACMILLAN, 1998.

PoisonedShadow. "Maybe Not." Ana, Mia, \& Moi: My life, body and self control, 10 Jun. 2010, WordPress, https://poisonedshadow.wordpress.com/2010/07/10/maybe- not/. Accessed Jun 17. 2017.

Puryear Keita, Gwendolyn. "Psychology's role in the recovery movement." American Psychological Association, vol. 43, no. 3, pp. 43. http://www.apa.org/monitor/2012/03/itpi.aspx. Accessed 25 Sept. 2017.

Rance, Nicola, Moller P. Naomi, and Clarke, Victoria. "'Eating disorders are not about food, they're about live': Client perspectives on anorexia nervosa treatment." Journal of Health Psychology, vol. 22, no. 5, 2015, pp. 582-594. DOI: 10.1177/1359105315609088. Accessed 30 Sept. 2017.

Shavin, Dana. The Body Tourist. Kindle ed., Little Feather Books, 2014.

Shavin, Dana. "my book." Dana Shavin, Macmedia, n.d., http://www.danashavin.com/book/. Accessed 24 Sept. 2017.

Steinberg, Michael. "Writing Literary Memoir: Are We Obliged to Tell the 'Real' Truth?" Fourth Genre: Explorations in Nonfiction, vol. 1, no. 1, 1999, pp. 142-147. JSTOR, http://www.jstor.org/stable/41938456. Accessed 28 Sept. 2017.

Valverde, Mariana. "Experience and Truth Telling in a Post-humanist World: A Foucauldian Contribution to Feminist Ethical Reflections." Feminism and the Final Foucault, edited by Dianne Taylor, Karen Vintges, University of Illinois Press, 2004, pp. 67-90. 
Conclusion

Since I began this dissertation in 2014, the culture of disordered eating has continued to flourish, transform, and spark more questions. In 2014, for instance, Lifetime released the film Starving in Suburbia, its first eating disorder focused film since 2003 (Newman 130), Stuart Murdoch of Belle and Sebastian directed God Save the Girl, a 2014 film about a girl overcoming anorexia, and Netflix released To the Bone one of the first eating disorder films to have an A list director and a high budget. Wasted has also remained in the public's consciousness largely due to Hornbacher's addition of a new afterword to the book in 2014. In a 2014 interview of Hornbacher the interviewer Alex Ronan addresses the legacy of Wasted. "Wasted has become something of a cult classic amongst eating-disorder memoirs, selling more than a million copies, which are often dog-eared and passed between teenage girls" (Ronan). Although this statement is a simplification of readers' and writers' interest with the memoir, Ronan's claims about the continuous interest in Wasted is true. In Purge Rehab Diaries Nicole Johns writes about Wasted's ban in eating disorder rehabs and PoisonedShadow professed her love for Wasted and published a personal e-mail she received from Hornbacher after reaching out to the author (PoisonedShadow). Emma Seaber asserts that Hornbacher's use of religious imagery and language to describe anorexia has influenced Pro Ana and Mia bloggers' worship of Ana and Mia and that Wasted has been much more influential than other memoirs on disordered eating (491-494). The literary effect of Wasted is further seen through the bloggers' personification of Ana and Mia, a personification that functions in a similar way in Wasted. Although Hornbacher does not refer to anorexia and bulimia as Ana and Mia 
she does write in the voice of the eating disorders, a writing choice that personifies anorexia into an entity similar to the entities of Ana and Mia.

The prevalent fascination with Wasted indicates that there are overlapping audiences interested in reading non-normative experiences of disordered eating and policing those non-normative stories of anorexia and bulimia. The public is also interested in fictional accounts of the experience in the form of conventionally published young adult novels as well as young adult and drama films. Unlike Wasted the novels and films have narratives that are very homogenous and are not about the creation of a self or ethos. Narratively the fictional accounts of anorexia and bulimia resemble the rhetoric of the YouTube videos where disordered eating is associated with shame, confession, and subjection. There are a number novels that explore disordered eating such as The Bell Jar, The Edible Woman, and She's Come Undone, but due to the limited space of this conclusion I will only explore the disordered eating narratives in young adult and drama films and the young adult literary genre. Unlike the young adult novels and teen and drama films adult eating disorder focused novels are vastly different and are largely defined by the non-young adult genre they are located in such as mystery, romance, inspirational, or drama. The Bell Jar, The Edible Woman, and She's Come Undone are also not books that are categorized by the presence of disordered eating in the narratives the way the young adult disordered eating novels are, and the books do not have a uniform structure. The complexities of these other narratives cannot be so easily summarized.

In young adult books and films usually the story takes place in the present and follows the main character as she, (it is almost always a she), practices disordered 
eating. After some sort of cathartic moment the character begins the process of recovery. The eating disordered habits are portrayed as shameful habits that the main character must eventually confess to her self or confess to others. After confessing, the healing process, which always occurs off screen or off page, can then begin. These conventions are evident in Wintergirls, written by Laurie Halse Anderson, where the main character Lia is able to move away from anorexia after she is hospitalized for a suicide attempt and finally learns how to express her emotions. The plot of Natasha Friend's Perfect is almost identical to Wintergirls' plot and follows Isabelle as she uses anorexia to cope with the death of her father. Once she finally grieves she discontinues her use of bulimia.

In 2009 The New York Times published an article addressing the role of young adult literature in sparking disordered eating. "The Troubling Allure of EatingDisorder Books," by Tara Parker-Pope, compares young adult novels on disordered eating to Pro Ana and Mia sites. In the article Parker-Pope questions how Wintergirls will affect young readers (Parker-Pope). Although Parker-Pope does not come to a conclusive view on the books, in the article she only presents evidence of the harmful influence of other disordered eating books, suggesting that she leans towards the thought that the genre of young adult fiction is dangerous to readers.

Eating disorder young adult and drama films also follow standard conventions. Most of the films with disordered eating as the central plot are located in the young adult or drama genres. The majority of the films are made for television films or movies that eventually air on Lifetime. In Hunger Point the main character Frannie stops purging after she makes amends with her domineering mother and 
grieves the loss of her sister Shelly. Like Wintergirls this recovery process is skipped over. In “'She needs some food' Eating Disorders, Lifetime and the Made-for-TV Movie" Emily L. Newman outlines the standard tropes of the eating disordered film and their effect on audiences. At the beginning of the film the main character's weight is criticized which leads her to seek guidance from a friend in how to purge, manage hunger pains, and hide disordered eating from parents and doctors. As the characters start to lose weight they are repeatedly praised until eventually the eating disorder starts to take a toll on their bodies and they begin to get injured or sick. At this point in the film the disordered eating has caused the protagonist to fail at some sort of goal like getting into college, getting the lead part in a ballet, or becoming a professional gymnast. The films end with the characters deciding to pursue recovery and present the characters as empowered through their rejection of their former disordered eating habits. Although Newman does not address the effects of creating uniform narratives of disordered eating, like critics of Wasted, she suggests that the movies guide rather than deter audiences to the practice of disordered eating (122133). Because the films all present the narratives of disordered eating in similar ways this essentialist story of disordered eating is also a concern. The assumption that all people experience disordered eating in the same way is just as problematic as the stories' potential to influence anorexic and bulimic habits because this essentialism silences non-normative narratives of disordered eating.

In the summer of 2017 Netflix released To The Bone, a film about a woman's attempt to recover from anorexia and repair her relationship with her family. Shortly before the release of the film Jezebel published an article called "Why is it so Hard to 
Make a Movie about Eating Disorders?" In the article Hazel Cills summarizes the lack of diverse narratives of disordered eating and while I disagree with her praise of To The Bone, the article and its' title importantly questions why filmmakers have such a problem in creating unique stories of disordered eating. At the end of the article Cills proposes the answer to her title question "may lie not in a grand unified explainer of eating disorders, but in telling a specific story of a specific person with an eating disorder" (Cills). As readers and scholars we should perhaps then not be focused on the potential danger of being triggered by Wasted but should be interested in why readers, writers, and bloggers respond so much to the representations of disordered eating. Because individual non-uniform narratives of disordered eating are rare as Cills' and Newman's investigations suggest, we should celebrate when alternative experiences of disordered eating are formed.

In my own writing about non-homogenous stories of disordered eating I have only begun to scratch the surface in exploring the complexities of non-fictional narratives and representations of disordered eating. In my movement from confessional stories of shame, pride, and catharsis on YouTube to literary representations of the creation of self, caring for the self, ways of life, truth telling, and self-betterment through anorexia and bulimia I argue that there are other ways to tell stories of disordered eating. By unpacking these narratives I have hoped to chronicle and champion the voices of alternative and controversial methods of selfcare, voices that have often been silenced by the media, medicine, and gender theory. These narratives are in opposition to the essentialist culture of branding and confession prominent in the medium of YouTube as well as the young adult genre 
and film. In this conclusion I wonder though if I can do justice to all storytellers who use the taboo and controversial method of self-starvation and purging to cultivate a non-normative ethos, an ethos that resists systems of power that routinely subjugate the writers?

Instead I hope this dissertation serves as a beginning. A beginning to understand, emphasize, hear, and to witness the philosophy of the representations of eating disorders to begin to question that there is a normative, nourishing, and better way of healing and existing. 


\section{Works Cited}

Cills, Hazel. "Why Is It So Hard to Make a Movie About Eating Disorders?" Jezebel, Gizmodo Media Group, 14 Jul. 2017. https://themuse.jezebel.com/theresonly-1-way-blockers-a-movie-about-parents-tryin-1819439728. Accessed 16 Oct. 2017.

Hornbacher, Marya. Interview by Alex Ronan. “'Like Seeing a Ghost': Wasted, 15 Years Later." The Cut, New York Media, LLC., 29 Jul. 2014, https://www.thecut.com/2014/07/like-seeing-a-ghost-wasted-15-yearslater.html. Accessed 16 Oct. 2017.

Johns, Nicole. Purge: Rehab Diaries, Seal Press, 2009.

Newman, Emily L. "“She needs some food' Eating Disorders, Lifetime and the Madefor-TV Movie." The Lifetime Network: Essays on 'Television for Women' in the $21^{\text {st }}$ Century, edited by Emly L. Newman and Emily Witsell, McFarland 7 Company, Inc., 2017, pp. 119-135.

PoisonedShadow. "Marya Hornbacher!!” Ana, Mia, \& Moi, WordPress, 25 Oct. 2010, https://poisonedshadow.wordpress.com/tag/marya-hornbacher/. Accessed 10 Jun. 2017.

Parker-Pope, Tara. "The Troubling Allure of Eating-Disroder Books.” The New York Times, The New York Times Company, 11 May 2009, https://well.blogs.nytimes.com/2009/05/11/the-troubling-allure-of-eatingdisorder-books $/$ ? $\mathrm{ph} p=$ true \& type=blogs\& r=0. Accessed 16 Oct. 2017.

Seber, Emma. "Reading Disorders: Pro-Eating Disorder Rhetoric and Anorexia LifeWriting." John Hopkins University Press, vol. 34, no. 2, Fall 2016, pp. 484508, http://doi.org/10.1353/lm.2016.0023. Accessed 16 Oct. 2017. 
Bibliography

American Psychiatric Association: DSM III-R: Diagnostic and Statistical Manuel of Mental Disorders. Brunner, 1987.

Anaisbeauty. "Ana is Beauty.” Anaisbeauty, Weebly, http://anaisabeauty.weebly.com/. Accessed 18 Jun. 2017.

AssociatedPress, "Pro-anorexia movement has cult-like appeal." NBCNEWS.com, 31 May 2005, NBCNEWS.COM, http://www.nbcnews.com/id/8045047/ns/health-mental health/t/proanorexia-movement-has-cult-like-appeal/\#.WUcsXRMrL8N. Accessed 9 Jun 2017.

Banet-Weiser, Sarah. "Branding the Post-Feminist Self: Girls' Video Production and YouTube."Mediated Girlhoods: New Explorations of Girls' Media Culture (Mediated Youth), edited by Sharon R Mazzarella, Peter Lang, 2011, pp. 277294.

Beauty. "My Story." Beauty From Pain, Weebly, http://beautyfrompain.weebly.com/story-of-beauty.html. Accessed 18 Jun. 2017.

---. "Welcome To The World Of Beauty From Pain." Beauty From Pain, Weebly, http://beautyfrompain.weebly.com/. Accessed 18 Jun. 2017.

Beck, Julie. "The Linguistics off 'YouTube Voice.'” The Atlantic, The Atlantic.com, 7 Dec. 2015, https://www.theatlantic.com/technology/archive/2015/12/thelinguistics-of-youtube-voice/418962/. Accessed 21 Oct. 2017.

blogilates. Blogilates, 2017, http://www.blogilates.com/. Accessed 3 Mar. 2017.

Bell, Brandi. "Private Writing in Public Spaces: Girls' Blogs and Shifting Boundaries." Growing Up Online: Young People and Digital Technologies, edited by Sandra Weber and Shanly Dixon, palgrave macmillan, 2007, pp. 95112.

"Blogilates admits to ED \& I am blocked on her instagram :( Response from comments". YouTube, uploaded by Izzy D, 2 Feb 2016, https://www.youtube.com/watch?v=ejRmJAd-z8U\&list=PLaYZ_A9ig4CKIr_IqI5aSGRhHms8HqBF\&index=8\&t=1s. Accessed 3 Mar. 2017.

Bordo, Susan. "Not Just a White Girl Thing." Critical Feminist Approaches to Eating Dis/orders, edited by Helen Malson, Routledge, 2009, pp. 46-59.

Bordo, Susan: Unbearable Weight: Feminism, Western Culture, and the Body. 
University of California Press, 1993.

Bray, Abigail. "The anorexic body: Reading disorders." Cultural Studies, 2006, vol. 10, no. 3, pp. 413-429. Academic Search Complete. 10.1080/09502389600490251. Accessed 10 Jun. 2017.

Brown, Catrina. "The Control Paradox: Understanding and Working with Anorexia and Bulimia." National Eating Disorder Information Centre, 1990, NEDIC, http://nedic.ca/sites/default/files/control-paradox-understanding-andworking-anorexia-and-bulimia.pdf. Accessed 18 Jun. 2017.

Bruch, Hilde. Eating Disorders: Obesity, Anorexia Nervosa, and the Person Within. Basic Books, 1973.

Burke, Elisa. "Pro-anorexia and the Internet: A Tangled Web of Representation and (Dis)Embodiment." Counseling, Psychotherapy, and Health, vol. 5, no. 1, 2009, pp. 60-81.

Burns, Marce. "Bodies as (im)material? Bulimia and Body Image Discourse." Critical Feminist Approaches to Eating Dis/orders, edited by Helen Malson, Routledge, 2009, pp. 124-134.

Buss, Helen. Repossessing the World: Reading Memoirs by Contemporary Women. Wilfrid Laurier University Press, 2002.

Castro, Teresa Sofia and Osorio, Antonio. "Online violence: Not beautiful enough... not thin enough. Anorectic testimonials in the web." PsychNology Journal, 2012, vol. 10, no. 3, pp. 169-186. Academic Search Complete, http://www.psychnology.org/. Accessed 10 Jun. 2017.

Cills, Hazel. "Why Is It So Hard to Make a Movie About Eating Disorders?" Jezebel, Gizmodo Media Group, 14 Jul. 2017. https://themuse.jezebel.com/theresonly-1-way-blockers-a-movie-about-parents-tryin-1819439728. Accessed 16 Oct. 2017.

Cocq, Coppélie. "Indigenous Voices on the Web: Folksonomies and Endangered Languages." The Journal of American Folklore, vol. 128, no. 509, 2-15, pp. 273-285. JSTOR, http:www.jstor.org/stable/10.5406/jamerfolk.128.509.0273. Accessed 10 Mar. 2017.

Custers, Kathleen. "The urgent matter of online pro-eating disorder content and children: clinical practice." Eur J Pediatr, vol. 174, 2015, pp. 429-433. Academic Search Complete. D01 10.1007?s00431_015_2487-7.

Dawson, Lisa, Rhodes, Paul, and Touyz, Stephen. "Defining recovery from anorexia nervosa: a Delphi study to determine expert practitioners' views." Advances 
in Eating Disorders, vol. 3, no. 2, pp, 2015, 165-176, DOI:

10.1080/21662630.2015.1009145. Accessed 2 Oct. 2017.

Day, Katy and Keys, Tammy. "Anorexia/bulimia as resistance and conformity in pro-Ana and pro-Mia virtual conversations." Critical Feminist Approaches to Eating Dis/orders, edited by Helen Malson. Routledge, 2009, pp. 87-96.

Delforterie, Monique J., Larsen, Junilla K., Bardone-Cone, Anna M., and Scholte, Ron H. J. "Effects of Viewing a Pro-Ana Website: An Experimental Study on Body Satisfaction, Affect, and Appearance Self-Efficacy." Eating Disorders, vol. 22, 2014, pp. 321-336. Academic Search Complete, 10.1080?10640266.2014.898982.

Depowski, Kristen and Hart, Kelly. "'Pro-Ana' Web Sites Glorify Eating Disorders." abcNEWS, 13 Jun. 2006, abcNEWS, http://abcnews.go.com/Health/story?id=2068728. Accessed 9 Jun 2017.

Dias, Karen. "The Ana Sanctuary: Women's Pro-Anorexia Narratives in Cyberspace." International Women's Studies, vol. 4, no. 2, Apr. 2003, pp. 3145. Academic Search Complete, http://vc.bridgew.edu/jiws/vol4/iss2/4.

Dobson, Amy. "Girls' 'pain memes' on YouTube: The production of pain and femininity in a digital network." Youth Cultures and Subcultures: Australian Perspectives, edited by Sarah Baker, Brady Robards, and Bob Buttigieg, Routledge, 2015, pp. 1-16.

Ell. "Saturday, 20 June 2015." A Journey to Bones, 20 Jun. 2015, blogspot, http://ajourneytobones.blogspot.com/. Accessed 18 Jun. 2017.

Emilytheslayer. "Those Anorexia stories on YouTube...." mpa. 13 Jun. 2014, http://www.myproana.com/index.php/topic/208694-those-anorexia-storieson-youtube/. Accessed 10 Mar. 2017.

Ewald, Francois and Fontana, Alessandro. "Foreword." The Courage of Truth: The Government of Self and Others II Lectures at the College De France 19831984. Translated by Graham Burchell. Palgrave Macmillan, 2008, pp. xi-xvi.

Fallon, Melanie A. Katzman, and Susan C. Wooley "Introduction." Feminist Perspectives on Eating Disorders, edited by Patricia Fallon, Melanie A. Katzman, and Susan C. Wooley. Guilford Press, 1996, pp. ix-xiv.

Fennig, Silvana, Brunstein Klomek, Anat, Shahar, Ben, Sarel-Michnik, Zohar, and Hadas, Arie. "Inpatient treatment has no impact on the core thoughts and perceptions in adolescents with anorexia nervosa." Early Intervention in Psychiatry, vol. 11, 2017, pp. 200-207, doi: 10.1111/eip.12234. Accessed 20 Sept. 2017. 
Foucault, Michel. "An Aesthetics of Existence." Foucault: Politics, Philosophy, Culture: Interviews and Other Writings 1977-1984. Translated by Alan Sheridan and Others, Routledge, 1988, pp. 47-53.

---. The Courage of Truth: The Government of Self and Others II Lectures at the College De France 1983-1984. Translated by Graham Burchell, Palgrave Macmillan, 2008.

---. "The Ethics of the Concern For Self as a Practice of Freedom." Ethics Subjectivity and Truth. Translated by Robert Hurley and Others. The New Press, 1994, pp. 281-302.

---. Discipline and Punish: The Birth of the Prison. Translated by Alan Sheridan, Vintage Books, 1975.

---. Fearless Speech, edited by Joseph Pearson, SEMIOTEXT(E), 2001.

---. "Hermeneutics of the Subject." Ethics Subjectivity and Truth. Translated by Robert Hurley and Others, The New Press, 1994, pp. 93-106.

---. "On The Genealogy of Ethics: An Overview of Work in Progress." Ethics, Subjectivity, and Truth. Translated by Robert Hurley, edited by Paul Rainbow, Penguin Books, 1997, pp. 253-280.

---. "Questions on Geography." Power/Knowledge: Selected Interviews and Others Writings: 1972-1977. Translated by Colin Gordon, Pantheon, 1980, pp. 6378.

---. "The Return to Morality." Foucault: Politics, Philosophy, Culture: Interviews and Other Writings 1977-1984. Translated by Alan Sheridan and Others, Routledge, 1988, pp. 242-254.

---. Security, Territory, Population: Lectures at the College de France, 1977-1978. Edited by Michel Senellart. Translated by Graham Burchell, palgrave macmillan, 2004.

---. "Self Writing." Ethics Subjectivity and Truth. Translated by Robert Hurley and Others, The New Press, 1994, pp. 207-222.

---. "The Subject and Power." Power. Translated by Robert Hurley and Others, The New Press, 1994, pp. 326-348.

---. "Subjectivity and Truth." Ethics Subjectivity and Truth. Translated by Robert Hurley and Others, The New Press, 1994, pp. 87-92. 
---. “Technologies of the Self." Ethics Subjectivity and Truth. Translated by Robert Hurley and Others, The New Press, 1994, pp. 223-251.

---. "What is Enlightenment?" Ethics Subjectivity and Truth. Translated by Robert Hurley and Others, The New Press, 1994, pp. 303-320.

Fredrickson, Barara L., Roberts, Tomi-Ann. “OBJECTIFCATION THEORY: Towards Understanding Women's Lived Experiences and Mental Health Risks." Psychology of Women Quarterly vol. 21, 1997, pp. 173-206.

Froriech, Franzisca V, Vartanian, Lenny R., Grisham, Jessica R, and Touyz, Stephen W. "Dimensions of control and their relation to disordered eating behaviours and obsessive-compulsive symptoms." Journal of Eating Disorders, 2016, pp. 1-9. Academic Search Complete, http://crossmark.crossref.org/dialog/?doi=10.1186/s40337-016-0104$4 \&$ domain $=$ pdf.

Giles, David. "Constructing identities in cyberspace: The Case of eating disorders." British Journal of Social Psychology, vol. 45, 2006, pp. 463-477. Academic Search Complete, DO1:10.1348?014466605X53596. Accessed 10 Jun. 2017.

Goo Goo Dolls. "Iris." City of Angles, Reprise Records, 1998.

Gornick, Vivian. The Situation and the Story: The Art of Personal Narrative. Farrar, Strauss, Giroux, 2001.

Gornick, Vivian. "Why memoir now?" The Women's Review of Books, vol. 13, no. 10/11, Jul. 1996, p. 5. JSTOR, http://www.jstor.org.stable/4022461. Accessed 30 Sept. 2017.

Gros, Frédéric. "Course Context." The Hermeneutics of the Subject: Lectures at the College de France 1981-1982. Translated by Graham Burchell, Picador, edited by Frédéric Gros 2005, pp. 507-550.

Hannon, Julia, Eunson, Lindsey, and Munro, Calum. "The patient experience of illness, treatment, and change, during intensive community treatment for severe anorexia nervosa." Eating Disorders, vol. 25, no. 4, 2017, pp. 279-296, DOI: 10.1080/10640266.2017.1318626. Accessed 2 Oct. 2017.

Hess, Amanda. "Let them Blog: The Panic Over Pro-Anorexia Websites and Social Media isn't Healthy." Slate, The Slate Group, 14 Jul. 2016, http://www.slate.com/articles/technology/users/2015/07/pro_anorexia_a nd_pro_bulimia_websites_blogs_and_social_media_moral_panic.html. Accessed 10 Feb. 2016.

Hildesheimer, Galya and Gur-Arie, Hemda. "Just Modeling? The Modeling Industry, 
Eating Disorders and the Law." International Journal of Feminist Approaches to Bioethics vol. 8, no. 2, 2015, pp. 103-138, JSTOR, http://www.jstor.org/stable/10.3138/intjfemappbio.8.2.103. Accessed Feb. 10 2016.

Holmes, Su. “'My anorexia story': girls constructing narrative of identity on YouTube." Routledge Taylor Francis Online, 2016, pp. 1-23. http://www.tandfonline.com/doi/full/10.1080/09502386.2016.1138978. Accessed Jul 182016.

Hornbacher, Marya. Interview by Alex Ronan. "'Like Seeing a Ghost': Wasted, 15 Years Later." The Cut, New York Media, LLC., 29 Jul. 2014, https://www.thecut.com/2014/07/like-seeing-a-ghost-wasted-15-yearslater.html. Accessed 16 Oct. 2017.

Hornbacher, Marya. Wasted: A Memoir of Anorexia and Bulimia. Harper Perennial, 1998.

Houston Grey, Stephanie. "A Perfect Loathing: The Feminist Expulsion of the Eating Disorder." Journal of the Kenneth Burke Society vol. 7. no. 2, 2011, pp. 10, http://kbjournal.org/grey. Accessed Feb. 2016.

"I blamed Blogilates for my exercise addiction." YouTube, uploaded by Izzy D, 2 Dec 2015, https://www.youtube.com/watch? v=Rf8oX30no2Y. Accessed 3 Mar. 2017.

i'llgettheresomeday. "Ana's Medicine Cabinet." ThinIntentions, blogspot, http://thinintentionsforever.blogspot.com/p/anas-medicine-cabinet.html. Accessed 18 Jun. 2017.

---. "Dieting." ThinIntentions, 11 Apr. 2011, blogspot, http://thinintentionsforever.blogspot.com/2013/04/dieting.html. Accessed 18 Jun. 2017.

---. "Different Diets." ThinIntentions, blogspot, http://thinintentionsforever.blogspot.com/p/different-diets.html. Accessed 18 Jun. 2017.

---. "First Post." ThinIntentions, 9 Apr. 2013, blogspot, http://thinintentionsforever.blogspot.com/2013/04/first-post.html. Accessed 18 Jun. 2017.

---. "Happy Foods." ThinIntentions, blogspot, http://thinintentionsforever.blogspot.com/p/happy-foods.html. Accessed 18 Jun. 2017. 
---. "Restaurant Rules." ThinIntentions, blogspot, http://thinintentionsforever.blogspot.com/p/restaurant-rules.html. Accessed 18 Jun. 2017.

James. “AboutPrettyThin.” PrettyThin. WordPress, 15 Jun. 2015, http://www.prettythin.cm/. Accessed 30 Sept. 2015.

Johns, Nicole. Purge: Rehab Diaries, Seal Press, 2009.

Johnston, Tim. R. "Transgressive Translations: Parrhesia and the Politics of Being Understood." philoSOPHIA, vol. 3, no. 1, 2013, pp. 84-97. Project Muse, http://muse.jhu.edu/article/516152. Accessed 29 Sept. 2017.

Kat not Jas. "105.” SkinnyLove, Jan. 18, 2011, Blogger, http://sk1nnylove.blogspot.com/2011/01/105.html. Accessed 17 Jun. 2017.

---. “105.2” SkinnyLove, 3 Jun, 2011, Blogger, http://sk1nnylove.blogspot.com/2011/06/1052.html. Accessed 17 Jun. 2017.

---. "7/2/13.” SkinnyLove, 2 Jul, 2011, Blogger, http://sk1nnylove.blogspot.com/2013/07/7213.html. Accessed 17 Jun. 2017.

---. "Are any of you guys good (or even just adequate will do) with guys?"SkinnyLove, 15 Aug, 2013, Blogger, http://sk1nnylove.blogspot.com/2013/08/are-any-of-you-good-or-evenjust.html. Accessed Jun. 182017.

---. "bleh." SkinnyLove, 18 Nov., 2013, Blogger, http://sk1nnylove.blogspot.com/2011/11/bleh.html. Accessed 18 Jun. 2017.

---. “(btw I think I probably was just being paranoid).” SkinnyLove, 29 Aug, 2013, Blogger, http://sk1 nnylove.blogspot.com/2013/08/btw-i-think-i-probably-wasjust-being.html. Accessed 18 Jun. 2017.

---. “Too much.” SkinnyLove, 16 July, 2011, Blogger, http://sk1nnylove.blogspot.com/2011/07/too-much.html. Accessed 12 Jun, 2016.

Kessler, Frank and Tobias Schafer, Mirko. "Navigating YouTube: Constructing a Hybrid Infromation Management System." The YouTube Reader, edited by Pelle Snickars and Patrick Vonderau, MEDIEHISTORISKT, 2009, pp. 275291.

Lodi, Marie. "Fitness queen Cassey Ho opens up about her eating disorder." Hello Giggles. People. 24 Jun 2016, http://hellogiggles.com/fitness-queen-casseyho-opens-eating-disorder/. Accessed 2 Mar. 2017. 
Loveheim, Mia. "YOUNG WOMEN'S BLOGS AS ETHICAL SPACES." Information, Communication, \& Society, 2011, vol 14, no. 3, pp. 338-354. Academic Search Complete, D01: 10. 1080/1369118X.2010.542822. Accessed 10 Jun. 2017.

Mager, Dan. "Defining Recovery." Psychology Today, Psychology Today, 23 Jun. 2014, https://www.psychologytoday.com/blog/some-assemblyrequired/201406/defining-recovery. Accessed 26 Sept. 2017.

McLaren, Maraget A. Feminism, Foucault, and Embodied Subjectivity, State University of New York Press, 2002.

Meyer, John. "War of My Life.” Battle Studies, Columbia, 2009.

"My Anorexia Story." YouTube, uploaded by Elizabeth Mitchell, 10 Nov. 2014, https://www.youtube.com/watch?v=DLs7dtBGsaA\&list=PLaYZ_A9ig4CKIr_IqI5aSGRhHms8HqBF\&index=6. Accessed 3 Mar. 2017.

"My Anorexia Story." YouTube, uploaded by indiefox 187, 1 Dec 2013, https://www.youtube.com/watch?v=LxtdK2qVM8A\&list=PLaYZ_A9ig4CKIr_IqI5aSGRhHms8HqBF\&index=5\&t=98s. Accessed 3 Mar. 2017.

"My Anorexia Story (Through Pictures)." YouTube, uploaded by AdamJernberg, 12 Feb. 2015, video removed.

"MY ANOREXIA STORY TRIGGER WARNING." YouTube, uploaded by rocket girl, 19 Dec 2015, https://www.youtube.com/watch?v=qWAJaUBgcIw\&list=PLaYZ_A9ig4CKIr_IqI5aSGRhHms8HqBF\&index=10\&t=2s. Accessed 3 Mar. 2017.

"My Anorexic Story." YouTube, uploaded by Charlxttte, 7 Feb 2007, https://www.youtube.com/watch? $\mathrm{v}=\mathrm{a} 36 \mathrm{gHdehgxw} \&$ list=PLaYZ_A9ig4CKIr_IqI5aSGRhHms8HqBF\&index=19\&t=76s. Accessed 3 Mar. 2017.

"My Eating Disorder." YouTube, uploaded by NikkiPhillippi, 4 Jan. 2014, https://www.youtube.com/watch?v=Gxm8jJE3AqI\&list=PLaYZ A9ig4CKIr_IqI5aSGRhHms8HqBF\&index=9\&t=140s. Accessed 3 Mar. 2017.

"My Eating Disorder Story.” YouTube, uploaded by Hylands, 12 Nov. 2014, video removed.

Newman, Emily L. “'She needs some food' Eating Disorders, Lifetime and the Madefor-TV Movie." The Lifetime Network: Essays on 'Television for Women' in the $21^{\text {st }}$ Century, edited by Emly L. Newman and Emily Witsell, McFarland 7 Company, Inc., 2017, pp. 119-135. 
Nilson, Herman. Michel Foucault and the Games of Truth. Translated by Rachel Clark, MACMILLAN, 1998.

Parker-Pope, Tara. "The Troubling Allure of Eating-Disroder Books." The New York Times, The New York Times Company, 11 May 2009, https://well.blogs.nytimes.com/2009/05/11/the-troubling-allure-of-eatingdisorder-books $/$ ? $\mathrm{ph} p=$ true \& type=blogs\& $\mathrm{r}=0$. Accessed 16 Oct. 2017.

PoisonedShadow. "A Little Late I Know." Ana, Mia, \& Moi: My life, body and self control, 27 Jun. 2010, WordPress, https://poisonedshadow.wordpress.com/2010/06/27/a-bit-late-i-know/. Accessed Jun 182017.

---. “Adulthood.” Ana, Mia, \& Moi: My life, body and self control, 27 Aug. 2012, WordPress, https://poisonedshadow.wordpress.com/2011/03/04/adulthood/. Accessed Jun 182017.

---. "Almost in Sight of $1^{\text {st }}$ Goal." Ana, Mia, \& Moi: My life, body and self control, 10 Jun. 2010, WordPress, https://poisonedshadow.wordpress.com/2010/06/10/almost-in-sight-of-1stgoal/. Accessed Jun 182017.

---. "Better..” Ana, Mia, \& Moi: My life, body and self control, 27 Aug. 2012, WordPress, https://poisonedshadow.wordpress.com/2012/08/27/better/. Accessed Jun 18. 2017.

---. “Calm After Storm.” Ana, Mia, \& Moi: My life, body and self control, 9 Jul. 2010, WordPress, https://poisonedshadow.wordpress.com/2010/07/09/calmafter-storm/. Accessed Jun 18. 2017.

---. "The Goals." Ana, Mia, \& Moi: My life, body and self control, WordPress, https://poisonedshadow.wordpress.com/the-goals/. Accessed 18 Jun. 2017.

---. "Here we go again." Ana, Mia, \& Moi: My life, body and self control, 13 Jul. 2011, WordPress, https://poisonedshadow.wordpress.com/2011/07/13/herewe-go- again/. Accessed Jun 18. 2017.

---. "I Know What I Said." Ana, Mia, \& Moi: My life, body and self control, 12 Jul. 2010, WordPress, https://poisonedshadow.wordpress.com/2010/07/12/iknow- what-i-said/. Accessed Jun. 182017.

---. It's Been a While <3." Ana, Mia, \& Moi: My life, body and self control, 5 Jun. 2011, WordPress, https://poisonedshadow.wordpress.com/2011/06/05/itsbeen-a-while-3/. Accessed Jun 17. 2017. 
---. “Marya Hornbacher!!” Ana, Mia, \& Moi, WordPress, 25 Oct. 2010, https://poisonedshadow.wordpress.com/tag/marya-hornbacher/. Accessed 10 Jun. 2017.

---. "Maybe Not." Ana, Mia, \& Moi: My life, body and self control, 10 Jun. 2010, WordPress, https://poisonedshadow.wordpress.com/2010/07/10/maybe-not/. Accessed Jun 17. 2017.

---. "Realisation." Ana, Mia, \& Moi: My life, body and self control, 21 Jun. 2012, WordPress, https://poisonedshadow.wordpress.com/2012/06/21/realisation/. Accessed 18 Jun. 2017.

---. "Shit." Ana, Mia, \& Moi: My life, body and self control, 5 Jul. 2010, WordPress, https://poisonedshadow.wordpress.com/2010/07/05/shit/. Accessed Jun 17. 2017.

---. "So Beautifully True." Ana, Mia, \& Moi: My life, body and self control, 27 Jun. 2010, WordPress https://poisonedshadow.wordpress.com/2010/06/27/sobeautifully-true/. Accessed 18 Jun. 2018.

---. "Weight." Ana, Mia, \& Moi: My life, body and self control, 18 Oct. 2012, WordPress, https://poisonedshadow.wordpress.com/2012/10/18/weight/. Accessed Jun 18. 2017.

Polak, Michele. "'I think We Must be Normal ... There are Too Many of Us for This to be Abnormal!!!': Girls Creating Identity and Forming Community in ProAna/Mia Websites." Growing Up Online: Young People and Digital Technologies, edited by Sandra Weber and Shanly Dixon, palgrave macmillan, 2007, pp. 81-94.

ProAnaGoddess. "HELLO BEAUTIFUL." PRO ANA GODDESS, WordPress, https://proanagoddess.wordpress.com/hello-beautiful\%E2\%9D\%A4\%EF\%B8\%8F/. Accessed Jun. 182017.

Probyn, Elspeth: Carnal Appetites Food Sex Identities. Routledge, 2000.

Puryear Keita, Gwendolyn. "Psychology's role in the recovery movement." American Psychological Association, vol. 43, no. 3, pp. 43. http://www.apa.org/monitor/2012/03/itpi.aspx. Accessed 25 Sept. 2017.

Queen Adreena. "My Silent Undoing.” Drink Me, Rough Trade Records, 2002.

Rance, Nicola, Moller P. Naomi, and Clarke, Victoria. “"Eating disorders are not about food, they're about live': Client perspectives on anorexia nervosa 
treatment." Journal of Health Psychology, vol. 22, no. 5, 2015, pp. 582-594. DOI: 10.1177/1359105315609088. Accessed 30 Sept. 2017.

Salazar, Edurado. "Hastags 2.0 - An Annotated History of the Hashtag and a Window to its Future." Icono 14, vol. 15, 2017, pp. 16-54. DOAJ Directory of Open Access Journals, doi: 10.7195/ri14.v15i2.1091. Accessed 19 Sept. 2017.

Saukko, Paula. The Anorexic Self: A Personal Political Analysis of a Diagnostic Discourse. State University of New York Press, 2008.

Schott, Danielle and Langan, Deborah. "Pro-anorexia/bulimia censorship and public service announcements: the price of controlling women." Media, Culture \& Society, 2015, vol. 37, no. 8, pp. 1158-1175. Academic Search Complete, D01: 10.1177?0163443715591672.

Seber, Emma. "Reading Disorders: Pro-Eating Disorder Rhetoric and Anorexia LifeWriting." John Hopkins University Press, vol. 34, no. 2, Fall 2016, pp. 484508, http://doi.org/10.1353/lm.2016.0023. Accessed 16 Oct. 2017.

Seid, Roberta P. "Too 'Close to the Bone': The Historical Context form Women's Obsession with Slenderness." Feminist Perspectives on Eating Disorders, edited by Patricia Fallon, Melanie A. Katzman, and Susan C. Wooley, Guilford Press, 1996, pp. 3-16.

Senkbeil, Karsten, and Hoppe, Nicola. “"The sickness stands at your shoulder...'; Embodiment and cognitive metaphor in Hornbacher's Wasted: A Memoir of Anorexia and Bulimia." Language and Literature, vol. 25, no. 1, 2016, pp. 317, DOI: 10.1177/0963947015608084. Accessed 16 Oct. 2017.

Shavin, Dana. The Body Tourist. Kindle ed., Little Feather Books, 2014.

Shavin, Dana. "my book." Dana Shavin, Macmedia, n.d., http://www.danashavin.com/book/. Accessed 24 Sept. 2017.

Silverman Bowen, Deborah. "e-Criture Feminine: Women's Online Diaries and the New Female Discourse." Webbing Cyberfeminist Practice: Communities, Pedagogies and Social Action, edited by Kristine Blair, Radhika Gajjala, and Christine Tulley, Hampton Press, Inc, 2009, pp. 309-326.

Skarderud, Finn. "Shame and Pride in Anorexia Nervosa: A Qualitative Descriptive Study." European Eating Disorders Review, 2007, pp. 1-17. Wiley Online, doi:10.1002/erv.774. Accessed 3 Mar. 2017.

Snickars, Pelle and Vonderau, Patrick. "Introduction." The YouTube Reader, edited by Pelle Snickars and Patrick Vonderau, MEDIEHISTORISKT, 2009, pp. 921. 
Springen, Karen, "THE DANGERS OF PRO-ANOREXIA WEB SITES." NewsWeek, 6 Dec. 2006, NEWWEEKLLC, http://www.newsweek.com/dangers-pro-anorexia-web-sites-105601. Accessed Jun 92017.

Steinberg, Michael. "Writing Literary Memoir: Are We Obliged to Tell the 'Real' Truth?" Fourth Genre: Explorations in Nonfiction, vol. 1, no. 1, 1999, pp. 142-147. JSTOR, http://www.jstor.org/stable/41938456. Accessed 28 Sept. 2017.

Syed-Abdul, Shabbir, Fernandez-Luque, Luis, Wen-Shan, Jian, Li, Yu-Chuan, Crain, Steven, Hsu, Min-Huei, Wang, Yao-Chin, Khandregzen, Dorjsuren, Chuluunbaatar, Enkhzaya, Nguyen, Phung Anh, and Liou, Der-Ming. "Misleading Health-Related Information Promoted Through Video-Based Social Media: Anorexia on YouTube." Journal of Medical Internet Research, vol. 15, no. 2, 2013, pp. JSTOR, https://creativecommons.org/licenses/by/2.0/. Accessed 3 Mar. 2017.

Thompson, Becky W. A Hunger So Wide and So Deep. University of Minnesota Press, 1994.

Tiggemann, Marika. "Objectification Theory: Of relevance for eating disorder researches and clinicians?" Clinical Psychologist, vol. 17, 2013, pp. 35-35.

Valverde, Mariana. "Experience and Truth Telling in a Post-humanist World: A Foucauldian Contribution to Feminist Ethical Reflections." Feminism and the Final Foucault, edited by Dianne Taylor, Karen Vintges, University of Illinois Press, 2004, pp. 67-90.

Vandereychken, Walter and van Deth, Roth. From Fasting Saints to Anorexic Girls. University Press, 1990.

"Why I will NEVER DIET Again." YouTube, uploaded by blogilates, 22 Jan 2016, https://www.youtube.com/watch?v=iZGL6rCDyXo. Accessed 3 Mar. 2017.

Williamson, Dan C. "An American Foucault." History of Philosophy Quarterly vol. 26, no. 2, Apr. 2009, pp. 189-207, JSTOR, jstor.org/stable/27745156. Accessed 3 Mar. 2017.

Wykes, Maggie and Gunter, Barrie. The Media and Body Image: If Looks Could Kill, Sage Publications, 2005. 